\title{
3. DIE ANFÄNGE DER MODERNEN AUSSENPOLITIK
}

\author{
3.1. Der Ruhrkampf
}

Der Ruhrkampf, »einer der großen, wenn nicht der [Herv. i.O.] Wendepunkt in der Geschichte der internationalen Beziehungen nach dem Ersten Weltkrieg " ${ }^{\prime}$, hatte in mehrerlei Hinsicht entscheidende Bedeutung für die Modernisierung der Außenpolitik. Das gilt natürlich zunächst für den Ausgang der Ruhrkrise, die, beginnend mit dem Dawes-Plan, die kurze Ära der Zusammenarbeit zwischen Deutschland und Frankreich einleitete. Es wäre jedoch falsch, die Bedeutung des Ruhrkampfs für die moderne Außenpolitik nur von seinem Ende her zu sehen, als Resultat einer vermeintlichen oder tatsächlichen französischen Niederlage und gestiegener deutscher Kooperationsbereitschaft. Wie im vorangegangenen Abschnitt zu sehen war, gab es schon seit Beginn der 1920er Jahre kooperative Ansätze zur Gestaltung der deutsch-französischen Beziehungen - wie den Seydoux-Plan oder das Wiesbadener Abkommen -, die jedoch nicht durchgesetzt werden konnten. Die Bedeutung des Ruhrkampfs besteht deshalb in erster Linie nicht darin, daß er zu einem radikalen Bruch in der deutschen und vor allem der französischen Außenpolitik seit dem Versailler Vertrag führte, sondern daß er half; den auf beiden Seiten vorhandenen verständigungsorientierten und im Sinne dieser Arbeit modernen auBenpolitischen Konzeptionen den Weg zu ebnen. Anders gesagt: Der Ruhrkampf war nicht nur ein Konflikt zwischen Deutschland und Frankreich, sondern auch eine Auseinandersetzung innerhalb des AA, des Quai d'Orsay, der Regierungen und der Parlamente um die zukünftige Außenpolitik beider Länder, in der die modernen Kräfte einen wichtigen Etappensieg erzielen, sich aber nicht vollständig durchsetzen konnten. In dieser Perspektive gewinnt der Ruhrkonflikt eine Bedeutung, die dessen eingehende Untersuchung unabdingbar macht.

Ganz allgemein betrachtet war die Besetzung des Ruhrgebiets - oder auch nur die Drohung damit - ein gutes und bewährtes Druckmittel der Alliierten, um die Deutschen gefügig zu machen: Bereits im März 1921 hatten alliierte Truppen einschließlich englischer Soldaten Düsseldorf, Duisburg und Ruhrort besetzt ${ }^{2}$. Das Londoner Ultimatum, mit dem die deutsche Regierung Anfang Mai 1921 zur Annahme der alliierten Reparationsforderungen gezwungen

\footnotetext{
${ }^{1}$ Klaus SCHWABE, Zur Einfuhrung, in: DERS. (Hg.), Die Ruhrkrise 1923. Wendepunkt der internationalen Beziehungen nach dem Ersten Weltkrieg, Paderborn 1984, S. 1-9, hier S. 1.

${ }^{2}$ Siehe KRÜGER, Außenpolitik, S. 124.
} 
wurde, bestand in der Androhung, das Ruhrgebiet vollständig zu okkupieren ${ }^{3}$. Das Ruhrgebiet war als Sanktionsobjekt deshalb so attraktiv, weil es das Zentrum der deutschen Schwerindustrie und ein wichtiger Verkehrsknotenpunkt war ${ }^{4}$. Wer das Ruhrgebiet beherrschte, hatte direkt oder indirekt die Kontrolle über große Teile der deutschen Wirtschaft, des Verkehrs und der Kommunikation. Es lag außerdem günstig an den bereits von Frankreich, Belgien und Großbritannien besetzten rheinischen Gebieten und eignete sich als "produktives Pfand «, indem ausstehende Reparationskohlen direkt von dort nach Frankreich transportiert werden konnten, um so den Kohlen- und vor allem den Koksbedarf der französischen Schwerindustrie zu decken.

Auch für die weiterreichenden Ziele französischer Hardliner ließ sich das Ruhrgebiet nutzen: Eine Abtrennung des Ruhrgebiets konnte eine sinnvolle wirtschaftliche Ergänzung für ein autonomes oder separates Rheinland sein, oder dazu beitragen, da $B$ Deutschland, seines wirtschaftlichen Herzens beraubt, zerfiel. Ein Verlust oder zumindest die Kontrolle des Ruhrgebiets würde die Deutschen, so hoffte man, auch von einer weiteren Zusammenarbeit mit der Sowjetunion, die sich in Rapallo angekündigt hatte, abhalten. Daneben konnte das Ruhrgebiet in französischer Hand nicht nur als Druckmittel gegenüber Deutschland, sondern auch gegenüber England und den USA eingesetzt werden, damit sie Frankreich doch noch die ersehnten Sicherheitsgarantien geben oder Zugeständnisse in der Schuldenfrage machen würden ${ }^{5}$. Kurz gesagt, eine Aktion an der Ruhr könnte Frankreich zur zufriedenstellenden Lösung der drei Probleme führen, die in den Augen vieler Franzosen durch den Versailler Vertrag nicht vollständig gelöst worden waren: Deutschland endlich zur Zahlung der Reparationen zu bringen, die langfristige Koksversorgung Frankreichs sicherzustellen und die Abspaltung des Rheinlands (und damit die Umsetzung der französischen Sicherheitswünsche) einzuleiten ${ }^{6}$.

Trotz der vielen Vorteile, die die Ruhrbesetzung zu bieten schien, konnte sich Poincaré, der unmittelbar nach dem Krieg noch die Rheinlandpolitik Fochs unterstützt hatte, zwischenzeitlich aber eine konziliantere Politik gegenüber Deutschland verfolgte, erst allmählich dazu durchringen. Der Einmarsch ins Ruhrgebiet war nämlich auch mit Risiken behaftet: Er kostete Geld und sein Erfolg war keineswegs gewiß; würde die deutsche Bevölkerung mit Widerstand reagieren - und was machte die Reichsregierung? Gab sie nach oder sollte es zu einem letzten verzweifelten Aufbäumen kommen, unter Um-

\footnotetext{
${ }^{3}$ Siehe BERNARD, Decline, S. 109.

${ }^{4}$ Zum folgenden siehe JEANNESSON, Poincaré, S. 44-48; BARIÉTY, Ruhrkrise, S. 19.

${ }^{5}$ Siehe Denise ARTAUD, Reparations and War Debts. The Restoration of French Financial Power, 1919-1929, in: Robert BoYCE (Hg.), French Foreign and Defence Policy, 19181940. The Decline and Fall of a Great Power, London, New York 1998, S. 89-106, hier S. 96.

${ }^{6}$ Siehe JEANnEsson, Poincaré, S. 49.
} 
ständen zusammen mit der Sowjetunion? Wie würden sich die Engländer verhalten - war London bereit, sich zu beteiligen oder nicht? Ein weiteres Problem bestand darin, daß Poincaré mit (mindestens) zwei Denkrichtungen konfrontiert war, die mit der Ruhrbesetzung grundlegend verschiedene Ziele verfolgten: Die Gruppe der »Rheinländer« um Paul Tirard und seine Mitarbeiter - wie beispielsweise Max Hermant, dem Chef der französischen Besatzungstruppen General Jean Degoutte und sein Stab, Foch und andere - wollte die Besetzung des Ruhrgebiets vor allem als Hebel benutzen, um das Rheinland entweder in Form eines autonomen Staates innerhalb des Deutschen Reiches oder als eigenen souveränen Pufferstaat abzutrennen. Sie verfolgten also vor allem (sicherheits-)politische Absichten?

Andererseits gab es aber auch die Gruppe der "Ökonomen«, die vor allem aus hohen Funktionären aus dem Quai d'Orsay (allen voran Jacques Seydoux), dem Ministerium für öffentliche Arbeiten (z.B. Émile Coste) und dem Finanzministerium (beispielsweise Jean Tannery) bestand. Sie sahen in der Ruhrbesetzung hauptsächlich ein Mittel, um wirtschaftliche Ziele zu erreichen, also um Deutschland zur Zahlung der Reparationen zu zwingen und die französische Kohlenversorgung langfristig sicherzustellen ${ }^{8}$. Der Konflikt zwischen den verständigungsbereiten Kräften und den Falken sollte das Verhalten Frankreichs im Vorfeld und während des Ruhrkampfs nachhaltig prägen ${ }^{9}$. Die Position Poincarés war dabei nicht immer eindeutig.

Aber zunächst zu den Ereignissen, die der Besetzung des Ruhrgebiets vorausgingen. Wie gesagt, schon in der Reparationskrise vom Frühjahr 1921 war die Besetzung des Ruhrgebiets eine Option gewesen. Anfang April 1921 hatte Philippe Berthelot, Generalsekretär des Quai d'Orsay, seinen Mitarbeiter Seydoux und Louis Loucheur - zu diesem Zeitpunkt Minister für die befreiten Gebiete - beauftragt, einen Aktionsplan aufzustellen, der am 22. April 1921 vorgelegt wurde ${ }^{10}$. Dieser Plan ging allerdings nicht so weit wie ein Projekt, das Tirard bereits am 10. Februar 1921 Briand vorgeschlagen hatte ${ }^{11}$. Der Präsident der H.C.I.T.R. hatte darin gefordert, eine Zollgrenze zwischen dem besetzten Gebiet und dem Restreich einzurichten, die preußischen Beamten auszuweisen und die öffentlichen Haushalte im Rheinland durch die H.C.I.T.R. kontrollieren zu lassen. Außerdem sollte ein conseil consultatif, bestehend aus rheinischen Industriellen, Bankiers, Arbeitervertretern usw., geschaffen werden, der gewissermaßen den Embryo eines rheinischen Parlaments und damit

\footnotetext{
${ }^{7}$ Siehe AUTIN, Foch, S. 344.

${ }^{8}$ Siehe BARIÉTY, Relations franco-allemandes, S. 65.

9 Der Ansicht Schötz', demzufolge das Ziel der französischen Politik »das ungeteilte französische Interesse an der Aufweichung der Einheit des deutschen Reiches, wie es sich bis Anfang 1924 in der praktischen Politik niederschlug«, war, kann ich mich nicht anschließen, SCHÖTZ, Deutschlandpolitik, S. 141.

${ }^{10}$ Siehe JEANNESSON, Poincaré, S. 59f.

${ }^{11}$ Siehe BARIÉTY, Relations franco-allemandes, S. 71-73.
} 
einer eigenen rheinischen Staatlichkeit bilden sollte. Die Besetzung des Ruhrgebiets als produktives Pfand sollte die ganze Aktion absichern. Seydoux und Loucheur lehnten in ihrem Bericht die weitgehenden Pläne Tirards ab. Sie definierten als Hauptziel der Ruhrbesetzung, daß Deutschland zur Zahlung der Reparationen gezwungen werden solle ${ }^{12}$.

Diesen entschärften Plänen konnte auch die englische Regierung zustimmen, obwohl sie eher gegen die Ausweitung der Besetzung eingestellt war. Sie trug nur deshalb das Londoner Ultimatum mit, um Frankreich von einem Alleingang abzuhalten. Lloyd George befürchtete außerdem, daß, falls er die Vorschläge Briands ablehnen würde, Poincaré wieder an die Macht käme ${ }^{13}$. Allerdings machte London wichtige Vorbehalte: Die Besetzung des Ruhrgebiets sollte zeitlich befristet werden, sie durfte nicht zu einer Aufteilung Deutschlands führen und sollte erst dann erfolgen, wenn Deutschland einem förmlichen Ultimatum nicht nachgekommen war $^{14}$.

Die Reichsregierung beugte sich jedoch am 11. Mai 1921 den alliierten Bedingungen ${ }^{15}$, und so blieben die Pläne für die Ruhrbesetzung zunächst in der Schublade. Zwischenzeitlich verbesserte sich durch den Seydoux-Plan und die Gespräche, die zum Wiesbadener Abkommen führen sollten, das deutschfranzösische Verhältnis, und die verständigungsbereiten Kräfte schienen die Oberhand zu gewinnen.

Das Tauwetter war aber nur von kurzer Dauer. Ausgelöst durch die für Deutschland enttäuschende Entscheidung des Völkerbunds in der Oberschlesienfrage, verschlechterte sich das Verhältnis zwischen Berlin und Paris wieder. Der Vertrag von Rapallo schließlich festigte die Meinung der Hardliner in Paris, die in den deutschen Friedensbeteuerungen reine Taktik sahen. Verstärkt wurde die allgemeine Krisenstimmung noch durch den unaufhaltbar scheinenden Wiederaufstieg der deutschen Schwerindustrie, während die französische darniederlag ${ }^{16}$. Auch für Poincaré, der nach dem Rücktritt Briands im Januar 1922 die Regierung übernommen hatte, ließ Rapallo die Alarmglocken schrillen und die Sicherheitsproblematik wieder in den Vordergrund treten. Er forcierte nun den Eintritt Polens in die Kleine Entente und versuchte, allerdings erfolglos, mit England die Gespräche über ein Sicherheitsabkommen wieder aufzunehmen ${ }^{17}$. Unterstützung fanden Poincarés Befürchtungen in einem Bericht Degouttes vom 2. Mai 1922, in dem dieser angesichts der Annäherung zwischen der Sowjetunion und Deutschland die Besetzung des Ruhrgebiets und die Beteiligung französischer Unternehmen an deutschen Gruben

\footnotetext{
${ }^{12}$ Siehe JEANNESSON, Poincaré, S. 60.

${ }^{13}$ Siehe KeIGER, Poincaré, S. 275.

${ }^{14}$ Siehe JEANNESSON, Poincaré, S. 61.

${ }^{15}$ Siehe WEILl-RAYNAL, Réparations, Bd. 1, S. $638 \mathrm{f}$.

${ }^{16}$ Siehe NIEDHART, Internationale Beziehungen, S. 55.

${ }^{17}$ Siehe JeANnESSON, Poincaré, S. $76 f$.
} 
vorschlug $^{18}$. In die gleiche Kerbe schlug der Report des Deputierten Adrien Dariac, der nach Abschlu $B$ einer Informationsreise in die besetzten Gebiete, auf der er auch mit Tirard zusammengetroffen war, eine Ruhrbesetzung vorschlug ${ }^{19}$. Gleichzeitig wütete in Deutschland eine heftige Pressekampagne gegen Poincaré, in der versucht wurde, ihm die Hauptschuld am Ausbruch des Ersten Weltkrieges zuzuschieben ${ }^{20}$.

Indes, festgelegt hatte sich Poincaré auch im Sommer 1922 noch nicht auf eine Ruhrbesetzung. Er fuhr zweigleisig ${ }^{21}$. Er versuchte weiterhin, das Wiesbadener Abkommen umzusetzen und unterstützte die Arbeiten eines Komitees - bestehend aus alliierten, amerikanischen, niederländischen und deutschen Bankiers -, das die Aufgabe hatte, die Bedingungen einer internationalen Anleihe für Deutschland auszuarbeiten, mit deren Hilfe die Stabilisierung der Mark erreicht werden sollte. Allerdings scheiterten diese Gespräche am 10. Juni 1922, da Poincaré die Verringerung der Reparationszahlungen als Vorbedingung für eine solche Anleihe nicht akzeptieren konnte ${ }^{22}$.

Der Fehlschlag dieser Verhandlungen bewegte jedoch die US-Regierung zu zunehmender diplomatischer Aktivität ${ }^{23}$. Der (inoffizielle) amerikanische Vertreter bei der RepKo, Ronald Boyden, und Secretary of State Charles Hughes entwickelten einen Plan, der in vielerlei Hinsicht das Verfahren des späteren Dawes-Komitees vorwegnahm: Er beinhaltete unter anderem die Einsetzung eines Expertenkomitees zur Beurteilung der deutschen Zahlungsfähigkeit. Die diplomatische Initiative von Hughes kam jedoch nicht zustande, da Balfour am 1. August 1922 erklärte, daß die englische Regierung nur noch Kriegsschulden in Höhe der eigenen Schulden bei den USA von seinen Gläubigern einfordern wolle. Diese Verletzung des amerikanischen Prinzips der Trennung von Reparationen und Kriegsschulden, das zudem noch die französischen Wünsche nach Streichung der Schulden verstärken mußte, ließ Washington erneut eine abwartende Haltung einnehmen.

Unterdessen trafen in Paris vermehrt Nachrichten ein, die die französische Führung zunehmend am guten Willen der Deutschen zweifeln ließen und die Ruhrbesetzung attraktiver erscheinen lassen mußten ${ }^{24}$ : Frankreich sah in der

${ }^{18}$ Siehe BARIÉTY, Relations franco-allemandes, S. 96.

${ }^{19}$ Siehe Alfred E. CORNEBISE, Gustav Stresemann und die Ruhrbesetzung. Die Entwicklung eines Staatsmannes, in: Wolfgang MICHALKA, Marshall M. LEE (Hg.), Gustav Stresemann, Darmstadt 1982 (Wege der Forschung, 539), S. 177-208, hier S. 179.

${ }^{20}$ Siehe KEIGER, Poincaré, S. 280-283.

${ }^{21}$ Siehe John F.V. KEIGER, Raymond Poincare and the Ruhr Crisis, in: Robert BOYCE (Hg.), French Foreign and Defence Policy, 1918-1940. The Decline and Fall of a Great Power, London, New York 1998, S. 49-70, hier S. 53.

${ }^{22}$ Siehe JEANNESSON, Poincaré, S. 87.

${ }^{23}$ Hierzu siehe Werner LINK, Die Vereinigten Staaten und der Ruhrkonflikt, in: Klaus SCHWABE (Hg.), Die Ruhrkrise 1923. Wendepunkt der internationalen Beziehungen nach dem Ersten Weltkrieg, Paderborn 1984, S. 40-51, hier S. 42-44.

${ }^{24}$ Siehe JEANNESSON, Poincaré, S. 87. 
Ermordung Rathenaus am 24. Juni 1922 das Wiedererwachen des deutschen Nationalismus. Der beschleunigte Verfall der Mark - bei gleichzeitig rauchenden Schornsteinen im Ruhrgebiet - wurde in Paris in steigendem Maße als mutwilliges Manöver wahrgenommen, dessen eigentliches Ziel in der Torpedienung französischer Reparationsansprüche lag. An dem Tag schließlich, als der französische Ministerrat die sofortige Anwendung des Wiesbadener Abkommens beschloß, am 12. Juli 1922, forderte die deutsche Regierung erneut ein Moratorium für die Reparationszahlungen für die Jahre 1922 bis $1924^{25}$. "[C]'en est trop pour Poincaré ${ }^{26}$, der darin ein weiteres Zeichen für den mangelnden guten Willen der Deutschen sah und am selben Tag eine interministerielle Kommission mit dem Auftrag einsetzte, eine Lösung für das Reparationsproblem zu finden. Am 19. August 1922 legte Seydoux, der zusammen mit Coste der Hauptimpulsgeber dieser Arbeitgruppe war, einen Plan vor, der eine Besetzung des Ruhrgebiets vorsah, die möglichst unsichtbar für die Bevölkerung und mit geringem militärischem Aufwand vonstatten gehen sollte, um damit dieses wichtige wirtschaftliche Pfand zur Durchsetzung der französischen Reparationsforderungen in die Hand zu bekommen ${ }^{27}$. Außerdem sollte eine zivile Kommission zur Überwachung der Ruhrindustrie geschaffen werden - dies nahm die im Zusammenhang mit der Ruhrbesetzung geschaffene Mission Interalliée de Contrôle des Usines et des Mines (M.I.C.U.M) vorweg. Die Anhebung der Kohlensteuer sowie die Einführung einer Exportabgabe waren ebenfalls geplant. Weitergehende Pläne, die zu einer Abtrennung des Rheinlandes hätten führen können, wie beispielsweise die Wiedererrichtung einer innerdeutschen Zollgrenze, wurden in dem Vorschlag nicht erwähnt. Dieser Plan erfuhr in der innerfranzösischen Diskussion Kritik von zwei Sei$\operatorname{ten}^{28}$ : Finanzminister Charles de Lasteyrie bezweifelte den Nutzen eines solchen Vorgehens und sah im Gegenteil unvorhersehbare Gefahren für den französischen Haushalt. Tirard auf der anderen Seite schlug Ergänzungen vor, die - ohne den Plan direkt zu kritisieren - den Charakter des seydouxschen Projekts völlig veränderten und es von einem vorwiegend wirtschaftlichen in ein hauptsächlich politisches Programm umformten: Er forderte neben den von Seydoux vorgeschlagenen Maßnahmen außerdem die Schaffung einer innerdeutschen Zollgrenze, die Ausweisung preußischer Beamter, die Schaffung einer rheinischen Währung und die Erweiterung der Befugnisse der H.C.I.T.R.

In der Zwischenzeit verhärtete sich die Haltung Poincarés in der sogenannten Pfandfrage. Am 30. Juli 1922, kurz vor dem Beginn einer neuerlichen Reparationskonferenz in London, erklärte er öffentlich, daß Frankreich einem deutschen Reparationsmoratorium nur dann zustimmen könne, wenn die Alli-

\footnotetext{
${ }^{25}$ Siehe DUROSELle, Histoire, S. 63.

${ }^{26}$ JEANNESSON, Poincaré, S. 87.

${ }^{27}$ Siehe BARIETTY, Relations franco-allemandes, S. 97; JEANNESSON, Poincaré, S. 94f.

${ }^{28}$ Siehe ibid., S. 5.
} 
ierten von Deutschland bestimmte "produktive Pfänder«, z.B. Bergwerke oder ähnliches erhielten ${ }^{29}$.

Die Erklärung Poincarés stieß in London, wo man die Pfänderpolitik ablehnte, auf Widerstand. Andererseits fühlte sich Paris durch die bereits erwähnte Erklärung Balfours düpiert, in der dieser einen Zusammenhang von englischen Reparationsforderungen und englischen Kriegsschulden in den USA hergestellt hatte, denn damit waren die französischen Hoffnungen, mit London zu einem gemeinsamen Standpunkt in der Schuldenfrage gegenüber Washington zu kommen, zunichte gemacht. Außerdem wurde Frankreich dadurch unter Druck gesetzt, seine eigenen Reparationsansprüche $z u$ verringern ${ }^{30}$. Da keine Aussicht darauf bestand, daß die USA ihre Schuldenansprüche verringern würden, hätte die Verringerung der Reparationen vor allem bedeutet, daß Frankreich weniger Geld für den Wiederaufbau zur Verfügung gehabt hätte ${ }^{31}$. Die Differenzen zwischen Frankreich und Großbritannien in der Türkeifrage ${ }^{32}$ vertieften die "mésentente cordiale « und ließen für die neuerliche Reparationskonferenz, die vom 7. bis 14. August 1922 in London stattfinden sollte, wenig Gutes erwarten. Poincaré lehnte dort erneut ein Moratorium für die deutschen Reparationszahlungen ohne entsprechende Garantien $a b^{33}$, während Lloyd George weiterhin die französische Pfänderpolitik kritisierte und forderte, daß Frankreich endlich anfangen solle, seine Kriegsschulden zu bezahlen. Der französische Ratspräsident wiederum konnte dies nicht akzeptieren und erklärte, daß Frankreich erst dann seine Schulden bezahlen werde, wenn es von Deutschland Reparationen erhalte. Die Konferenz scheiterte an diesen unüberbrückbaren Gegensätzen ${ }^{34}$.

Der Ausgang der Londoner Konferenz bestätigte Poincaré in seiner Auffassung, daß sich eine Verhandlungslösung in der Reparationsfrage nicht mehr erreichen lasse und nur noch die Politik der produktiven Pfänder zu einer Lösung führen könne ${ }^{35}$. Allerdings dachte er bei diesen Pfändern weniger an eine Besetzung des Ruhrgebiets, die er - um die Engländer nicht ganz zu vergraulen - ablehnte, sondern an Aktionen im Rheinland, wie die Wiedererrichtung einer innerdeutschen Zollmauer oder Kapitalbeteiligungen an deutschen Unternehmen ${ }^{36}$.

${ }^{29}$ Siehe DUROSELLE, Histoire, S. 63.

${ }^{30}$ Siehe HEYDE, Reparationen, S. 16.

${ }^{31}$ Siehe FISCHER, Ruhr Crisis, S. 24.

${ }^{32}$ Siehe JEANNESSON, Poincaré, S. $91 \mathrm{f}$.

${ }^{33}$ Siehe Klaus SCHWABE, Großbritannien und die Ruhrkrise, in: DERS. (Hg.), Die Ruhrkrise 1923. Wendepunkt der internationalen Beziehungen nach dem Ersten Weltkrieg, Paderborn 1984, S. 53-87, hier S. 55.

${ }^{34}$ Siehe Duroselle, Histoire, S. 63.

${ }^{35}$ Siehe BARIÉTY, Relations franco-allemandes, S. 104.

${ }^{36}$ Siehe SCHWABE, Ruhrkrise, S. 56. 
Wie wenig Zuversicht die französische Regierung in die Londoner Konferenz gesetzt hatte, war daran deutlich geworden, daß zeitgleich von Seydoux und Coste der bereits erwähnte Plan über die im Ruhrgebiet zu ergreifenden Maßnahmen ausgearbeitet worden war ${ }^{37}$.

In der Folgezeit lösten immer neue deutsche Moratoriumsgesuche, die Frankreich als unzureichend ablehnte, weil sie keine Pfänder vorsahen, und immer neue Ruhrpläne, in denen die »Rheinländer« um Tirard und Degouttezunehmend ihre Vorstellungen durchsetzen konnten, einander ab.

Es waren schließlich zwei Ereignisse, die Poincaré in Richtung Ruhrbesetzung tendieren ließen, ohne daß an dieser Stelle im Detail auf die Frage eingegangen werden soll, wann genau sich der französische Ministerpräsident dazu entschied $^{38}$. Das eine war die neue Reichsregierung unter Führung Wilhelm Cunos, den Poincaré für eine Marionette von Hugo Stinnes und seinesgleichen hielt, und in dessen Amtsantritt er einen gefährlichen Rechtsruck in Deutschland ausmachte ${ }^{39}$. Das zweite war der Sturz Lloyd Georges und der Regierungsantritt Bonar Laws. Das persönliche Verhältnis zwischen Lloyd George und Poincaré war denkbar schlecht gewesen und der britische Premier hatte sich hartnäckig den französischen Bündnisavancen widersetzt ${ }^{40}$. In Lloyd George hatte die französische Regierung die stärkste Opposition für ihre Ruhrpläne gesehen. Bonar Law - keineswegs ein Befürworter einer Ruhrbesetzung, aber um eine Verbesserung des angeschlagenen französischbritischen Verhältnisses bemüht - hinterließ bei Poincaré den Eindruck zumindest der wohlwollenden Neutralität gegenüber einer französischen Ruhraktion $^{41}$. Dieser Eindruck wurde durch vom französischen Geheimdienst abgefangene, geheime britische Dokumente bestätigt ${ }^{42}$. Obwohl es bei einem neuerlichen französisch-britischen Gipfeltreffen in London am 9. Dezember 1922 zu keiner Übereinkunft in der Reparations- und Ruhrfrage kam, fühlte sich die französische Seite durch die veränderte Haltung Großbritanniens so ermutigt, daß von Coste ein abgeschwächter Ruhrplan ausgearbeitet wurde, der zunächst nur die Entsendung einer Ingenieursmission nach Essen (dem Sitz des Kohlensyndikats) vorsah. Nach diesem Plan sollte nur im Falle man-

\footnotetext{
${ }^{37}$ Siehe JeAnNESSON, Poincaré, S. 94f.

${ }^{38}$ Bariéty geht davon aus, daß Poincaré sich erst Ende November endgültig entschieden hat (BARIETY, Relations franco-allemandes, S. 107), während Jeannesson die Ansicht vertritt, daß Poincaré bereits nach dem Scheitem der Londoner Konferenz die Ruhraktion plante und sich in der Folgezeit nur noch Zielsetzung und Vorgehensweise geändert haben (JEANNESSON, Poincaré, S. 117). Auch Keiger datiert den Beginn konkreter Besetzungspläne auf April 1921 (KEIGER, Poincaré, S. 285). Für den Zusammenhang dieser Arbeit ist die Klärung dieser Frage jedoch unerheblich.

${ }^{39}$ Siehe BARIÉTY, Relations franco-allemandes, S. 106f.

${ }^{40}$ Siehe KEIGER, Poincaré, S. $286 f$.

${ }^{41}$ Siehe SCHWABE, Ruhrkrise, S. 56.

${ }^{42}$ Siehe KEIGER, Poincaré, S. 296.
} 
gelnder deutscher Kooperationsbereitschaft eine militärische Besetzung wenn möglich einschließlich britischer Truppen - erfolgen ${ }^{43}$.

In Frankreich wurden die Signale also zunehmend auf Okkupation gestellt: Die Reparationskommission stellte am 26. Dezember 1922 formell fest, daß Deutschland seinen Reparationsverpflichtungen nicht nachgekommen $\operatorname{sei}^{44}$. Die Entscheidung kam gegen die Stimme des britischen Delegierten Bradbury zustande. Daß die Entscheidung der RepKo eine Alibifunktion hatte, läßt sich daran erkennen, daß der Wert der nichtgeleisteten Lieferungen (es handelt sich um die berühmt-berüchtigten Telegrafenmasten und Holzlieferungen) lediglich zwei Millionen GM ausmachte, also nur einen Bruchteil des Gesamtvolumens der Sachlieferungen für das Jahr 1922, das 274 Millionen GM umfaßt hatte ${ }^{45}$.

Auf angloamerikanischer Seite setzte nun ein reges diplomatisches Treiben ein, um eine französisch-belgische Ruhrbesetzung - die belgische Regierung hatte Ende November 1922 nicht ohne Bedenken und unter nicht unerheblichem französischen Druck einer gemeinsamen Aktion zugestimmt ${ }^{46}-$ noch in letzter Minute zu verhindern. In einer Rede in New Haven am 29. Dezember 1922 schlug der amerikanische Außenminister Hughes, im Rückgriff auf die nicht zur Ausführung gekommenen amerikanischen Pläne vom Sommer, die Einsetzung einer unabhängigen Sachverständigenkommission zur Untersuchung der deutschen Zahlungsfähigkeit vor ${ }^{47}$. Allerdings lehnte Hughes erneut die Verknüpfung von Kriegsschulden und Reparationen ab und bot auch keinerlei Unterstützung der amerikanischen Regierung an ${ }^{48}$. Für Frankreich war der Vorschlag in dieser Form deshalb wertlos. Die Engländer versuchten, durch ein weiteres Treffen und neue Vorschläge Paris von seinen Ruhrplänen abzuhalten. Auf der Konferenz von Paris (2.-4. Januar 1923) stellte Bonar Law sein Programm vor ${ }^{49}$ : Großbritannien werde die Kriegsschulden Frankreichs streichen, wenn Frankreich im Gegenzug einer Verringerung seines Anteils an den deutschen Reparationszahlungen zustimme. Die Kriegsschulden, die die osteuropäischen Staaten in Frankreich hatten, sollten auf

\footnotetext{
${ }^{43}$ Siehe JEANNESSON, Poincaré, S. 120.

${ }^{44}$ Siehe DUROSELLE, Histoire, S. 64.

${ }^{45}$ Siehe JEANNESSON, Poincaré, S. 127. Lee und Michalka kommen zu anderen, in der Tendenz aber ähnlichen Ergebnissen, siehe LEE, German Foreign Policy, S. 44.

${ }^{46}$ Siehe François ROTH, La Belgique dans les rapports franco-allemands au moment de l'affaire de la Ruhr, in: Christian BAECHLER, Klaus-Jürgen MÜLLER (Hg.), Les tiers dans les relations franco-allemandes - Dritte in den deutsch-französischen Beziehungen, München 1996, S. 127-137, hier S. 132.

${ }^{47}$ Siehe LINK, Ruhrkonflikt, S. 44.

${ }^{48}$ Text von Hughes New Haven Rede in: „Hughes Discloses Policy in Speech«, New York Times (20.12.1922). Nach dem Scheitern der Konferenz in Paris bekräftigte die USRegierung ihre Ablehnung, direkt involviert zu werden: "We Stand on Hughes's Hint«, New York Times (5.1.1923).

${ }^{49}$ Siehe JeANNESSON, Poincaré, S. $122 \mathrm{f}$.
} 
Großbritannien übertragen werden. Ferner sollten Frankreich und die anderen Alliierten auf die Goldreserven, die sie während des Krieges in England hinterlegt hatten, verzichten. Die deutsche Reparationsschuld sollte zunächst um $50 \mathrm{Mrd}$. GM, später eventuell um weitere $17 \mathrm{Mrd}$. GM gesenkt und das deutsche Finanzgebaren durch einen von der RepKo unabhängigen Rat ausländischer Experten überwacht werden. Der Plan sah weiterhin ein zweijähriges Moratorium für deutsche Reparationen, ausschließlich der Sachlieferungen, vor. Pfänder waren in dem Programm nicht vorgesehen, nur für den Fall deutscher Nichterfüllung hielt London eine Pfandnahme für möglich.

Im Gegensatz dazu sah der französische Vorschlag ${ }^{50}$ vor, daß die deutsche Reparationsbelastung nur in dem Umfang reduziert werden sollte, in dem auch die interalliierten Schulden verringert würden. Die Mark sollte stabilisiert und der Haushalt des Deutschen Reiches einer strikten Kontrolle durch den der RepKo angegliederten comité des garanties unterworfen werden. Ein zweijähriges Moratorium, das nicht für Sachlieferungen gelten sollte, sollte durch Pfänder abgesichert werden, die sich an dem von Coste Ende Dezember 1922 ausgearbeiteten Plan orientierten. Eine militärische Besetzung sollte also weitgehend vermieden werden. Nur im Falle deutschen Widerstandes sollte die Okkupation auf das ganze Ruhrgebiet ausgeweitet und eine innerdeutsche Zollgrenze errichtet werden.

Obwohl die französischen Vorschläge große Zugeständnisse an die englische Position bedeuteten, blieb der grundsätzliche Widerspruch zwischen London und Paris bestehen. Die französische Kritik bestand dabei vor allem in den folgenden Punkten ${ }^{51}$ : die Unabhängigkeit des von England ins Spiel gebrachten Kontrollrats für die deutschen Finanzen von der RepKo, die Nichteinbeziehung der alliierten Kriegsschulden bei den USA und die Übertragung der französischen Gläubigerrechte auf Großbritannien, weil Paris dahinter vor allem die Absicht vermutete, daß London den wirtschaftlichen Einfluß Frankreichs in Osteuropa zurückdrängen wollte. Wichtigster Konfliktpunkt blieb aber die Frage der Pfänder, für die England inakzeptabel strikte Bedingungen forderte. Allerdings hatte sich im Laufe des Jahres 1922 innerhalb der französischen Position eine gewisse Radikalisierung - im Sinne einer stärkeren $\mathrm{Zu}$ wendung zu politischen Zielen anstelle von rein wirtschaftlichen Pressionen eingestellt. Dieser Wandel erklärt zum Teil, weshalb die deutschen und britischen Vorschläge zur Lösung der Reparationsfrage, die sich im gleichen Zeitraum den weniger radikalen Wünschen der französischen Regierung aus der ersten Hälfte des Jahres 1922 annäherten, in Paris weitgehend ungehört verhallten $^{52}$. Da die Vorschläge Bonar Laws auch die Interessen Belgiens und Ita-

\footnotetext{
${ }^{50}$ Siehe ibid. S. $121 \mathrm{f}$.

${ }^{51}$ Siehe ibid. S. 122-124.

${ }^{52}$ Siehe ibid. S. $113 \mathrm{f}$.
} 
liens weitgehend außer acht gelassen hatten, rückten Rom und Brüssel enger an Frankreich heran.

Obwohl auf der Konferenz keine inhaltliche Annäherung erzielt worden war, ging die französische Regierung mit dem durchaus richtigen Gefühl aus den Gesprächen, daß England sich zwar an einer Ruhraktion nicht beteiligen, aber auch nichts dagegen unternehmen würde ${ }^{53}$. Die Motive für dieses nachsichtige Verhalten Londons lagen darin, daß bei den anstehenden Verhandlungen in Lausanne über die Zukunft Griechenlands und der Türkei Großbritannien von Frankreich Verständnis für den Standpunkt Griechenlands erwartete. Die neue britische Regierung brachte außerdem dem französischen Sicherheitsverlangen mehr Verständnis (oder vielleicht besser: weniger Unverständnis) entgegen als ihre Vorgängerin und befürchtete, daß ein offener Bruch die Lage nur noch verschlimmern würde: Ihre Einflußmöglichkeiten würden weiter sinken und der deutsche Widerstand bei einer offenen englischen Ablehnung der Aktion nur noch angeheizt werden. Einige englische Regierungsmitglieder waren auch fest vom Scheitern der französischen Ruhraktion überzeugt; danach, so die Einschätzung, werde es einfacher sein, mit den Franzosen zu reden ${ }^{54}$. Folgerichtig beschlo $ß$ das englische Kabinett am 13. Januar 1923, daß sich die britischen Vertreter in allen interalliierten Gremien, vor allem also der Botschafterkonferenz, der Reparationskommission und der Rheinlandkommission, bei Fragen, die die Besetzung weiterer Teile Deutschlands betrafen, der Stimme enthalten sollten. Diese Entscheidung erlaubte es Frankreich, in den neu zu besetzenden Gebieten fast ungehindert zu schalten und zu walten ${ }^{55}$.

Poincaré setzte nun die lange vorbereiteten Pläne zum Einmarsch in das Ruhrgebiet in die Tat um: Noch während der Pariser Konferenz hatte der französische Ministerrat beschlossen, einen Plan Fochs, der eine schrittweise Besetzung des Ruhrgebiets in verschiedenen Zonen vorsah, durchzuführen ${ }^{56}$. Die RepKo stellte am 9. Januar 1923 - wiederum gegen die Stimme Bradburys fest, daß Deutschland auch mit der Lieferung von Reparationskohlen in Verzug $\mathrm{sei}^{57}$, und am Tag darauf überreichten der französische Botschafter in Berlin, Pierre de Margerie, und sein belgischer Kollege, Adrien Nieuwenhuys, dem deutschen Außenminister Rosenberg eine Note ihrer Regierungen, in der die Entsendung einer alliierten Ingenieursmission zur Überwachung der Arbeit des Kohlensyndikats angekündigt wurde ${ }^{58}$. Französische und belgische Truppen sollten diese Mission beschützen. Begründet wurde die Aktion mit Para-

\footnotetext{
${ }^{53}$ Siehe SCHWABE, Ruhrkrise, S. $61 \mathrm{f}$.

${ }^{54}$ Siehe FISCHER, Ruhr Crisis, S. 30.

${ }^{55}$ Siehe JEANNESSON, Poincaré, S. 124.

${ }^{56}$ Siehe ibid. S. 127.

${ }^{57}$ Siehe ibid.

${ }^{58}$ Siehe CORNEBISE, Ruhrbesetzung, S. 179.
} 
graph 18 der Anlage II des Teils VIII des Versailler Vertrags ${ }^{59}$. Am 11. Januar 1923 rückte die alliierte Kommission, die die deutschen Kohlenlieferungen sicherstellen soll, die Mission Interalliée de Contrôle des Usines et des Mines (M.I.C.U.M.), begleitet von einem belgisch-französischen Expeditionskorps, ins Ruhrgebiet ein ${ }^{60}$.

Die M.I.C.U.M. ${ }^{61}$ war ein interalliiertes Organ unter französischer, belgischer und italienischer Beteiligung und bestand aus 72 Ingenieuren (64 Franzosen, 6 Belgier und 2 Italiener), die entweder von der H.C.I.T.R., von Ministerien oder der Privatwirtschaft abgestellt worden waren. Die Kommission war unabhängig von der H.C.I.T.R. und eigens für den Zweck der Ruhrbesetzung geschaffen worden. Ihre Aufgaben bestanden darin, die tatsächliche Leistungsfähigkeit der Gruben und Fabriken im Ruhrgebiet festzustellen, die Programme des Kohlensyndikats, welches die Reparationslasten auf die einzelnen Gruben verteilte, zu überprüfen und gegebenenfalls neue Reparationspläne aufzustellen.

Die Ruhrbesetzung begann mit einem Fehlschlag. Das Kohlensyndikat, Hauptziel der Nachforschungen der M.I.C.U.M., hatte zwei Tage vor Beginn der Ruhraktion seine gesamten Unterlagen nach Hamburg geschafft ${ }^{62}$, und der passive Widerstand, den die Reichsregierung kurz nach der Besetzung erklärt hatte, traf die belgischen und französischen Stellen weitgehend unvorbereitet. Man hatte zwar mit symbolischem Widerstand und Einzelaktionen gerechnet, eine Massenbewegung aber nicht erwartet ${ }^{63}$.

Auf die Verkündung des passiven Widerstands reagierte die französische Regierung auf zweifache Weise. Zum einen mit Zwangsmaßnahmen, wie die Ausweisung von Beamten und Eisenbahnpersonal, die am 30. Januar 1923 in

${ }^{59}$ Es ist für den Zusammenhang dieser Arbeit relativ unerheblich, ob die Ruhrbesetzung rechtmäßig war oder nicht. Ich schließe mich dennoch der Auffassung Weill-Raynals an, daß sie es nicht war. Er argumentierte wie folgt: $1 . \S 18$ würde die Klauseln des Versailler Vertrags, die die Verlängerung eines Besatzungsregimes im Falle deutscher Nichterfüllung ermöglichen (Artikel 430 des Versailler Vertrags) überflüssig machen; 2. Bei der ersten Fassung des $\S 18$ auf der Friedenskonferenz wurden die Sanktionsmöglichkeiten noch einzeln aufgeführt. Die Forderung Klotz', auch territoriale Sanktionen aufzunehmen, wurde bei der Diskussion des $\S 18$ jedoch ausdrücklich abgelehnt; 3. Die Interpretation des $\S 18$ liegt bei der RepKo, nicht bei der französischen Regierung. In Fragen, die die Interpretation des Versailler Vertrags betreffen, mußte die RepKo einstimmig entscheiden, nicht, wie bei der Ruhrbesetzung geschehen, mit einer belgisch-französischen Mehrheit; 4. Frankreich hatte sich nach einem Alleingang bei der Besetzung einiger rechtsrheinischer Gebiete 1920 Großbritannien gegenüber verpflichtet, nur noch gemeinsam mit den Alliierten weitere Gebietsbesetzungen vorzunehmen. Siehe WEILL-RAYNAL, Réparations, Bd. 1, S. 544 und DERS., Réparations, Bd. 2, S. 368-375.

${ }^{60}$ Siehe GiraulT, Europe, S. 133.

${ }^{61}$ Siehe JEANNESSON, Poincaré, S. 157f.; BARIÉTY, Relations franco-allemandes, S. 109f.

${ }^{62}$ Siehe Pierre JOLLY, Dossier inédit ... de la guerre de la Ruhr ... de ses conséquences, Paris 1974, S. 172.

${ }^{63}$ Siehe CORNEBISE, Ruhrbesetzung, S. 181. 
großem Umfang begann und besonders solche Personen betraf, die nicht aus dem Rheinland stammten oder sich beim passiven Widerstand besonders exponiert hatten. Zwischen Januar und November 1923 wurden 147000 Deutsche aus dem Rheinland ausgewiesen ${ }^{64}$. Zum anderen begannen die französischen und belgischen Besatzer mit der wirtschaftlichen Abschnürung des besetzten Gebiets vom Restreich ${ }^{65}$. Damit beabsichtigten sie, die Bevölkerung im Rheinland gefügig zu machen und Deutschland, das den passiven Widerstand finanzierte, der Mittel dazu zu berauben. Darüber hinaus diente diese Politik dem Zweck, das Ruhrpfand produktiv zu machen, indem die Steuerund Zolleinnahmen sowie die Gewinne aus den staatlichen Domänen (vor allem Forste und Bergwerke) als Reparationen gepfändet wurden. Folgerichtig wurde erneut eine innerdeutsche Zollgrenze errichtet und zahlreiche Verbote erlassen, die die Ausfuhr bestimmter Güter (besonders Kohlen) aus dem besetzten Gebiet in das unbesetzte Deutschland betrafen. Ausgenommen waren jedoch Lebensmittellieferungen, da sich die Besatzer nicht des Vorwurfs schuldig machen wollten, das Ruhrgebiet auszuhungern ${ }^{66}$. Ein weiteres Ziel der französischen Seite war, durch die wirtschaftliche Abtrennung der besetzten Gebiete vom Reich auch deren politische Abspaltung vorzubereiten. Diesem Zweck dienten die Errichtung der Eisenbahnregie, die die Strecken im Rheinland verwaltete, und die Versuche zur Schaffung einer rheinischen Währung.

Die Schaffung einer rheinischen Währung war schon seit langem von Tirard geplant worden ${ }^{67}$. Der Verfall der Mark konnte dabei als guter Vorwand dienen, ökonomische Notwendigkeit mit politischen Absichten zu verknüpfen, und am 22. Januar 1923 erhielt Tirard von Poincaré den Auftrag, sich um die Währungsfrage zu kümmern ${ }^{68}$. Parallel dazu gab es Vorüberlegungen einiger interessierter Privatbanken, vor allem von der Société générale alsacienne de Banque und von Lazard frères ${ }^{69}$, die sich vor allem an den in Ägypten und Syrien geschaffenen Kolonialbanken orientierten ${ }^{70}$. Im Grunde genommen drehte sich die Diskussion um die Schaffung einer rheinischen Währung um drei Pro-

\footnotetext{
${ }^{64}$ Siehe BARIÉTY, Relations franco-allemandes, S. 114. Nach anderen Quellen wurden mehr als 187000 Personen ausgewiesen, siehe Aufzeichnung ohne Unterschrift (15.1.1924), BArch R 3101, 20436.

${ }^{65}$ Siehe JEANNESSON, Poincaré, S. 194; BARIETY, Relations franco-allemandes, S. 114.

${ }^{66}$ Durch die französischen Besatzungstruppen wurden sogar 77 neue öffentliche Suppenkïchen eingerichtet, siehe JEANNESSON, Poincaré, S. 207. Soziale Maßnahmen im Zusammenhang mit der französischen Rheinlandpolitik gehen bereits auf die Zeit Napoleons I. zurück, siehe TIRARD, Rhin, S. 279.

${ }^{67}$ Siehe BARIÉTY, Relations franco-allemandes, S. 114.

${ }^{68}$ Siehe JeANNESSON, Poincaré, S. 218f.

${ }^{69}$ Siehe Debrix an Atthalin (1.2.1923), Banque de Paris et de Pays-Bas (BPPB), 1 Cabet $1,187$.

${ }^{70}$ Namentlich der Banque Nationale d'Égypte und der Banque de la Syrie, siehe Bérard an Atthalin (29.1.1923), BPPB, 1 Cabet 1, 187.
} 
jekte, die das Jahr 1923 hindurch mit unterschiedlichen Akzentuierungen und Abwandlungen diskutiert wurden: Das erste Projekt wurde vom Generaldirektor der Société générale alsacienne de Banque, René Debrix, und Vertretern von Lazard frères vorgelegt. Darin wurde vorgeschlagen, eine stabile rheinische Währung zu schaffen, deren Banknoten durch französische Schatzwechsel gedeckt sein sollten ${ }^{71}$. Ein weiterer Plan, der auf den Generalsekretär der H.C.I.T.R., Hermant, zurückging, bestand aus einer rheinischen Währung, die durch Gold gedeckt sein sollte und erregte, wie auch der erste Vorschlag, sofort den Widerspruch des Finanzministeriums ${ }^{72}$. Ein anderes Projekt, vorgelegt von Edmond Giscard D'Estaing und Poisson, die beide im Stab Tirards tätig waren, sah die Schaffung einer privaten Bank vor, in die zunächst französische, später aber auch Kreditinstitute aus anderen Ländern Kapital einbringen sollten. Als weitere Variante dieses Plans schlug der Direktor der im März 1923 geschaffenen Eisenbahnregie, Henri Bréaud, vor, die rheinischen Eisenbahnen als Deckung für eine neue rheinische Währung zu verwenden ${ }^{73}$.

Letztendlich scheiterten die französischen Versuche zur Einführung einer rheinischen Währung daran, daß einige Privatbanken, vor allem einige Pariser Großbanken, dem Projekt skeptisch bis ablehnend gegenüberstanden ${ }^{74}$. Eine Ansicht, die von der Banque der France geteilt wurde, die Gefahren für die Stabilität und Konvertibilität des Franc sah ${ }^{75}$. Vor allem aber wollte der französische Staat, besonders Finanzminister de Lasteyrie, angesichts der schwierigen Lage, in denen sich die öffentlichen Finanzen in Frankreich befanden, keine staatlichen Garantien übernehmen ${ }^{76}$. Es waren aber nicht nur finanzielle, sondern auch politische Probleme, die die Einführung einer rheinischen Währung scheitern ließen. Belgien, das Poincaré, um dem Unternehmen einen interalliierten Anstrich zu geben, unbedingt im Boot haben wollte, war zwar durch die Banque Nationale de Belgique an den Verhandlungen beteiligt, verschleppte diese aber, weil es hinter den französischen Plänen - nicht zu unrecht - politische Hintergedanken vermutete ${ }^{77}$. Aber auch auf französischer Seite machte man sich Gedanken über die politischen Vorbedingungen einer rheinischen Währung. In einem "Plan d'action monétaire en pays occupé « ${ }^{78}$ vom 24. September 1923 - zwei Tage, bevor die Reichsregierung mehr oder weniger bedingungslos den passiven Widerstand beenden mußte, zu einem Zeitpunkt also, als der französische Triumph im Ruhrkampf total zu sein

${ }^{71}$ Siehe Debrix an Atthalin (1.2.1923), BPPB 1 Cabet 1, 187.

${ }^{72}$ Siehe BARIÉTY, Relations franco-allemandes, S. 115.

${ }^{73}$ Siehe Breaud an Tirard und Degoutte (5./6.9.1923), Banque de France (BdF) 1370200008/76.

${ }^{74}$ So z.B. Atthalin [?] an Berard (31.1.1923), BPPB 1 Cabet 1, 187.

${ }^{75} \mathrm{Vgl}$. Aufzeichnung ohne Unterschrift und Datum, BdF, 1370200008/76.

${ }^{76}$ Siehe JEANNESSON, Poincaré, S. 317.

${ }^{77}$ Siehe ibid. S. 221.

${ }^{78}$ O.V. (24.9.1923), BdF 1370200008/76. 
schien - wurde festgestellt, daß die Einführung einer rheinischen Währung zwei Bedingungen genügen müsse: Erstens müsse die finanzielle und administrative Autonomie der besetzten Gebiete von Deutschland bzw. den deutschen Ländern erreicht werden und zweitens müsse der Anstoß zur Lösung der Währungsfrage von der dortigen Bevölkerung kommen. In der Tat verschärfte sich die wirtschaftliche Lage in den besetzten Gebieten bald so weit, daß von seiten der Rheinländer Ende Oktober/Anfang November 1923 der Wunsch nach einer eigenen Währung vorgetragen wurde ${ }^{79}$. Als Gründe für die Errichtung einer »Rheinischen Goldnotenbank« führten die Befürworter, vor allem der Kölner Bankier Louis Hagen, aber auch andere Wirtschaftsführer und Politiker aus dem Rheinland, wie Robert Pferdmenges und Hugo Stinnes, an, daß die Wirtschaft in den besetzten Gebieten wegen der desolaten Lage unbedingt ausländisches Kapital brauche (welches durch die Beteiligung ausländischer Teilhaber an der Goldnotenbank eingebracht würde) ${ }^{80}$. Außerdem sei bei einer deutschen Weigerung zu befürchten, daß Franzosen und Belgier eine Notenbank ganz ohne deutsche bzw. Theinische Beteiligung gründen würden ${ }^{81}$. Die wirtschaftliche Not in den besetzten Gebieten spiele zudem den Separatisten in die Hände ${ }^{82}$. Die französische Regierung war diesen Plänen gegenüber zwar prinzipiell positiv eingestellt, es entbrannte aber mit den rheinischen Bankiers eine Auseinandersetzung darüber, wer die Kontrolle über das neu einzurichtende Institut haben sollte ${ }^{83}$. Die Reichsregierung hatte jedoch schwere Bedenken bezüglich der Bankpläne ${ }^{84}$ : Das Projekt bedrohe die Währungseinheit des Reiches und damit auch die wirtschaftliche und politische Einheit Deutschlands. Allerdings bestand für die geplante gesamtdeutsche Währungssanierung die Gefahr, daß, falls das neue Geld auch in den besetzten Reichsgebieten eingeführt würde, die Besatzungsbehörden durch ihre Praxis, Gelder für den Unterhalt der Besatzungstruppen zu beschlagnahmen, die Stabilität der neuen Währung sofort wieder unterminieren würden ${ }^{85}$. Deswegen und unter dem Druck der vereinigten rheinisch-westfälischen Wirtschaftinteressen stimmte die Reichsregierung dem am 1. Dezember 1923 vorgelegten Statut für eine Rheinisch-Westfälische Goldnotenbank widerwillig und unter strengen

${ }^{79}$ Auf einer "Besprechung mit den Vertretern der besetzten Gebiete« (25.10.1923) hatte Louis Hagen darauf hingewiesen, $\gg d a ß$ es unbedingt notwendig sei, mit einer Währungsreform im Rheinland schnellstens vorzugehen«, AdR Stresemann I/II Bd. 2, Nr. 179.

${ }^{80}$ „Besprechung des Kabinetts mit Interessenten der Rheinisch-Westfälischen Goldnotenbank« (17.12.1923), AdR Marx I/II Bd. 1, Nr. 29.

${ }^{81}$ Siehe Hagen an Marx (31.12.1923), AdR Marx V/I Bd. 1, Nr. 44.

${ }^{82}$ Siehe Kabinettssitzung (9.11.1923), AdR Stresemann I/I Bd. 2, Nr. 233.

${ }^{83}$ Siehe JEANNESSON, Poincaré, S. 353-355.

${ }^{84}$ Siehe Kabinettssitzung (17.12.1923), AdR Marx III Bd. 1, Nr. 28.

${ }^{85} \mathrm{Vgl}$. Besprechung mit den Vertretern der besetzten Gebiete (25.10.1923), AdR Stresemann I/II Bd. 2, Nr. 179. 
Auflagen $\mathrm{zu}^{86}$. Letztendlich scheiterte die rheinische Währung an der erfolgreichen Einführung der Rentenmark, die eine Sonderregelung für das Rheinland obsolet machte. Großbritannien stützte die Rentenbank in der kritischen Anfangsphase durch einen 100 Mio. GM Kredit der Bank of England und machte damit deutlich, daß ein wirtschaftlich und währungspolitisch an Frankreich gebundenes Rheinland nicht englischen Interessen entsprach ${ }^{87}$.

Das zweite Instrument, das Frankreich zur Durchsetzung seiner politischen Rheinlandpläne nutzen wollte, war die Eisenbahnregie. Sie war zunächst aus der Not geboren, denn der passive Widerstand hatte den Eisenbahnverkehr im ganzen Ruhrgebiet und Rheinland lahmgelegt. Formell wurde die Regie, also der Betrieb der Eisenbahnen in den besetzten Gebieten unter Aufsicht der Alliierten und zum Teil mit Personal aus Frankreich und Belgien, am 12. März 1923 eingerichtet. Im Sommer 1923 stellten sich Erfolge ein, die die Politik des passiven Widerstands der Berliner Regierung zunehmend schwäch$\operatorname{ten}^{88}$. Die Eisenbahnregie war aber auch sicherheitspolitisch wichtig, denn die dauerhafte Kontrolle über die Eisenbahnen würde einen deutschen Truppenaufmarsch im Rheinland unmöglich machen ${ }^{89}$. Getragen von diesen Überlegungen, legte der Direktor der Regieeisenbahnen, Bréaud, am 15. Juni 1923 einen weitreichenden Plan zur Umgestaltung der Eisenbahn in den besetzten Gebieten vor ${ }^{90}$. Sein Projekt beinhaltete die Umwandlung der rheinischen Eisenbahnen in eine internationale Gesellschaft nach französischem Recht mit Sitz in Paris. Der Generaldirektor sollte seinen Sitz bei der H.C.I.T.R. in Koblenz haben, der harte Kern der Angestellten sollte aus 15-20000 fránzösischen und belgischen Arbeitern bestehen, zu denen weitere 80-100 000 aus dem Rheinland kommen sollten. Das Kapital von 50 Mio. Francs sollte zu 15 Prozent von den Rheinländern selbst gezeichnet werden, die übrigen 85 Prozent nach dem in Spa vereinbarten Schlüssel für die Reparationen auf die Alliierten verteilt werden. Wie auch bei den Plänen zur Schaffung einer rheinischen Währung scheiterte Frankreich letztendlich an der Errichtung einer selbständigen rheinischen Eisenbahngesellschaft ${ }^{91}$. Neben juristische Probleme - das Reich hätte als Eigentümer der Eisenbahnen der Besitzübertragung zustimmen müssen - traten wiederum vom französischen Finanzministerium vorgebrachte Vorbehalte: Es lehnte staatliche Zuschüsse und Garantien ab, was das Projekt für mögliche private Anleger unattraktiv machen mußte. Selbst in Frankreich setzte sich außerdem während und nach den Ver-

\footnotetext{
${ }^{86} \mathrm{Vgl}$. Marx an Hagen (22.12.1923), AdR Marx III Bd. 1, Nr. 36.

${ }^{87}$ Siehe Curzon an Kilmarnock (3.12.1923), in: DBFP 1 XXI, Nr. 485; Tyrell an SaintAulaire (12.12.1923), ibid. Nr. 491; vgl. SCHÖTZ, Deutschlandpolitik, S. 140f.

${ }^{88}$ Siehe BARIETTY, Relations franco-allemandes, S. 117.

${ }^{89}$ Siehe JEANNESSON, Poincaré, S. 231.

${ }^{90}$ Siehe ibid. S. 308.

${ }^{91}$ Siehe ibid. S. $365 f$.
} 
handlungen des Dawes-Komitees die Auffassung durch, daß Deutschland nur dann seine Reparationsverpflichtungen würde leisten können, wenn es über sein ganzes Eisenbahnnetz verfügte.

Im Zusammenhang mit den Maßnahmen, die Frankreich ergriff, um Deutschland einerseits zum Nachgeben $z u$ zwingen und um andererseits das Ruhrpfand "produktiv" zu machen, sind auch die Versuche zu sehen, Bergwerke und Kokereien im Ruhrgebiet direkt auszubeuten. Ab September 1923 wurden sukzessive ausgewählte Bergwerke und Kokereien besetzt, um vor allem die Koksversorgung der französischen Schwerindustrie sicherzustellen. Bis Dezember 1923 konnte aus den besetzten Gruben und Kokereien Kohlen und Koks nach Frankreich geliefert werden, die etwa einem Drittel der festgelegten Sachlieferungen entsprachen ${ }^{92}$. Diese Aktionen standen im Zusammenhang mit Fühlungnahmen zwischen dem Verband der französischen Eisenindustriellen, dem Comité des forges, und den an der Ruhraktion beteiligten Ministerien, vor allem dem Quai d'Orsay und dem Ministerium für öffentliche Arbeiten $^{93}$. Bereits Anfang des Jahres 1923 hatte der Comité des forges seinen Generalsekretär Robert Pinot beauftragt, einen Bericht über die Schwierigkeiten der französischen Schwerindustrie zu verfassen, der am 16. April 1923 übergeben wurde. Dieser Bericht, der den entsprechenden Ministerien vorlag, von dort aber wohl keine offizielle Antwort erfuhr, bezeichnete als das Kernproblem der französischen Industrie die Abhängigkeit der Eisenproduktion von deutschem und englischem Koks. Aufgrund der Ausfälle der deutschen Sachlieferungen nach der Ruhrbesetzung habe die Produktion der lothringischen Eisenwerke auf die Hälfte zurückgefahren werden müssen. Als Abhilfe forderte der Comité des forges, der allerdings erst am 29. Oktober 1923 den Bericht Pinots zu seiner offiziellen Linie machte ${ }^{94}$, von den politischen Stellen, Vorzugslieferungen von 1,5 Mio. $t$ Koks bei der deutschen Industrie durchzusetzen, die alten Absatzgebiete der lothringischen Schwerindustrie, vor allem das Ruhrgebiet und den süddeutschen Raum, wiederherzustellen und die Übertragung der Eigentumsrechte derjenigen Ruhrbergwerke, die vor dem Krieg die lothringischen Eisenwerke versorgt hatten, auf deren neue französi-

${ }^{92}$ Siehe ibid. S. 310 f.

${ }^{93}$ Zur Einflußnahme des Comité des forges siehe ibid. S. 366-369.

${ }^{94}$ Als Grund für diese lange Phase der Passivität zwischen der Vorlage des Pinot-Berichts und den Vorstößen des Comité des forges bei den politischen Stellen dürften wohl Auseinandersetzungen innerhalb der französischen Industrie eine Rolle gespielt haben: Der französische Kohlenproduzentenverband, der Comité central des houillères de France (C.C.H.F.), lehnte die Pläne des Comité des forges ab, weil es eine Schwächung der französischen Bergwerksbesitzer gegenüber den Eisenindustriellen befürchtete, falls diese auch noch ihre eigene Koksversorgung, zumindest teilweise, sicherstellen konnten. Aber auch innerhalb des Comité des forges gab es Widerstände, vor allem von den de Wendels: Sie besaßen bereits Bergwerke in Deutschland und fürchteten um ihren Vorsprung gegenüber den Konkurrenten, sollten diese nun auch Bergwerke oder zumindest Beteiligungen in Deutschland erhalten, siehe ibid. 
sche Besitzer, die jetzt diese Werke betrieben. Der Quai d'Orsay, die H.C.I.T.R. und die M.I.C.U.M. machten sich nun die Vorstellungen des Comité zu eigen, und in einem gemeinsamen Bericht vom 20. Dezember 1923 forderten Guillaume und der neue Chef der M.I.C.U.M., Paul Frantzen ${ }^{95}$, eine Beteiligung französischer Unternehmen an deutschen Bergwerken. Eine Übertragung der vollen Eigentumsrechte wurde jedoch verworfen, weil man in diesem Fall eine Diskriminierung der Bergwerke in französischem Besitz, z.B. beim Transport, befürchtete, und weil man in Frankreich nur an Koks interessiert war; um die nicht verkokbare Kohlen aus diesen Bergwerken sollten sich dann die deutschen Anteilseigner kümmern.

Im Sommer des Jahres 1923 begannen die französischen Pressionen Wirkung zu zeigen: Der passive Widerstand bröckelte, und das Ruhrpfand wurde durch die Eisenbahnregie und die Konfiszienung von Kohlen und Geld nun tatsächlich produktiv.

Die Reichsregierung hatte schon recht bald nach der Ausrufung des passiven Widerstandes erkannt, daß sie diese Abwehrmaßnahme gegen Frankreich nur begrenzte Zeit würde aufrechterhalten können ${ }^{96}$. Trotz aller öffentlichen Durchhalteparolen hatte Cuno bereits frühzeitig über Mittelsmänner Kontakt mit den Alliierten aufnehmen lassen, um zu einer Lösung für das Ruhrproblem zu kommen. Zum einen bemühte man sich, direkt mit Frankreich ins Gespräch zu kommen: Stinnes versuchte Ende März 1923 über seinen Emissär in Paris, Alfred Schmidt, und den Pariser Korrespondenten der Stinnes nahestehenden "Deutschen Allgemeinen Zeitung" (DAZ), Werner Sinn, Kontakt zu verschiedenen französischen Politikern wie beispielsweise Millerand, Loucheur oder Herriot aufzunehmen, allerdings ohne Erfolg ${ }^{97}$. Erfolglos blieb auch die Fühlungnahme Maltzans Mitte April mit Oswald Hesnard ${ }^{98}$, um zu einer Übereinkunft auf Basis der Vorschläge von Hughes' New Haven-Rede und dem Angebot eines Sicherheitspakts zu kommen, der sowohl die westlichen wie auch die östlichen Grenzen einschloß. Gleichzeitig bemühte sich die Reichsregierung, über Frankreichs ehemalige Verbündete Paris zum Einlenken zu bewegen. Einer Demarche des deutschen Botschafters in London, Friedrich Sthamer, beim Foreign Office in London war aber ebenso wenig Erfolg beschieden

${ }^{95}$ Émile Coste, der als zu weich galt, wurde im März 1923 durch Frantzen an der Spitze der M.I.C.U.M. abgelöst, siehe ibid. S. 427.

${ }_{96}$ Zum folgenden siehe ibid. S. 176-178.

${ }^{97}$ Zu Einzelheiten vgl. Peter WULF, Hugo Stinnes. Wirtschaft und Politik 1918-1924, Stuttgart 1979 (Kieler Historische Studien, 28), S. 356-379.

${ }_{98}$ Die Rolle, die Hesnard in der französischen Botschaft in Berlin spielte, ist etwas diffus: Er war kein Botschaftsmitglied, aber an die Botschaft angegliedert, vgl. T. DE MOREMBERT, art. "Hesnard (Oswald)«, in: Roman D'AMAT, R. LIMOUZIN-LAMOTHE (Hg.), Dictionnaire de biographie française, Bd. 17, Paris 1989, Sp. 1164; Jacques BARIÉTY, Finances et relations internationales: $\grave{A}$ propos du "plan du Thoiry“ (septembre 1926), in: Relations internationales 21 (1980), S. 51-70, hier S. 51, 55f. 
wie den Gesprächen des deutschen Botschafters in Rom, Konstantin von Neurath, mit Mussolini.

Durch den Rücktritt des amtsmüden Cuno und den Regierungsantritt Stresemanns am 13. August $1923^{99}$ kam neuer Schwung in die Vermittlungsbemühungen $^{100}$. Das Ziel Stresemanns war zunächst einmal die Beendigung des passiven Widerstandes. Erst wenn dieses Faß ohne Boden gestopft war, konnte die deutsche Währung saniert und eine erträgliche Reparationsregelung gefunden werden. Diesen Überlegungen lag das Kalkül zugrunde, daß vor allem die USA und England nicht mehr länger dem wirtschaftlichen Verfall Deutschlands - und somit dem Verlust eines wichtigen Exportmarktes und potentiellen Kreditnehmers - zusehen wollten. Auch für Frankreich war nach Ansicht Stresemanns die Ruhrbesetzung nur die zweitbeste Lösung: Die Kosten für Frankreich waren politisch wie wirtschaftlich hoch, und Paris mußte ein Interesse an dauerhaft gesicherten Reparationen haben. Jedoch: Stresemann wollte, solange der passive Widerstand noch leidlich funktionierte, diese letzte verbliebene Trumpfkarte nicht ohne Gegenleistungen ausspielen, zumal seine Position, sollte er den Ruhrkampf bedingungslos abbrechen, nicht nur politisch höchst gefährdet gewesen wäre: $» F$ alls die Regierung eine bedingungslose Aufgabe des passiven Widerstandes vertreten wolle, würde, wie mir der Führer der Deutschnationalen Exzellenz Hergt gesagt habe, der Reichskanzler ein - mindestens politisch - toter Mann sein « ${ }^{101}$.

Zur gleichen Zeit mehrten sich die Anzeichen dafür, daß vor allem England und die USA das Vorgehen Frankreichs nicht mehr weiter hinnehmen wollten. England stellte in einer Note vom 11. August 1923 erstmals die Rechtmäßigkeit der Ruhraktion in Frage ${ }^{102}$, und Präsident Harding schlug erneut die Einsetzung einer Expertenkommission oder einer Regierungskonferenz zur Lösung der Reparationsfrage vor ${ }^{103}$. Trotz dieser für Deutschland positiven Signale scheiterten zunächst die Versuche Stresemanns, die englische Regierung zu einer aktiveren Haltung gegenüber Frankreich zu bewegen ${ }^{104}$. Die Reichsregierung setzte nun auf Brüssel, das man für konzilianter als Paris hielt. Gegenüber dem belgischen Gesandten in Berlin, dem Comte Della Faille, schlug Stresemann am 1. September 1923 als Gegenleistung für das Ende

\footnotetext{
${ }^{99}$ Zur Entstehung des Kabinetts Stresemann siehe BAECHLER, Stresemann, S. $341 \mathrm{f}$.

${ }^{100} \mathrm{Zu}$ den Zielen und Vermittlungsbemühungen Stresemanns siehe Karl Dietrich ERDMANN, Alternativen der deutschen Politik im Ruhrkampf, in: Klaus SCHWABE (Hg.), Die Ruhrkrise 1923. Wendepunkt der internationalen Beziehungen nach dem Ersten Weltkrieg, Paderborn 1984, S. 29-38, hier S. 31-33.

${ }^{101}$ Besprechung des Reichskanzlers mit dem belgischen Gesandten (16.9.1923), AdR Stresemann I/II Bd. 1, Nr. 61.

${ }^{102}$ Siehe Jonathan WRIGHT, Stresemann and Locarno, in: Contemporary European History 4 (1995), S. 109-131, hier S. 114. Text der Note: DBFP 1.XXI, Nr. 330.

${ }^{103}$ Siehe DUROSELlE, Histoire, S. 67.

${ }^{104}$ Siehe BAECHLER, Stresemann, S. 354.
} 
der Ruhrbesetzung den Abbruch des passiven Widerstandes und einen Sicherheitspakt ähnlich des später in Locarno zustande gekommenen vor. Als Pfand für die Reparationen bot er die Belastung der deutschen Industrie und Landwirtschaft sowie der Eisenbahnen durch eine Hypothek zugunsten der Alliierten $a^{105}$. Eine Beteiligung belgischer und französischer Industrieller an deutschen Unternehmen stellte er ebenfalls in Aussicht. Einen Tag später, bei einer Rede in Stuttgart, unterstrich Stresemann zwar die Forderung nach einem Moratorium und einer Anleihe für Deutschland, gleichzeitig bekundete er aber auch den Willen zur deutsch-französischen Zusammenarbeit auf wirtschaftiichem und politischem Gebiet ${ }^{106}$. Am Tag darauf übermittelte er die Vorschläge, die er bereits Della Faille gemacht hatte, dem französischen Botschafter in Berlin, de Margerie ${ }^{107}$. Zwei Wochen später kam es zu einem neuerlichen Gespräch mit dem belgischen Gesandten, in dem Stresemann nochmals die Bedingungen für den Abbruch des passiven Widerstands nannte: die Freilassung der politischen Gefangenen und Rückkehr der Ausgewiesenen sowie Garantien für die Einheit des Reiches ${ }^{108}$, womit vor allem die Rückkehr zum Rheinlandstatut und zum Status quo ante des 11. Januar 1923 sowie die Rückgabe der Regieeisenbahnen unter deutsche Verwaltung gemeint waren ${ }^{109}$.

Allerdings: Poincaré lehnte die deutschen Vorschläge rundheraus ab und instruierte seinen Botschafter sogar, sich nicht einmal auf offiziöse Gespräche diesbezüglich einzulassen ${ }^{110}$ : Jetzt auf Verhandlungen einzugehen, hieße, einen wichtigen Trumpf aus der Hand zu geben, wo der passive Widerstand sowieso nur noch für wenige Tage oder Wochen aufrechterhalten werden kön$\mathrm{ne}^{111}$.

Das Treffen zwischen dem neuen englischen Premier Baldwin und Poincaré am 19. September 1923 dämpfte den deutschen Optimismus weiter. Zwar kam es bezüglich der Ruhrfrage zu keiner einheitlichen Position, doch wurden die Irritationen, die durch die englische Note vom 11. August ausgelöst worden waren, beigelegt ${ }^{12}$. Die Hoffnungen Deutschlands, durch eine Intervention Englands doch noch einige Vorteile aus der Aufgabe des passiven Widerstands ziehen zu können, schwanden zusehends ${ }^{113}$. Da Poincaré zwischenzeit-

\footnotetext{
${ }^{105}$ Siehe JEANNESSON, Poincaré, S. 294.

${ }^{106}$ Siehe BAECHLER, Stresemann, S. 356.

${ }^{107}$ Siehe JEANNESSON, Poincaré, S. 294.

${ }^{108}$ Siehe Unterredung des Reichskanzlers mit dem belgischen Gesandten (16.9.1923), AdR Stresemann I/II Bd. 1, Nr. 61.

${ }^{109}$ Siehe Kabinettssitzung (18.9.1923), AdR Stresemann I/II Bd. 1, Nr. 64.

110 Siehe Unterredung des Reichskanzlers mit dem franzosischen Botschafter (17.9.1923), AdR Stresemann I/II Bd. 1, Nr. 62 und Aufzeichnung Stresemann (18.9.1923), ADAP A VIII, Nr. 152.

${ }^{111}$ Siehe BARIÉTY, Relations franco-allemandes, S. 226f.

${ }^{112}$ Siehe JEANNESSON, Poincaré, S. 192f.

${ }^{113}$ Siehe Hoesch an AA (21.9.1923), ADAP A VIII, Nr. 158.
} 
lich durch Zugeständnisse an Italien in der Korfufrage sich auch der Unterstützung Roms in der Ruhrpolitik versichern konnte, sah sich Deutschland weiterhin isoliert ${ }^{114}$.

Intern liefen bei der Reichsregierung derweil die Vorbereitungen, den passiven Widerstand bedingungslos abzubrechen. Bei einer Besprechung mit Parteivertretern aus den besetzten Gebieten am 24. September 1923 sprachen sich bis auf den Vertreter der Deutschnationalen Volkspartei (DNVP) alle für einen Abbruch des passiven Widerstandes aus ${ }^{115}$. Am gleichen Tag traf Stresemann mit Wirtschaftsvertretern zusammen, die ebenfalls für die Beendigung des Ruhrkampfs waren ${ }^{116}$. Auch die Ministerpräsidenten der Länder votierten mehrheitlich dafür ${ }^{117}$.

Am 26. September 1923 verkündete die Regierung Stresemann die Beendigung des passiven Widerstandes ${ }^{118}$. Tags darauf wurden per Dekret alle im Zusammenhang damit erlassenen Verordnungen und Gesetze aufgehoben ${ }^{119}$.

Warum und woran scheiterte der passive Widerstand letztlich? Der Ruhrkampf wurde zunehmend unfinanzierbar, und, so stellte Maltzan fest, "[d]iese Tatsache ist von entscheidender Bedeutung ${ }^{120}$. Der passive Widerstand verschlang täglich $40 \mathrm{Mio}$. $\mathrm{GM}^{121}$, denen keinerlei Einnahmen aus dem besetzten Gebiet gegenüberstanden. So führte dieses immer größer werdende Ungleichgewicht der öffentlichen Finanzen auch zur immer dramatischeren Entwertung der Mark, nachdem die letzten verzweifelten Stabilisierungsversuche im April 1923 gescheitert waren ${ }^{122}$. Der Verfall der Währung und die wirtschaftlichen Repressalien führten außerdem zu sozialen Spannungen. Bereits im Juni 1923 lag die Arbeitslosigkeit im Ruhrgebiet bei über vier Prozent, acht Mal so hoch wie noch im Vorjahresmonat, und da die Währung schneller an Wert verlor als die Löhne stiegen, wurde auch die Versorgung derjenigen Arbeiter, die noch in Lohn und Brot standen, immer schwieriger ${ }^{123}$. Voraussetzung für die Sanierung der Währung war aber wiederum die Beendigung des passiven Widerstands ${ }^{124}$. Die wirtschaftliche Not und die aus ihr resultierenden Unruhen führten darüber hinaus zu einer politischen Radikalisierung besonders bei

${ }^{114}$ Schubert an Stresemann (20.9.1923), ADAP A VIII, Nr. 157.

115 Siehe Besprechung mit Vertretern der 5 Parteien und Vertretern des besetzten Gebiets (24.9.1923), AdR Stresemann VII Bd. 1, Nr. 76.

${ }^{116}$ Siehe Besprechung mit Vertretern der Wirtschaftsverbände und Beamtenorganisationen des besetzten Gebiets (24.9.1923), AdR Stresemann I/II Bd. 1, Nr. 77.

117 Besprechung mit den Ministerpräsidenten (25.9.1923), AdR Stresemann I/I Bd. 1, Nr. 79.

${ }^{118}$ Siehe GIRAULT, Europe, S. 134.

${ }^{119}$ Siehe JEANNESSON, Poincaré, S. 296.

${ }^{120}$ Runderlaß Maltzan (10.9.1923), ADAP A VII, Nr. 138.

${ }^{121}$ Siehe ibid.

${ }^{122}$ Siehe JEANNESSON, Poincaré, S. 274.

${ }^{123}$ Siehe Leipart an Walker (29.8.1923), AdR Stresemann I/II Bd. 1, Nr. 32.

${ }^{124}$ Siehe Kabinettssitzung (7.9.1923), AdR Stresemann III Bd. 1, Nr. 47. 
Kommunisten und extremen Nationalisten. Der passive Widerstand wurde gewalttätiger und richtete sich zunehmend nicht nur gegen die Besatzer, sondern auch gegen die verhaßte Regierung in Berlin ${ }^{125}$. Außerdem entfremdete der kommunistische und nationalistische Terror auch die Bevölkerung des besetzten Gebiets vom Reich ${ }^{126}$. Im Zusammenhang mit diesen politischen Auflösungserscheinungen waren auch die monarchistischen Umtriebe in Bayern und die kommunistischen Unruhen in Thüringen und Sachsen zu sehen, die den Bestand des Reiches und seiner republikanischen Institutionen zunehmend bedrohten ${ }^{127}$. Besonders augenscheinlich wurde dies aber an den im Herbst 1923 wieder aufbrechenden separatistischen Unruhen im Rheinland ${ }^{128}$. Der Erfolg Frankreichs bei der Nutzbarmachung des Ruhrpfandes mußte den deutschen Durchhaltewillen weiter erschüttern ${ }^{129}$. So wurde der passive Widerstand schließlich nur noch weitergeführt, um einige Zugeständnisse zu erhalten und um nicht das Gesicht zu verlieren. Doch die Lage wurde immer verzweifelter: "Allgemeine Überzeugung: Sofort Verhandlungen mit Frankreich - passiven Widerstand aufrechterhalten, damit Zeit zu Verhandlungen ${ }^{130}$. Aber Ende September war der deutsche Spielraum völlig erschöpft ${ }^{131}$ und fast alle politischen Kräfte waren zur Aufgabe bereit ${ }^{132}$.

Auch außenpolitisch stand das Reich mit dem Rücken an der Wand, denn so sehr begrüßenswert die englische Note vom 11. August 1923 auch war, "so muß gleichwohl eine nüchterne Beurteilung der ganzen englischen Haltung während der Ruhrkrisis zu dem Schluß gelangen, daß die Haltung Englands in dem Ruhrkonflikt nicht als aktiver Faktor für die deutsche Politik betrachtet und eingesetzt werden könne. Dasselbe mußte von der Haltung der italienischen Politik gelten ${ }^{133}$. Poincaré hatte also gewonnen, auf der ganzen Linie: Deutschland lag wirtschaftlich und politisch am Boden. Langsam, aber stetig steigend, strömte Koks über Eisenbahnen, die fest in französisch-belgischer Hand waren, zu den lothringischen Hochöfen, und man hatte weder den Deut-

\footnotetext{
${ }^{125}$ Siehe JEANNESSON, Poincaré, S. 262.

${ }^{126}$ Siehe ibid. S. 264.

${ }^{127}$ Siehe BARIÉTY, Relations franco-allemandes, S. $237 \mathrm{f}$.

${ }_{128} \mathrm{Vgl}$. Bericht über die Haltung der Parteien im Ruhrgebiet [Aufzeichnung Dinger] (15.9.1923), AdR Stresemann I/II Bd. 1, Nr. 60 und Bericht über die Sitzung der Arbeitsgemeinschaft der politischen Parteien des alt- und neubesetzten Gebiets in Elberfeld [Aufzeichnung Rausch] (19.9.1923), AdR Stresemann I/II Bd. 1, Nr. 70.

${ }^{129}$ Siehe JeANNESSON, Poincaré, S. 268.

${ }^{130}$ Besprechung mit rheinischen Abgeordneten (6.9.1926), AdR Stresemann I/II Bd. 1, Nr. 43.

131 Besprechung mit Vertretern der 5 Parteien und Vertretern des besetzten Gebiets (24.9.1923), AdR Stresemann I/II Bd. 1, Nr. 76.

${ }_{132}$ Bericht über die Haltung der Parteien im Ruhrgebiet [Aufzeichnung Dinger] (15.9.1923) AdR Stresemann I/II Bd. 1, Nr. 60.

${ }^{133}$ Runderlaß Maltzan (10.9.1923), ADAP A VII, Nr. 138.
} 
schen noch den Engländern oder Belgiern irgendwelche Zugeständnisse machen müssen.

Allerdings, so eindeutig und total wie der französische Sieg Ende September 1923 schien, war er keinesfalls. Fünf große Entwicklungslinien, zum Teil eng miteinander verwoben, sorgten dafür, daß sich bis Ende 1923 eine grundlegende Änderung der Situation, in der sich Deutschland und Frankreich befanden, einstellen sollte. Diese fünf Faktoren waren die grundlegende Änderung des außenpolitischen Umfelds, die Privatverhandlungen zwischen den Besatzungsbehörden und der deutschen Wirtschaft, die Vorarbeiten zum Dawes-Plan sowie das Aufflammen des Separatismus im Rheinland und die Verschiebungen in den innenpolitischen Kräfteverhältnissen beider Länder.

Bereits im Sommer des Jahres 1923 deutete sich an, daß weder die USA noch Großbritannien bereit waren, die französische Politik im Rheinland und im Ruhrgebiet langfristig zu dulden. In beiden Ländern mehrten sich Befürchtungen, daß die Auflösungserscheinungen Deutschlands zu einer Destabilisierung ganz Europas beitragen und der kommunistischen Bewegung neuen Auftrieb geben würden ${ }^{134}$. Der dauerhafte Ausfall Deutschlands als wichtigem Absatzmarkt und Auffangbecken für Investitionen sowie die Sorge einer sowohl wirtschaftlichen als auch politischen Hegemonie Frankreichs in Europa verstärkten die Befürchtungen in London und Washington ${ }^{135}$.

Die Vereinigten Staaten hatten sich nach der Rede Hughes in New Haven Ende des Jahres 1922 zunächst passiv verhalten. Erst im Sommer des Jahres 1923 kam erneut Bewegung in die amerikanische Politik. Zum einen waren die USA jetzt stärker an einer Lösung der Reparationsfrage interessiert ${ }^{136}$ : Durch das Wadsworth-Abkommen ${ }^{137}$ vom 25. Mai 1923, das beinhaltete, daß die amerikanischen Besatzungskosten nicht mehr durch konfisziertes deutsches Eigentum, sondern aus den deutschen Reparationszahlungen geleistet werden sollten, und durch das Schuldenabkommen zwischen England und den Vereinigten Staaten vom 18. Juni $1923^{138}$ entstand ein noch engerer Nexus zwischen Reparations- und Schuldenfrage, obwohl das offizielle Washington stets diesen Zusammenhang leugnete. Da der Ruhrkampf aber die deutschen Leistungen so gut wie zum Erliegen gebracht hatte, mußte es auch im ameri-

\footnotetext{
${ }^{134}$ Siehe KRÜGER, Außenpolitik, S. 219; GIRAULT, Europe, S. 135.

${ }^{135}$ Siehe LINK, Ruhrkonflikt, S. 46; KRÜGER, Außenpolitik, S. 219.

${ }^{136}$ Siehe LiNK, Ruhrkonflikt, S. 45.

${ }^{137}$ Text des Abkommens: Wadsworth an Hughes (26.5.1923), Papers Relating to the Foreign Relations of the United States, hg. v. Department of State [FRUS], 1923, II, Washington D.C. 1938 , S. $180-186$.

${ }^{138}$ Bereits seit Anfang Februar hatte man sich jedoch auf die Grundprinzipien eines Abkommens geeinigt, siehe Combined Annual Reports of the World War Foreign Debt Commission. With additional Information regarding Foreign Debts due to the United States Fiscal Years 1922, 1923, 1924, 1925 and 1926, hg. v. World War Foreign Debt Commission, Washington D.C. 1927, S. 11 f.
} 
kanischen Interesse sein, zu einer Lösung des Reparationsproblems zu kommen. Außerdem mehrten sich in den Sommermonaten die negativen Folgen des Ruhrkampfs furr die US-Wirtschaft: Die Agrar- und Kapitalexporte gingen zurück, und die Stimmen, die vor einer wirtschaftlichen Balkanisierung Europas warnten - eine Befürchtung, die durch die völlig aus dem Ruder laufende Inflation nicht nur in Deutschland noch verstärkt wurde - mehrten sich ${ }^{139}$. Der plötzliche Tod Präsident Hardings am 2. August $1923^{140}$ und die Amtsübernahme durch Calvin Coolidge bewirkten eine Änderung der Haltung Washingtons, weil der neue Präsident vor allem in Frankreich den "stumbling block « ${ }^{141}$ für die Reparationsfrage erblickte. Die Verhandlungen zum deutschamerikanischen Handelsvertrag, die im Sommer 1923 begannen, machten dabei das wirtschaftliche Interesse der USA an Deutschland deutlich. Dieser Vertrag hatte Modellcharakter, weil er die Ziele der amerikanischen Außenwirtschaftspolitik in Europa definierte: Die USA wollten den möglichst ungehinderten Zugang zu allen europäischen Märkten, was durch Handelsverträge, die auf der Meistbegünstigung basierten, erreicht werden sollte. Eine in Washington befürchtete wirtschaftliche Hegemonie Frankreichs in Europa hatte in diesem Konzept keinen Platz ${ }^{142}$.

Ähnlich wie die USA hatte sich auch Großbritannien zunächst abwartend gegenüber der französischen Politik verhalten und wohlwollende Neutralität gegenüber den belgischen und französischen Aktionen gezeigt. Ein Grund für diesen Attentismus war die bereits angesprochene Befürchtung, in Paris vollends an Einfluß zu verlieren, sollte es zum endgültigen Bruch mit Frankreich kommen ${ }^{143}$. Auch innenpolitische Überlegungen ließen London zunächst von einer eindeutigen Positionsbestimmung zurückschrecken, denn neben der Ablehnung der Ruhrbesetzung durch die oppositionelle Labour Party ${ }^{144}$ gab es insbesondere am rechten Rand der regierenden konservativen Partei starke frankophile Strömungen ${ }^{145}$. Außerdem verdiente Großbritannien anfangs sehr gut am Ruhrkampf und konnte seine Kohlenexporte, da die deutsche Förderung infolge des passiven Widerstands daniederlag, kräftig ausweiten, bei gleichzeitig steigenden Kohlenpreisen. Auch andere Wirtschaftszweige profitierten zunächst vom Ausfall der deutschen Konkurren $z^{146}$. Allerdings endete diese Katastrophenkonjunktur bereits im August, und die negativen wirtschaft-

\footnotetext{
${ }^{139}$ Siehe LINK, Ruhrkonflikt, S. 45f.

${ }^{140}$ Siehe William A. DEgREgorIo, The Complete Book of U.S. Presidents, New York ${ }^{3} 1991$, S. 442.

${ }^{141}$ Dieckhoff an AA (13.10.1923), ADAP A LX, Nr. 189.

${ }^{142}$ Siehe LINK, Ruhrkonflikt, S. 45.

${ }^{143}$ Siehe SCHWABE, Ruhrkrise, S. $62 \mathrm{f}$.

144 Siehe Leipart an Walker (29.8.1923), AdR Stresemann I/II Bd. 1, Nr. 32.

145 Siehe Aufzeichnung Stresemann (17.8.1923), AdR Stresemann III Bd. 1, Nr. 8, siehe auch SCHWABE, Ruhrkrise, S. 63.

${ }^{146}$ Siehe JeANNESSON, Poincaré, S. $240 \mathrm{f}$.
} 
lichen Folgen des Ruhreinbruchs machten sich auch in England immer stärker bemerkbar: Der deutsche Markt war weitgehend zusammengebrochen, und die Hausse der Kohlepreise ließ in dem Maße nach, in dem es Frankreich gelang, das Ruhrpfand in den Griff $\mathrm{zu}$ bekommen ${ }^{147}$. Außerdem setzte sich in der Presse wie im Parlament eine zunehmend kritischere Haltung gegenüber Frankreich durch, die ihre Grundlagen vor allem darin hatte, daß das Ruhrpfand nun tatsächlich Gewinn abzuwerfen schien und mit der französischen Herrschaft über die Ruhr ein deutsch-französischer Wirtschaftsblock entstehen könnte, der die britischen Wirtschaftsinteressen bedrohte ${ }^{148}$. Entscheidend für die Änderung der englischen Politik gegenüber Frankreich war, daß Paris, nachdem Deutschland den passiven Widerstand aufgegeben hatte, weiter an seiner unnachgiebigen Politik gegenüber Berlin festhielt ${ }^{149}$. Für London wurde damit endgültig klar, daß Frankreich eben keine Lösung für das Reparationsproblem suchte, sondern weitreichende (sicherheits-)politische Interessen an Rhein und Ruhr verfolgte. Zunehmende Verbitterung erfuhr auch, daß Frankreich weiterhin seine osteuropäischen Verbündeten mit Rüstungskrediten versorgte, sich aber gleichzeitig weigerte, seine Kriegsschulden in England zu bezahlen ${ }^{150}$. Die zweideutige Haltung Frankreichs bei den separatistischen Unruhen ab Ende Oktober 1923, der französische Widerstand bei der Einsetzung des Dawes-Komitees, die Pläne für die-Eisenbahnregie und eine rheinische Notenbank verstärkten dieses Mißtrauen gegenüber der französischen Politik nur noch weiter ${ }^{151}$. Nachdem die Labour Party bei den Wahlen im November starke Zugewinne erzielen konnte, gewannen die Frankreichkritischen Kräfte weiter an Gewicht ${ }^{152}$.

Auch in Belgien, das aufgrund seiner Position als Zünglein an der Waage in vielen alliierten Gremien, wie z.B. der H.C.I.T.R. oder der RepKo, eine wichtige Rolle spielte, fand eine außenpolitische Reorientierung statt. Brüssel hatte von Anfang an in der Ruhraktion ein Mittel zum Zweck - in diesem Falle: zur Lösung des leidigen Reparationsproblems - gesehen ${ }^{153}$. Zur Teilnahme der Ruhraktion hatte sich die belgische Regienung auch erst dann entschlossen, als London den Wünschen der Belgier nicht entgegengekommen war ${ }^{154}$. Die sich zunehmend manifestierenden politischen Ambitionen Frankreichs im Rheinland beunruhigten dagegen Brüssel. Stand nicht zu befürchten, daß, wenn im

\footnotetext{
${ }^{147}$ Siehe ibid. S. 241.

${ }^{148}$ Siehe SCHWABE, Ruhrkrise, S. $67 \mathrm{f}$.

${ }^{149}$ Zum folgenden siehe ibid. S. 76-78.

iso Siehe Aufzeichnung Schubert (21.11.1923), ADAP A IX, Nr. 10. Ausführlich hierzu vgl. WURM, Sicherheitspolitik, S. 30-54.

${ }^{151}$ Siehe Jules LAROCHE, Au Quai d'Orsay avec Briand et Poincaré, 1913-1926, Paris 1957, S. 182.

${ }^{152}$ Siehe KRÜGER, Versailles, S. 122.

${ }^{153}$ Siehe ROTH, Belgique, S. 132.

${ }^{154}$ Siehe ibid. S. 131.
} 
Rheinland ein profranzösischer Satellitenstaat entstünde, Belgien gewissermaBen von Frankreich umzingelt sei? Und könnte die französische Unterstützung für den rheinischen Separatismus nicht auch den flämischen Separatisten als Vorwand zu neuerlicher Aktivität dienen ${ }^{155}$ ? Als man sich in London nun gemüßigt sah, eine aktivere Politik gegenüber Frankreich zu betreiben, war dies nur im belgischen Interesse ${ }^{156}$.

Auch das ebenfalls in verschiedenen alliierten Gremien vertretene Italien ${ }^{157}$ war, was die französischen Ziele in der Ruhr anging, skeptisch. Mussolini fürchtete ebenfalls einen deutsch-französischen Wirtschaftsblock. Italiens Teilnahme am Ruhrkampf war in erster Linie dadurch motiviert, dies zu verhindern. Als sich der Wind gegen Frankreich zu drehen begann, nahm auch die italienische Regierung zunehmend Abstand zu Frankreich.

Betrachtet man diese außenpolitischen Veränderungen, so hatte Frankreich, im Vergleich zum Sommer, im Herbst 1923 mit wesentlich stärkerem Widerstand zu rechnen, während die deutsche Lage sich etwas rosiger darstellte, auch wenn eine substantielle Unterstuitzung nach wie vor kaum erfolgte.

Eng im Zusammenhang mit den Verschiebungen auf außenpolitischem Gebiet sind die Entwicklungen zu sehen, die zur Einberufung eines Expertenkomitees zur Feststellung der deutschen Zahlungsfähigkeit, dem späteren Dawes-Komitee, führten. In vielerlei Hinsicht verlief die Entwicklung parallel zu den außenpolitischen Ereignissen. Die Initiative zu einer Kommission, die die deutsche wirtschaftliche Leistungsfähigkeit - und somit die Fähigkeit Deutschlands, Reparationen zu zahlen - feststellen sollte, ging, wie gesagt, von den USA aus: Hughes hatte bereits im Sommer 1922 und erneut in seiner New Haven-Rede ein solches Gremium ins Spiel gebracht. Am 20. Juli 1923 sandte die britische Regierung eine Note an Frankreich ${ }^{158}$, in der der HughesPlan zur Lösung der Reparationsfrage erneut aufgegriffen wurde und die sim Kontext intensiver diplomatischer Beratungen zwischen der britischen und amerikanischen Führung zu sehen ist ${ }^{159}$. Durch den Tod Präsident Hardings wurden die Bemühungen zunächst unterbrochen ${ }^{160}$. Am 12. Oktober 1923 unternahm London einen erneuten Versuch, die USA zur Teilnahme an der Lösung der Reparationsfrage zu bewegen, da die britischen Versuche bei den eu-

${ }^{155}$ Die Haltung Belgiens bei den separatistischen Unruhen im Rheinland ist ebenfalls nicht ganz eindeutig; zu Einzelheiten s.u. Zur Frage des flämischen Separatismus im Zusammenhang mit den Unruhen im Rheinland siehe Bericht des Reichspostministers über Lage und Aussichten der separatistischen Bewegung in Düsseldorf (28.9.1923), AdR Stresemann III Bd. 1, Nr. 89.

${ }^{156}$ Siehe ROTH, Belgique, S. 134.

${ }^{157}$ Zur Haltung Italiens siehe JEANNESSON, Poincaré, S. $246 \mathrm{f}$.

${ }^{158}$ Siehe Curzon an Saint-Aulaire (20.7.1923), DBFP 1 XXI, Nr. 306.

${ }^{159}$ LINK, Ruhrkonflikt, S. 47. Zum folgenden siehe ibid. S. 47f.

${ }^{160}$ Siehe Melvyn P. LefFLeR, The Elusive Quest. America's Pursuit of European Stability and French Security, 1919-1933, Chapel Hill 1979, S. 87. 
ropäischen Alliierten nichts bewirkt hätten, aber "without such action, not merely Germany, but Europe appears to be drifting into economic disaster ${ }^{161}$. Am 15. Oktober 1923 stimmten die USA dem endlich $\mathrm{zu}^{162}$, und am 19. Oktober 1923 beauftragte die britische Regierung ihren Botschafter in Paris, Crewe, der französischen Regierung mitzuteilen, daß die USA bereit seien, sich an einer Regierungskonferenz oder einem Expertengremium zur Bestimmung der wirtschaftlichen Leistungsfähigkeit Deutschlands zu beteiligen ${ }^{163}$. Auslöser für diesen Stimmungswandel in Washington waren die Verhandlungen zwischen der M.I.C.U.M. und den Ruhrindustriellen, die in den USA und in Großbritannien die Furcht vor einem deutsch-französischen Wirtschaftsblock nährten. Hughes' Andeutung gegenüber dem französischen Geschäftsträger in Washington am 22. Oktober 1923, die eine mögliche Verbindung des Reparations- mit dem Kriegsschuldenproblem erkennen lie $\beta^{164}$, bewegte wohl Poincaré dazu, am 25. Oktober 1923 den angloamerikanischen Vorschlägen zur Einsetzung eines Expertenkomitees (eine Regierungskonferenz lehnte er ab) zuzustimmen ${ }^{165}$, allerdings unter Auflagen ${ }^{166}$ : Die Experten sollten im Auftrag der RepKo arbeiten, und ihre Expertise sollte sich lediglich auf die Feststellung der Leistungsfähigkeit Deutschlands zur Zahlung der Reparationen (einschließlich des deutschen Kapitals, das ins Ausland verschoben worden war) beschränken. Über die Höhe der von Deutschland zu leistenden Reparationszahlungen - die in Spa festgelegten $132 \mathrm{Mrd}$. GM - sollten nicht verhandelt werden. Auch die Ruhrbesetzung und die M.I.C.U.M.-Verträge sollten ausdrücklich ausgeklammert bleiben und die Räumung des Ruhrgebiets nur nach Maßgabe der deutschen Zahlungen erfolgen.

Die deutsche Reparationsnote vom 24. Oktober $1923^{167}$ hatte die Entscheidung der französischen Regierung sicherlich erleichtert, denn Deutschland hatte sich mit der Berufung auf Art. 234 des Versailler Vertrags, der die

\section{${ }^{161}$ Curzon an Chilton (12.10.1923), DBFP 1 XXI, Nr. 392.}

${ }^{162}$ Siehe Hughes an Chilton (15.10.1923), FRUS 1923, II, S. 70-73.

${ }^{163}$ Siehe Curzon an Crewe (19.10.1923), DBFP 1 XXI, Nr. 403.

${ }^{164}$ Die Aussage war jedoch sehr vage gehalten: "If, instead of attempting the futile task of obtaining the cancellation of debts, the European Governments were to proceed to settle their financial matters and to adjust the reparation problem and to give reason to believe that there would be European cooperation in the interest of peace and the reduction of expenses which were unnecessary, a different feeling would be likely to exist in this country; although it was unlikely that there would be any willingness to cancel the debts, yet terms, conditions and time of payment could be considered in such a way that consideration would be taken of the actual conditions of the European debtors in the light of what settlements were made. For the reasons he stated, the secretary said, he could give no definite assurance in the matter «, Hughes an Whitehouse (24.10.1923), FRUS 1923, II, S. 79-83.

${ }^{165}$ Siehe ERDMANN, Alternativen, S. 33; BARIÉTY, Relations franco-allemandes, S. 263265. Die entsprechende Verbalnote an die britische Regierung ist abgedruckt in: DBFP 1

XXI, Nr. 415, Anm. 1.

${ }^{166}$ Hierzu siehe BARJÉTY, Relations franco-allemandes, S. $272 \mathrm{f}$.

${ }^{167}$ Text der Note: MICHAELIS u.a., Ursachen und Folgen, Bd. 6, Nr. 1249. 
Überprüfung der Reparationszahlungen durch die RepKo vorsah, auch für Poincaré eindeutig wieder auf die Grundlage des Friedensvertrags gestellt. Zwar dauerte es noch bis zum 13. November 1923, bis Frankreich endgültig dem Verfahren der Expertenkommission zustimmte, die Würfel waren jedoch schon seit dem 25. Oktober 1923 gefallen. Am 30. November schließlich setzte die RepKo offiziell die Experten-Kommissionen ein ${ }^{168}$. Ebenso wie die vergrößerte Bereitschaft vor allem der angelsächsischen Mächte, an der Lösung des Ruhrproblems mitzuwirken, trug auch die Einsetzung des DawesKomitees - eine direkte Folge dieser Bemühungen - dazu bei, die Positionen Frankreichs und Deutschlands zu modifizieren. Durch das Eingehen auf die internationale Lösung verringerte sich Frankreichs Spielraum in der Ruhr- und Reparationspolitik, während Deutschland weniger stark vom Wohlwollen der Pariser Regierung abhängig wurde.

Wie gesagt, die veränderte außenpolitische Lage war nur ein Aspekt der Entwicklung. Wie wirkten sich die Verhandlungen zwischen den Besatzungsbehörden und der deutschen Wirtschaft auf die Situation beider Staaten aus ${ }^{169}$ ? Im Mittelpunkt der französischen Aktivitäten, das Ruhrpfand produktiv zu machen, standen die Verhandlungen zwischen der M.I.C.U.M. und den deutschen Schwerindustriellen, die $z \mathfrak{u}$ den sogenannten M.I.C.U.M.-Verträgen führten. Bereits im Juni 1923 war der Kölner Stahlgroßhändler Otto Wolff ${ }^{10}$, der Cunos Politik des passiven Widerstandes ablehnte, in Kontakt zu den französischen Besatzungsbehörden getreten. In einem Gespräch zwischen ihm und dem Direktor des Phoenix-Konzerns (der ebenfalls Wolff gehörte), Werner Carp, mit General Denvignes von der französischen Besatzungsarmee schlug Wolff eine weitgehende politische und wirtschaftliche Zusammenarbeit zwischen Deutschland und Frankreich vor. Poincaré blieb jedoch zunächst skeptisch. Er sah in dem Vorhaben Wolffs einen Versuch, ihn um die Früchte des bevorstehenden Sieges im Ruhrkampf zu bringen. Erst Ende August, als sich die Anzeichen mehrten, daß der passive Widerstand mehr und mehr zerfaserte und die Reichsregierung bald würde aufgeben müssen, stimmte der französische Ratspräsident schließlich Gesprächen mit deutschen Industriellen zu. Bereits Anfang Oktober kam es zu einem Abkommen ${ }^{171}$ zwischen Wolff und den französischen Besatzungsbehörden, in dem sich Wolff verpflichtete, rückwirkend die seit dem Einmarsch der französischen und belgischen Truppen nicht mehr abgeführte Kohlensteuer nachzuzahlen und auch künftig die Zahlungen

${ }^{168}$ Der Text der Entscheidung der RepKo ist abgedruckt in: Rufus C. DAWES, The Dawes Plan in the Making, Indianapolis 1925, S. 297f.

${ }^{169}$ In diesem Zusammenhang stehen natürlich auch die Verhandlungen über eine rheinische Goldnotenbank, die bereits oben dargestellt wurden, und auf die im folgenden nur kursorisch eingegangen werden soll.

${ }^{170} \mathrm{Zu}$ den Gesprä̀chen Otto Wolffs siehe JEANNESSON, Poincaré, S. $312 \mathrm{f}$.

${ }^{171}$ Siehe Besprechungen über Verhandlungen der Phoenix- und Rheinstahlgruppe mit den zivilen Besatzungsbehörden (10.10.1923), AdR Stresemann I/I Bd. 2, Nr. 123. 
wieder vorzunehmen, kostenlos Reparationskohlen zu liefern, den Besatzungstruppen unentgeltlich Kohlen zur Verfügung zu stellen, und der Eisenbahnregie zu festgelegten Preisen Kohlen zu verkaufen. Im Gegenzug wurden die von den Besatzungsbehörden blockierten Stahlwaren freigegeben und Exportlizenzen ausgestellt.

Das Abkommen zwischen Wolff und der M.I.C.U.M. hatte eine zweifache Bedeutung: Erstens stellte es den Präzedenzfall für die späteren M.I.C.U.M.Abkommen dar und setzte die anderen Schwerindustriellen unter Zugzwang. Wolff hatte auf eigene Faust mit den Franzosen verhandelt und nun als erster die Freigabe seiner Produktion erreicht. Derart unter Druck gesetzt, mußte nun auch der Bergbauliche Verein, dessen Interessen durch die sogenannte "Sechserkommission ${ }^{172}$ vertreten wurden, mit den Besatzungsbehörden zu einer Einigung kommen. Die Industrievertreter versuchten, durch die Verhandlungen mit der M.I.C.U.M. aber nicht nur gegenüber dem Konkurrenten Wolff gleichzuziehen, sie bemühten sich auch darum, die Gespräche zu nutzen, wichtige sozialpolitische Errungenschaften der Weimarer Republik, allen voran den 8-Stunden-Tag, wieder rückgängig zu machen ${ }^{173}$. Weitere Forderungen umfaßten das Ende der von den Besatzungsbehörden verhängten Zwangsmaßnahmen, vor allem die Freigabe der Lagerbestände an Roh- und Fertigprodukten, die Freigabe des Eisenbahnverkehrs, ein Ende der Beschlagnahme von Geld, die Einstellung von Ausweisungen usw. sowie den Zugang zu Auslandskrediten und die Verringerung der Kohlensteuer ${ }^{174}$. Zweitens wurde durch die Gespräche Wolffs mit den Besatżungsbehörden die Position der Reichsregierung erheblich geschwächt, die ja stets die Unrechtmäßigkeit der französischen Ruhrbesetzung betont hatte, welche jedoch nun durch die privaten Abkommen mit den Besatzungsbehörden quasi legitimiert wurde ${ }^{175}$. Die Autorität Berlins, die nach der Aufgabe des Ruhrkampfs, den Querelen in Sachsen, Thüringen und Bayern und der separatistischen Bedrohung im Rheinland schon stark gelitten hatte, wurde dadurch weiter untergraben. Allerdings war die wirtschaftliche Lage so desolat ${ }^{176}$, daß die Produktion im

${ }^{172}$ Die Sechserkommission bestand aus Albert Vögler (deutsch-luxemburgische Bergwerksund Hütten A.G.), Albert Janus (Vorsitzender des rheinisch-westfälischen Kohlensyndikats), Georg Lübsen (Direktor der Gutehoffnungshütte), Otto von Velsen (Generaldirektor der Hibernia), Peter Klöckner (Klöckner Werke A.G.) und Hugo Stinnes (u.a. Dortmunder Union, deutsch-luxemburgische Bergwerks- und Hütten A.G., Stinnes Zechen, Essen), siehe Besprechung der Sechserkommission mit General Degoutte in Düsseldorf (5.10.1923), AdR Stresemann I/II Bd. 1, Nr. 111.

${ }^{173}$ Siehe ibid.

174 Siehe ibid.

175 Siehe Besprechungen über Verhandlungen der Phoenix- und Rheinstahlgruppe mit den zivilen Besatzungsbehörden (10.10.1923), AdR Stresemann I/II Bd. 2, Nr. 123.

${ }^{176}$ Allein im besetzten Gebiet war etwa die Hälfte der Bevölkerung von Arbeitslosigkeit betroffen und die Währungslage blieb prekär, vgl. StS Fischer vor der RepKo (23.11.1923), 
Ruhrgebiet unbedingt wieder aufgenommen werden mußte. Auch die geplante Währungsstabilisierung konnte nur dann glücken, wenn die Wirtschaft wieder in Gang kam und die Sozialleistungen, die infolge der hohen Arbeitslosigkeit explodiert waren, reduziert werden konnten. Besonders an dem Punkt der Sozialleistungen offenbarte sich das Dilemma der Reichsregierung. Um die neue Währung erfolgreich einzuführen, mußten die Zahlungen an das besetzte Gebiet aufhören. Hörten aber die Zahlungen auf, verringerte sich der ohnehin geringe Einfluß der Reichsregierung dort weiter. Die Ingangsetzung der Wirtschaft, die nach Lage der Dinge ganz von den Franzosen abhing, würde zwar die Finanzlage des Reiches verbessern, aber ebenfalls zu einem weiteren Einflußverlust führen.

In dieser Situation traten die Industriellen von Rhein und Ruhr an die Reichsregierung heran. Sie forderten ${ }^{177}$, daß Berlin die von Frankreich rückwirkend verlangte Kohlensteuer übernehmen und die Kohlensteuer ganz abschaffen solle. Außerdem sollte sich die Regierung bereit erklären, die von der Industrie an Frankreich zu leistenden Reparationszahlungen zu erstatten, Anlaufkredite zur Verfügung zu stellen und die Arbeitszeit zu verlängern. Die Reichsregierung lehnte die Forderungen der Industrie zunächst ab, mußte aber, nachdem die Industriellen erklärt hatten, andernfalls könne die Produktion nicht wieder aufgenommen werden, zustimmen, zumindest die Kosten für die Reparationskohlen und die rückwirkend erhobene Kohlensteuer zu tragen ${ }^{178}$.

Trotz dieser Zugeständnisse der Reichsregierung gestalteten sich die Verhandlungen zwischen Wirtschaftsvertretern und Besatzungsbehörden schwierig $^{179}$. Bis zum 25. Oktober 1923 hatten zwar 24 Firmen, die etwa 20 Prozent der Produktion des besetzten Gebiets ausmachten, Verträge mit der M.I.C.U.M. abgeschlossen ${ }^{180}$. Erst am 23. November 1923 kam es jedoch zur Unterzeichnung eines allgemeinen Rahmenvertrags, der alle davor geschlos-

ADAP A DX, Nr. 16 und Bezirkssekretär Heinrich Meyer an den Vorstand des ADGB (25.10.1923), AdR Stresemann I/II Bd. 2, Nr. 177.

i77 $\mathrm{Zu}$ den Forderungen der Industrie siehe Besprechung mit Ruhrindustriellen im Reichstagsgebäude (9.10.1923), AdR Stresemann I/II Bd. 2, Nr. 121.

${ }_{178}$ Siehe ERDMANN, Alternativen, S. 32 und Stresemann an die Sechserkommission des Bergbaulichen Vereins (1.11.1923), AdR Stresemann VII Bd. 2, Nr. 213.

${ }_{179}$ Zum Verhandlungsverlauf s. Besprechung mit Hugo Stinnes und anschließende Ministerbesprechung (31.10.1923), AdR Stresemann III Bd. 2, Nr. 208; Vermerk Ministerialrats Kiep über den Stand der Verhandlungen zwischen Sechserkommission und Micum (8.11.1923), AdR Stresemann I/II Bd. 2, Nr. 229; Besprechung betreffend Verhandlungen der Sechserkommission (13.11.1923), AdR Stresemann I/I Bd. 2, Nr. 246; Sechserkommission des Bergbaulichen Vereins an die Micum (14.11.1923), AdR Stresemann I/II Bd. 2, Nr. 258, Chefbesprechung (16.11.1923), AdR Stresemann I/II Bd. 2, Nr. 262.

${ }^{180}$ Siehe JeANNESSON, Poincaré, S. 315. 
senen Verträge ersetzte bzw. ergänzte und bis zum 15. April 1924 gültig sein sollte ${ }^{181}$.

Durch die M.I.C.U.M.-Verträge konnte Frankreich also das Ruhrpfand endlich voll funktionsfahig machen und erreichen, daß die Schornsteine an Rhein und Ruhr wieder rauchten. »Im Endergebnis erlangten die Franzosen durch die M.I.C.U.M.-Verträge eine vollkommene Kontrolle der Ruhrwirtschaft ${ }^{182}$.

War es tatsächlich so? Die M.I.C.U.M.-Verträge hatten einige Schönheitsfehler. Einer davon war, daß sie zeitlich begrenzt waren, und eine Verlängerung mit den gleichen für Frankreich vorteilhaften Bedingungen nur dann gelingen konnte, wenn Paris eine ähnlich starke wirtschaftliche und politische Pression auf die Ruhrindustrie bzw. auf die deutsche Politik würde ausüben können. Der zweite Schönheitsfehler bestand paradoxerweise darin, daß es gerade die M.I.C.U.M.-Verträge waren, die die französische Position im Ruhrgebiet schwächten. Gewiß, die M.I.C.U.M.-Verträge waren sehr vorteilhaft im französischen Sinne und sehr restriktiv für die deutsche Industrie. Aber dennoch stellten sie für Deutschland eine erhebliche Verbesserung der Lage dar und erlaubten es dem Reich, sich langsam aus den französischen Fesseln zu befreien: Sie ermöglichten es, daß die deutsche Produktion wieder anlief und trugen so dazu bei, daß die Währungsreform erfolgreich durchgeführt werden konnte. Indem die Wirtschaft sich erholte und der Wohlstand zumindest nicht mehr weiter schrumpfte, wurde die Grundlage auch für die Stabilisierung der politischen Lage in Deutschland geschaffen. Insofern konnten die M.I.C.U.M.-Verträge also auch durchaus zum Eigentor für die französische Politik werden, zumal es Frankreich nicht gelang, die Wirtschaftsabkommen in einen politischen (etwa durch die Schaffung eines wie auch immer gestalteten Rheinstaats) oder wirtschaftlichen Kontext (etwa durch die Gründung einer rheinischen Notenbank) zu stellen. Auch der weitere Ausbau des französischen Einflusses auf die deutsche Privatwirtschaft - durch die Beteiligung französischer Unternehmen an der deutschen Industrie - gelang nicht, obwohl es Ansätze dazu gegeben hatte.

Von einem gewissen Interesse und bezeichnend fur den Fehlschlag dieses Ansatzes sind die Aktivitäten des Industriellen, Publizisten und Bildhauers

${ }^{181}$ Siehe BARIÉTY, Relations franco-allemandes, S. 276. Die Verträge der M.I.C.U.M. betrafen jedoch nicht nur die Schwerindustrie und die chemische Industrie, sondern so gut wie jeden Industriezweig, wie die Zuckerindustrie, den Holzhandel, die Lederwaren- und Textilindustrie usw. Siehe Aufzeichnung des Reichsministers für Wiederaufbau über die Reparationsverträge der Besatzungsbehörden mit den Wirtschaftsverbänden (ohne Unterschrift) (18.1.1924), BArch R 3101, 14769. Zusammenfassend zu den M.I.C.U.M.-Verträgen: Was bedeuten die Micum-Verträge? (Richtlinie Nr. 85), hg. v. Reichszentrale für Heimatdienst, Berlin 1924.

${ }^{182}$ ERDMANN, Alternativen, S. 33. 
Arnold Rechberg ${ }^{183}$, die dieser Ende des Jahres 1923 entfaltete ${ }^{184}$. Rechberg hatte vorgeschlagen, daß die französische Wirtschaft zu 30 Prozent an der deutschen Industrie beteiligt werden sollte. Dafür sollten im Gegenzug das Ruhrgebiet und das Rheinland geräumt werden. Ziel seines Plans war, sowohl das Reparationsproblem als auch das Sicherheitsproblem zu lösen. In Frankreich war die Resonanz - zumindest in politischen Kreisen ${ }^{185}$ - auf die Vorschläge Rechbergs gro $\beta^{186}$. Deutscherseits stießen die rechbergschen Pläne dagegen auf erheblichen Widerstand. Viele Industrielle lehnten die Pläne ab und die Politik schloß sich dieser Haltung a ${ }^{187}$. Auch in Großbritannien sah man die Vorschläge $"$ mit Besorgnis ${ }^{188}$, schien sich doch hier der befürchtete deutsch-französische Wirtschaftsblock anzudeuten. Interessanter ist aber, daß die französische Regierung trotz der guten Ausgangslage nicht versuchte, diese sich bietende Chance als Ergänzung, ja als Perpetuierung der durch die M.I.C.U.M.-Verträge geschaffenen wirtschaftlichen Vorteile zu nutzen: $» H e r r$ Poincaré hat mir bekanntlich mitgeteilt, daß eine große Anzahl von deutschen Industriellen aus den besetzten Gebieten dauernd in Frankreich Gespräche mit der französischen Industrie anzuknüpfen suchte und daß er bisher die französischen Industriellen gebremst habe, damit einer Gesamtverständigung nicht vorgegriffen werde ${ }^{189}$. Dadurch verschlechterte sich die französische Position nicht nur auf internationalem Parkett, sondern auch auf wirtschaftlichem Gebiet - und das paradoxerweise gerade durch die M.I.C.U.M.-Verträge.

Ein weiterer Faktor, der die Lage Deutschlands und Frankreichs in der zweiten Hälfte des Jahres 1923 verändern sollte, waren die separatistischen Umtriebe im Rheinland. Bereits im Sommer und Frühherbst hatte es in den besetzten Gebieten verschiedentlich separatistische Manifestationen gegeben ${ }^{190}$.

${ }^{183}$ Zur Person siehe Werner BÜHRER, art. »Rechberg, Arnold«, in: Wolfgang BENZ, Hermann GRAML (Hg.), Biographisches Lexikon zur Weimarer Republik, München 1988, S. $265 f$.

${ }^{184}$ Zum folgenden vgl. Kabinettssitzung (31.12.1923), AdR Marx I/II Bd. 1, Nr. 43, Anm. 12, Hoesch an AA (29.12.1923), ADAP A DX, Nr. 77, und Auszug aus dem Journal Officiel Chambre des Députés - $2^{\mathrm{e}}$ séance du 28 décembre 1923 aus BArch R 3101, 20437 und Karl Dietrich ERDMANN, Adenauer in der Rheinlandpolitik nach dem Ersten Weltkrieg, Stuttgart 1966, S. 161f.

${ }^{185}$ Die französische Wirtschaft war dagegen skeptischer, sie fürchtete von der deutschen Seite übervorteilt zu werden, siehe Aufzeichnung ohne Unterschrift (11.1.1924), BArch R $3101,14767$.

${ }^{186}$ Hoesch an AA (29.12.1923), ADAP A IX, Nr. 77.

${ }^{187}$ Siehe ERDMANN, Adenauer, S. 161f.

${ }^{188}$ Sthamer an AA (10.1.1924), ADAP A IX, Nr. 90.

${ }^{189}$ Hoesch an AA (29.12.1923), ADAP A IX, Nr. 77.

${ }^{190}$ Siehe Bericht über die Haltung der Parteien im Ruhrgebiet [Dinger] (15.9.1923), AdR Stresemann I/II Bd. 1, Nr. 60; Bericht über die Sitzung der Arbeitsgemeinschaft der politischen Parteien des alt- und neubesetzten Gebiets [Rausch] (19.9.1923), AdR Stresemann I/I Bd. 1, Nr. 70; Bericht des Reichspostministers [Höfle] über Lage und Aussichten der separatistischen Bewegung in Düsseldorf (28.9.1923), AdR Stresemann V/I Bd. 1, Nr. 89. 
$\mathrm{Zu}$ einer Bedrohung wurde der rheinische Separatismus jedoch erst mit den Unruhen, die am 21. Oktober 1921 in Aachen ausbrachen und die sich dann auf weitere Städte im besetzten Gebiet ausweiteten ${ }^{191}$. Aachen lag in der belgischen Besatzungszone, und die Beteiligung der verschiedenen belgischen Stellen am Putsch war etwas dubios: Involviert in die Putschvorbereitungen war vor allem der Comité de politique nationale belge ${ }^{192}$, der die Schaffung eines "Großbelgiens" unter Einschluß niederländisch-Flanderns, Luxemburgs und Limburgs forderte. Abgesichert werden sollte dieses Großbelgien nach Osten durch einen von Belgien abhängigen Pufferstaat im nördlichen Teil des besetzten Rheinlands, während im südlichen Teil ein französisch dominiertes Gebilde entstehen sollte. Dieser Comité de politique nationale erfuhr zwar eine gewisse Unterstützung durch einige Offiziere der belgischen Besatzungsarmee, nicht jedoch durch die von Henri Jaspar geführte Regierung, die in der Ruhraktion lediglich ein Mittel dazu sah, Deutschland zum Zahlen der Reparationen zu zwingen, und die sich im Laufe des Herbstes mehr und mehr von der intransigenten Politik Frankreichs abzuwenden begann.

Paris indes war von den Vorgängen in Aachen - obwohl es natürlich Kontakt $z \mathfrak{u}$ diversen separatistischen Grüppchen unterhielt - völlig überrascht, und es herrschte eine gewisse Konfusion, wie mit der neuen Lage umzugehen sei: Zunächst wies die Regierung die Truppen an, sich den Separatisten gegenüber neutral zu verhalten ${ }^{193}$, am 24 . Oktober jedoch beauftragte Poincaré Tirard, die Separatisten zu unterstützen ${ }^{194}$. Diese Anweisung war für viele in Paris unverständlich: Seydoux und Laroche, zu diesem Zeitpunkt directeur-adjoint des affaires politiques et commerciales im Quai d'Orsay, bemerkten, daß die Separatisten nur dann Erfolg haben könnten, wenn sie die Unterstützung des Zentrums, der weitaus stärksten politischen Kraft im Rheinland, erhielten, dies aber höchst unwahrscheinlich sei - eine Einschätzung, der sich selbst Tirard anschlo $\beta^{195}$.

Das Verhalten Poincarés in der Separatistenfrage hat zu vielerlei Spekulationen Anlaß gegeben ${ }^{196}$. War es Folge eines Kommunikationsproblems, das den französischen Ratspräsidenten dazu veranlaßte, die Stärke der Bewegung zu überschätzen? Tirard hatte in diesem Zusammenhang auf den Übereifer von General Mangin hingewiesen, der den Einfluß der Separatisten zu hoch eingeschätzt und so eine richtige Beurteilung der Ereignisse in Paris behindert ha$\mathrm{be}^{197}$. War die ganze Aktion gar eine belgische Finte, durch die Poincaré ge-

\footnotetext{
${ }^{191}$ Siehe JOLLY, Ruhr, S. 242f.

${ }^{192}$ Siehe hierzu BARIÉTY, Relations franco-allemandes, S. 251.

${ }^{193}$ Siehe ibid. S. 253.

${ }^{194}$ Siehe JEANNESSON, Poincaré, S. 333.

${ }^{195}$ Siehe BARIÉTY, Relations franco-allemandes, S. 254f.

${ }^{196}$ Zusammenfassend siehe JEANNESSON, Poincaré, S. 336; ROTH, Poincaré, S. 443-445.

${ }^{197}$ Siehe TIRARD, Rhin, S. 287f. Die Ausfiuhrungen Tirards waren wahrscheinlich aber auch dazu gedacht, seine eigene Rolle in den separatistischen Unruhen zu relativieren. Allerdings
} 
zwungen werden sollte, die wahren Motive seiner Rheinlandpolitik offenzulegen ${ }^{198}$ ? Wollte Peretti de la Rocca, Directeur des Affaires Politiques et Commerciales, der ein Anhänger eines separaten Rheinstaates war, versuchen, Poincaré in seinem Sinne zu beeinflussen? Oder hatte der französische Ratspräsident nicht vielmehr die Absicht, die Separatistenunruhen als Hebel zu einer Lösung der Reparationsfrage, sowohl gegenüber London als auch gegenüber Berlin zu nutzen?

In Berlin, wo die Lage im Angesicht der Hyperinflation, die das Wirtschaftsleben mehr und mehr lähmte, und der politischen Probleme schon schwierig genug war, brach die Nachricht von den Aufständen im Rheinland als weitere Katastrophe über die Regierung herein. Zwischen Berlin und Köln wurden verschiedene Lösungsmöglichkeiten diskutiert, die, überspitzt gesagt, alle nur die Wahl zwischen Pest und Cholera waren.

Der Kölner Oberbürgermeister Konrad Adenauer sah die einzige Lösung in der Schaffung eines eigenen rheinischen Bundesstaates, wäußersten Falles auch eine Loslösung vom Reiche im Wege der Verständigung “ ${ }^{199}$ :

Die Lage in Deutschland sei so trostlos, daß mit dem Auseinanderfallen des Reichs gerechnet werden müsse. Ein Eingreifen Englands sei in den nächsten Jahren nicht zu erwarten, es sei vorläufig ohnmächtig und dränge auf eine Einigung mit Frankreich. Die Schaffung eines Bundesstaates wäre für Frankreich günstig. Die Besorgnis, Kriegsschauplatz zu sein, würde diesen Bundesstaat, der eine maßgebende Stelle im Reiche einnehme, veranlassen, kriegerische Verwicklungen zu vermeiden. Die Verbindung mit der französischen Industrie, die früher nach Lothringen bestanden hätte, würde wieder aufleben. Ein Pufferstaat dagegen wäre für Frankreich durchaus ungünstig, er würde so bestehen und einen Revanchekrieg nur beschleunigen. Trotz vielfacher Kritik erblicke er in der Zersetzung Preußens und in der Schwächung der Präsidialmacht eine schwere Gefahr. Immerhin bedeute die Loslösung von Preußen nach seiner Meinung das kleinere Übel, wenn dann der dauernde Friede zwischen Deutschland und Frankreich erreicht werden könne. Das Opfer, das mit der Schaffung eines Bundesstaates gebracht würde, hätte aber nur einen Zweck, wenn erreicht würde: 1) die Lösung der Reparationsfrage, 2) die Errichtung eines wirklichen Bundesstaates, nicht einer französischen Kolonie. Dies setze voraus die Beseitigung der Interalliierten Rheinlandkommission und der Besetzung. Daß man in dieser Voraussetzung weiterkomme, sei zwar wenig aussichtsvoll, er schätze die Aussicht auf vielleicht $1 \%^{200}$.

Nach Auffassung von Finanzminister Luther ${ }^{201}$, der vor allem die gerade begonnene Währungsstabilisierung im Auge hatte (am 15. Oktober 1924 war die

stand Mangin bereits seit Beginn der französischen Besetzung im Rheinland mit den Separatisten in Kontakt, vgl. Charles MANGIN, Lettres de Rhénanie, in: Revue de Paris, 43/7 (1936), S. 481-526.

${ }_{198}$ Jeannesson selbst stellt dazu fest: "Rien [...] dans les archives belges, ne permet de conclure au double jeu de Bruxelles«, JEANNESSON, Poincaré, S. 340.

${ }^{199}$ Besprechung mit den Vertretern der besetzten Gebiete (25.10.1923), AdR Stresemann III Bd. 2, Nr. 179.

${ }^{200}$ MinR. Adelmann an RMbesGeb. [Fuchs] (26.11.1923), ADAP A IX, Nr. 20. Andere Zahlen bei JOLLY, Ruhr, S. 263.

${ }^{201}$ Siehe ERDMANN, Alternativen, S. 34. 
Rentenmarkverordnung in Kraft getreten, und einen Monat später sollte mit der Ausgabe der Rentenbanknoten begonnen werden), sollte das besetzte Gebiet sich selbst überlassen werden. Das Reich sollte seine Zahlungen an die besetzten Gebiete einstellen und die dortige Bevölkerung selbst zu einem modus vivendi mit Frankreich kommen. Nur so konnte seiner Ansicht nach die Währungsstabilisierung gelingen, denn eine weitere Finanzierung der besetzten Gebiete war - vor dem Hintergrund, daß dort aufgrund der französischen Beschlagnahme von Geldern und der daniederliegenden Wirtschaft keine Steuern eingenommen wurden bei weiter laufenden Kosten - völlig unkalkulierbar. In eine ähnliche Richtung gingen auch die Überlegungen des Reichstagsabgeordneten der Deutschen Volkspartei (DVP) Moldenhauer, der keine de jure, sondern nur eine faktische Übertragung von einigen Befugnissen auf das besetzte Gebiet wollte, "um die wichtigsten wirtschaftlichen Bedürfnisse des besetzten Gebiets zu erfüllen, namentlich auch eine eigene Währung und ein eigenes Budget, ein eigenes Steuerrecht einzuführen ${ }^{202}$, ohne jedoch die französisch-belgischen Maßnahmen dadurch explizit zu sanktionieren. Auch die Überlegungen des Duisburger Oberbürgermeisters Karl Jarres gingen in Richtung einer »Versackungspolitik « à la Luther und Moldenhauer, jedoch wollte Jarres die faktische Ablösung des Rheinlands mit einer "gro$\mathrm{Be}[\mathrm{n}]$ außenpolitische[n] Handlung ${ }^{203}$ verbinden, wobei er an eine Aussetzung des Versailler Vertrags dachte, bis die Franzosen den Status quo ante vom 11. Januar 1923 wiederhergestellt hatten.

Stresemann unterdessen war sowohl gegen die Rheinlandpläne Adenauers wie auch die Versackungspolitik. Besonders die "große außenpolitische Handlung« seines Parteifreundes Jarres - die Kündigung oder Aussetzung des Versailler Vertrags - lehnte er ab, "[d]enn wie die Dinge heute liegen, gibt uns der [Versailler, R.B.] Vertrag auch Rechte. Der Vertrag gibt uns zum mindesten das Recht, daß das Ruhrgebiet rechtswidrig besetzt ist, daß für das Rheinland nur das Rheinlandabkommen gilt, aber nicht die Vergewaltigungen, die heute dort bestehen ${ }^{204}$. Allerdings mußte er - in Ermangelung anderer Machtmittel und angesichts der bevorstehenden Währungsreform - den Rheinländern zugestehen, zunächst selbst ihr Schicksal in die Hand zu nehmen. Stresemann verfolgte dabei eine doppelte Strategie. Innenpolitisch blieb ihm wenig übrig, als abzuwarten und es den Rheinländern selbst zu überlassen, zu einer Regelung mit Frankreich zu kommen, bzw. die Lage so lange offenzuhalten, bis sich für die Berliner Regierung neue Eingriffsmöglichkeiten ergaben. Die Aussichten dafür waren nicht schlecht. Die separatistische Bewegung war in

${ }^{202}$ Besprechung mit den Vertretern der besetzten Gebiete (25.10.1923), AdR Stresemann V/II Bd. 2, Nr. 179.

${ }^{203}$ Ibid.

204 Ibid. 
sich gespalten, hatte kein geeignetes Führungspersonal ${ }^{205}$ und der Rückhalt in der Bevölkerung war gering ${ }^{206}$ - keine der etablierten Parteien oder andere gesellschaftliche Gruppen, seien es Gewerkschaften oder Kirchen, unterstützten die Separatisten, die durch die vermeintliche oder tatsächliche Kollaboration mit den französischen Besatzern diskreditiert wurden ${ }^{207}$. Außenpolitisch setzte Stresemann vor allem auf die englische Karte. Über Oswald Spengler hatte er sich mit Jan Smuts, dem südafrikanischen Premierminister, in Verbindung gesetzt. Smuts hatte während der Imperial Conference, die vom 1. Oktober bis zum 9. November 1923 in London stattfand, die Pfänderpolitik und die Unterstützung des Separatismus durch Frankreich scharf kritisiert, eine Reparationskonferenz gefordert und seiner Sorge über den Zerfall Deutschlands Ausdruck gegeben ${ }^{208}$. Die übrigen Teilnehmer machten sich diese Haltung zu eigen und so wurde $» D e u t s c h l a n d$ gegenüber [...] als fundamentaler Grundsatz festgestellt, daß der Zerfall des Deutschen Reiches auf keinen Fall zugelassen werden dürfe ${ }^{209}$. Diese härtere Haltung gegenüber Frankreich machte die englische Regierung auch in einer Note vom 31. Oktober 1923 an die französische Regierung deutlich, in der sie ankündigte, daß sie den Versailler Vertrag als gegenstandslos betrachten würde, zerfiele das Reich in einzelne Gliedstaaten, denn der Vertrag sei ja mit dem Deutschen Reich als ganzem abgeschlossen worden ${ }^{210}$.

Auch für Paris wurden die Separatisten immer mehr zum Klotz am Bein. Das angeschlagene Renommee Frankreichs wurde durch die Unterstützung für die Separatisten nur noch weiter geschädigt und nährte bei Amerikanern, Belgiern und Briten nur die Furcht vor einer französischen Vorherrschaft auf dem Kontinent ${ }^{211}$, wie Hoesch feststellte: „Gerade augenblicklich, wo Frankreich Vorteile aus Aufgabe passiven Widerstands sicherstellen will, kann es weitere Belastung französischen Rufs schwer ertragen ${ }^{212}$. Tirard machte aus seiner Skepsis keinen Hehl, was die Erfolgsausichten anging ${ }^{213}$.

${ }^{205}$ Siehe JEANNESSON, Poincaré, S. $285 \mathrm{f}$.

${ }^{206}$ Siehe Besprechung mit den Vertretern der besetzten Gebiete (25.10.1923), AdR Stresemann I/II Bd. 2, Nr. 179 und Kabinettssitzung (9.11.1923), AdR Stresemann I/II Bd. 2, Nr. 233.

${ }^{207}$ Siehe JEANNESSON, Poincaré, S. 287f.

${ }^{208}$ Siehe ERDMANN, Adenauer, S. 104.

${ }^{209}$ Aufzeichnung Schubert (21.11.1923), ADAP A DX, Nr. 10.

${ }^{210}$ Siehe BARIÉTY, Relations franco-allemandes, S. 268.

${ }^{211}$ Siehe SCHWABE, Ruhrkrise, S. 74.

${ }^{212}$ Hoesch an AA (5.11.1923), ADAP A VIII, Nr. 229.

${ }^{213}$ Siehe Tirard an Quai d'Orsay (4.11.1923), AdR Stresemann I/II Bd. 2, Nr. 199, Anm. 4. Es gilt allerdings zu unterscheiden zwischen den pfälzischen Separatisten, die im Gegensatz zu den Gruppienungen andernorts anfänglich durchaus die Sympathie der Bevölkerung auf ihrer Seite hatten. Sie waren weniger radikal, und die Situation in der Pfalz, die ja zu Bayern gehörte, das gerade im Strudel rechter Putsche zu versinken drohte, eine besondere. Von die- 
Anfang November mehrten sich zudem die beunruhigenden Nachrichten aus Berlin, Nationalisten und Schwerindustrielle wollten die Regierung Stresemann stürzen und durch eine Rechtsdiktatur ersetzen ${ }^{214}$, was keinesfalls im Sinne der französischen Regierung sein konnte. Peu à peu zog sich die französische Regierung deshalb aus dem separatistischen Abenteuer zurück und machte dies im Februar 1924 auch offiziell deutlich ${ }^{215}$. Allerdings gelang es ihr auch nicht, den Gesprächsfaden mit den Anhängern einer begrenzten Autonomie des Rheinlandes innerhalb des Deutschen Reiches - also der Politik, die von Adenauer vertreten wurde - wieder aufzunehmen. Am 26. Oktober 1923 versuchte ein Komitee, bestehend aus rheinischen Würdenträgern aus Wirtschaft und Politik, mit Adenauer an der Spitze, zu einer Lösung der Probleme im Rheinland zu kommen. Tirard lehnte es ab, dieses Komitee, das Plänen für einen rheinischen Bundesstaat durchaus wohlgesonnen war, überhaupt zu empfangen ${ }^{216}$. Er hatte strikte Anweisungen von seiner Regierung erhalten, die sich, wenige Tage nach Ausbruch der separatistischen Unruhen, auf die Unterstützung der Putschisten festgelegt hatte. Auch wenn nicht anzunehmen ist, daß die Ablehnung Tirards, am 26. Oktober 1923 mit Adenauer zu verhandeln, der zentrale Fehler war, den die französische Politik begangen hatte $^{217}$, so mußte sich doch die französische Position um so mehr verschlechtern, je länger es ihr nicht gelang, die momentane Schwäche Deutschlands auszunutzen. Als die deutsche Wirtschaft wieder Tritt faßte und im November endlich die Währung stabilisiert wurde, schmolz die deutsche Bereitschaft, zu einer autonomistischen Lösung der Rheinlandfrage in Form eines von Preußen abgetrennten Bundesstaates zu kommen, dahin. Am 23. Januar 1924 mußte auch Adenauer seine Pläne bezüglich des Rheinlandes auf zunehmenden Druck der Reichsregierung und vor allem Stresemanns aufgeben $^{218}$.

Im Januar 1924 war im Vergleich zum Spätsommer des Vorjahres eine deutliche Verschlechterung der Position Frankreichs eingetreten. Durch die wirtschaftliche und politische Stabilisierung, die nicht zuletzt durch die M.I.C.U.M.-Verträge eingeleitet wurde, verloren die Autonomie- oder gar Abtrennungspläne für das Rheinland rasant an Boden ${ }^{219}$. Frankreich befand sich in einem Zustand der fast vollständigen diplomatischen Isolation ${ }^{220}$. Auch in-

sen Gruppierungen sagte sich die französische Regierung erst im Januar 1924 los, vgl. JEANNESSON, Poincaré, S. 385-387.

${ }^{214}$ Siehe Margerie an Quai d'Orsay (4.11.1923), MAE 1918-1929 Z (Europe) Allemagne, 482; Aufzeichnung Stresemann (9.11.1923), ADAP A VIII, Nr. 240.

${ }^{215}$ Siehe BARIETY, Relations franco-allemandes, S. 295.

${ }^{216}$ Siehe JEANNESSON, Poincaré, S. 341.

${ }^{217}$ In diesem Sinne BARIÉTY, Relations franco-allemandes, S. 261.

${ }^{218}$ Siehe ERDMANN, Adenauer, S. 180.

${ }^{219}$ Siehe JEANNESSON, Poincaré, S. 358.

${ }^{220}$ Siehe BAECHLER, Stresemann, S. 447. 
nenpolitisch schwand der Rückhalt für Poincarés Ruhrpolitik ${ }^{221}$. Ursachen hierfür waren jedoch nicht nur die zunehmende internationale Isolierung und die aufkeimenden Zweifel an Sinn und Nutzen des Ruhrunternehmens, sondern auch der Verfall des französischen Franc, der im Dezember und vor allem im Januar verstärkt einsetzte, die außenpolitische Handlungsfreiheit Frankreichs wesentlich einschränkte und die französischen Bürger beunruhig$\mathrm{te}^{222}$, zumal offensichtlich gezielt gegen den Franc spekuliert wurde ${ }^{223}$.

Nach den politischen Veränderungen im Herbst 1923, die den Abbruch des Ruhrkampfs und eine Intensivierung der internationalen Vermittlungsbemühungen gebracht hatte, erscheint es sinnvoll, eine Zwischenbilanz zu ziehen. Was hat der Ruhrkampf gekostet? Was hat er gebracht? Der Schaden für die deutsche Wirtschaft betrug etwa 3,6 Mrd. GM ${ }^{224}$.

Seit Beginn der Ruhraktion bis Ende des Monats September wurden

132 Personen getötet,

11 " zum Tode verurteilt,

5 “ zu lebenslänglichem Zuchthaus oder lebenslänglicher

Zwangsarbeit verurteilt,

1454 Jahre Freiheitsstrafen (Zuchthaus, Gefängnis, Zwangsarbeit)

1659 Milliarden Papiermark)

22070 Goldmark ) (Geldstrafen verhängt

111874 Frs )

187617 Personen von Haus und Hof vertrieben, davon

172006 “ aus ihrer Heimat ausgewiesen,

165 Zeitungsverbote erlassen

ferner allein im preußischen [sic] Einbruchs- und Sanktionsgebiet:

209 Schulen mit 2313 Klassen für 127900 Schüler und Schülerinnen beschlagnahmt.

Die Drangsalierung der Bevölkerung, die in diesen Zahlen zum Ausdruck kommt, ist ohne Zweifel eine Quelle wirtschaftlicher Schädigung. Alles in allem werden die materiellen und ideellen Folgen der Ruhrbesetzung noch lange Zeit wie eine Krankheit nachwirken, von der sich der Körper erst allmählich erholen kann ${ }^{225}$.

Frankreich ${ }^{226}$ kostete die Ruhrbesetzung 153,7 Mio. GM. Durch Beschlagnahme und die »Produktivmachung« des Ruhrpfandes ab ungefähr April 1923 wurden Einnahmen von ca. 1050 Mio. GM erzielt, also ein "Gewinn« von 895,7 Mio. GM, der auf die beteiligten Alliierten verteilt wurde. Darin sind al-

\footnotetext{
${ }^{221}$ Dazu siehe Hoesch an AA (16.11.1923), PAAA R, 23233.

${ }^{222}$ Siehe Hoesch an AA (25.12.1923), ADAP A IX, Nr. 73.

${ }^{223}$ Hauptsächlich jedoch nicht als Teil einer ausländischen Verschwörung gegen Frankreich, sondern von den französischen Industriellen. $\mathrm{Zu}$ den Hintergründen vgl. JEANNENEY, L'argent caché, S. 169-199.

${ }^{224}$ Siehe Aufzeichnung ohne Unterschrift (15.1.1924), BArch R 3101, 20436.

${ }^{225}$ Ibid.

${ }^{226} \mathrm{Zu}$ den französischen Kosten siehe JEANNESSON, Poincaré, S. 405f.
} 
lerdings nicht die Produktionsausfälle eingerechnet, die der französischen Industrie dadurch entstanden waren, daß die Kohlenlieferungen aus dem Ruhrgebiet nach dem Einmarsch ins Ruhrgebiet zunächst ausgefallen waren und teurere Kohlen aus England gekauft werden mußten.

Die Bedeutung des Ruhrkampfs ging aber weit über diese unmittelbaren Folgen hinaus und hatte tiefgreifende Konsequenzen fur die deutschfranzösischen Beziehungen ebenso wie für das gesamte europäische Staatensystem. Inwiefern aber wurde der Ruhrkampf zu einem Wendepunkt in den deutsch-französischen Beziehungen der 1920er Jahre und welchen Einfluß hatten diese Ereignisse auf die Modernisierung der Außenpolitik? Bevor diese Frage beantwortet werden kann, muß man sich darüber klar werden, was Frankreich mit dem Ruhrkampf beabsichtigte und welche Position Deutschland während des Ruhrkampfs vertrat.

Die deutschen Ziele sind schnell zusammengefaßt: Erhaltung der Reichseinheit, Wiederherstellung des Status quo ante vom 11. Januar 1923 bzw. soweit als möglich die Vermeidung eines Verzichts auf deutsche Rechte. Voraussetzung dafür war die Stabilisierung der Währung und der wirtschaftlichen Lage. Außenpolitisch versuchte Deutschland, nachdem Frankreich bilaterale Verhandlungen mit Berlin abgelehnt hatte, vor allem Großbritannien und die USA zu mobilisieren. Zwischenzeitlich versuchte die Reichsregierung, so wenige Zugeständnisse wie möglich an Frankreich zu machen, um die französische Position nicht noch weiter zu stärken oder zu sanktionieren. Die deutsche Taktik bestand also aus der Sicherung internationaler Unterstützung, nationaler Wiederaufrichtung durch Ingangsetzung der Wirtschaft und Sanierung der Währung (als Voraussetzung dafür mußte wiederum der passive Widerstand aufgegeben werden) und der Vermeidung langfristig bindender Abmachungen mit Frankreich, die den Status der besetzten Gebiete kompromittiert hätten. Allerdings war der Spielraum der Reichsregierung sehr eng, so daß sie oft nur reagieren konnte. Insgesamt gesehen war die deutsche Politik erfolgreich, oder - was vielleicht der Wahrheit näher kommt - Deutschland hatte Glück gehabt: Die Reichseinheit blieb erhalten, die Währung konnte saniert werden, in der Reparationsfrage deutete sich nach Einberufung der Sachverständigenkonferenz eine erträgliche Lösung an.

Was aber wollte Frankreich? Es ist eine nach wie vor umstrittene - und wohl auch nie völlig lösbare ${ }^{227}$ - Frage, welchen Zweck die französische Regierung und allen voran Poincaré mit dem Ruhrkampf erreichen wollten. Eine These ist, daß Frankreich den im August sicher geglaubten Sieg im Ruhrkampf leichtfertig verspielt habe und letztendlich aus dem Ruhrabenteuer sicherheitspolitisch genauso wenig abgesichert wie zuvor hervorgegangen sei, dabei aber seine Währung ruiniert, die Welt gegen sich aufgebracht und auch

${ }^{227}$ Dies ergibt sich teilweise aus dem Mangel an Quellen: sil n'y a pas de documentation sur la pensée profonde de Poincaré à cette date«, BARIÉTY, Relations franco-allemandes, S. 249. 
in der Reparationsfrage keinen wirklichen Durchbruch erreicht hatte ${ }^{228}$. Es gibt zwei Komplexe, die die Interpretationsfreude der historischen Zunft besonders angefacht haben. Warum hat Poincaré, nachdem Deutschland am 26. September 1923 den passiven Widerstand aufgeben hatte, über einen Monat nicht auf deutsche Gesprächsangebote reagiert und die Situation zur Durchsetzung weitreichender Ziele, z.B. zur Schaffung eines autonomen Rheinlandstaates genutzt? Und wieso hatte er die angelsächsischen Vorschläge für eine Expertenkonferenz zur Lösung der Reparationsfrage zuerst abgelehnt (am 20. Oktober 1923) und dann, nur fünf Tage später, doch zugestimmt? Die abwartende Haltung Poincarés hatte meines Erachtens eine Ursache darin, daß er Deutschland im besonderen, jedem anderen im allgemeinen mit tiefem Mißtrauen begegnete, wie Schubert feststellte: "Poincaré ist von grenzenlosem Mißtrauen erfüllt: Sein Mißtrauen allein würde genügen, ihn zu seiner jetzigen Haltung zu bringen, ganz abgesehen davon, welche finsteren Pläne er sonst noch verfolgt ${ }^{229}$.

Poincaré mußte also erst davon überzeugt sein, daß der passive Widerstand tatsächlich beendet war ${ }^{230}$. Die deutsche Weigerung, französische Offiziere an den Kontrollen durch die IMKK teilnehmen zu lassen ${ }^{231}$ und die Sachlieferungen wiederaufzunehmen ${ }^{232}$, ließen ihn vermuten, daß die deutschen Erklärungen vom 26. September 1926 nur ein Bluff gewesen waren ${ }^{233}$. In Poincarés Augen war die Ruhrbesetzung außerdem nicht nur gegen Deutschland gerichtet, sondern in vielleicht genauso großem Maße gegen die ehemaligen Alliierten, also vor allem England und die USA. Bereits die ganze Vorgeschichte der Ruhrbesetzung hatte gezeigt, daß Frankreich darin den letzten Ausweg sah, mit den Verbündeten doch noch zu einer funktionierenden und zu einer für Frankreich befriedigenden Reparationsregelung zu gelangen. Der Einwand Jeannessons, daß Poincaré an der Einbeziehung der Alliierten gar nicht mehr interessiert gewesen sei, weil ja diese seit Monaten Vorschläge gemacht hätten, die Frankreich stets abgelehnt hätte, und er durch die M.I.C.U.M.Verhandlungen deutlich gemacht habe, daß er statt dessen direkt mit Deutschland $\mathrm{zu}$ einer Einigung kommen wolle ${ }^{234}$, halte ich in diesem Zusammenhang für nicht plausibel. Poincaré wollte die Amerikaner und Briten sehr wohl im Boot haben, aber zu seinen Bedingungen. $\mathrm{Zu}$ Recht ist deshalb auf die Bedeu-

\footnotetext{
${ }^{228}$ Siehe JEANNESSON, Poincaré, S. 16.

${ }^{229}$ Aufzeichnung Schubert (5.10.1923), ADAP A VIII, Nr. 177.

${ }^{230}$ Siehe JOLLY, Ruhr, S. 237.

${ }^{231}$ Siehe Aufzeichnung Köpke (6.10.1923), ADAP A VIII, Nr. 180.

${ }^{232}$ Siehe Kabinettssitzung (20.10.1923), AdR Stresemann I/II Bd. 2, Nr. 156.

${ }^{233}$ In diesem Sinne sah Poincaré das deutsche Angebot, über die Wiederaufnahme der Arbeit der Eisenbahn in den besetzten Gebieten zu verhandeln, siehe Poincaré an Brüssel (16.10.1923), MAE 1918-1929 Z (Europe) Allemagne, 482.

${ }^{234}$ Siehe JEANNESSON, Poincaré, S. 302. Andere Auffassung sind u.a. KEIGER, Poincaré, S. 305 und Daniel AMSON, Poincaré, l'acharné de la politique, Paris 1997, S. 332.
} 
tung der Gespräche zwischen dem französischen Botschafter in Washington und Hughes im Oktober 1923 hingewiesen worden, in denen der amerikanische Außenminister erstmals die Bereitschaft angedeutet hatte, das Schuldenund Reparationsproblem - eine der zentralen französischen Forderungen - im Zusammenhang zu betrachten ${ }^{235}$. Die französische Regierung mußte deshalb den Druck auf Deutschland aufrechterhalten, nicht nur bis Deutschland selbst nachgab, sondern bis endlich auch die USA und England den französischen Bedingungen zustimmten. Denn nur eine internationale und dauerhafte Lösung des Reparations- und Schuldenproblems kam für Frankreich in Frage. Es war ja gerade das Grundaxiom der französischen Politik, daß Frankreich langfristig Deutschland wirtschaftlich wie demographisch unterlegen sein würde und es deshalb auf Dauer abgesicherte internationale Regelungen brauchte. Es ist deshalb nicht ganz glaubhaft, daß Frankreich, im Augenblick eines nur bitter errungenen Sieges im Ruhrkampf, diese Urangst einfach abstreifte und nun meinte, die zweitgrößte Industrienation der damaligen Zeit, deren Bevölkerung ein Drittel größer war als die eigene und die unaufhörlich weiterzuwachsen schien, auf einmal beherrschen zu können. Grundlage für diese französische Politik war der Versailler Vertrag und seine Interpretation durch Poincaré. Poincaré war zwar während : der Friedensvertragsverhandlungen 1919 ein Gegner des Versailler Vertrags gewesen. Er war aber auch Jurist, und als Jurist wußte er, daß auch ein schlechter Vertrag die Unterzeichnenden band $^{236}$ und besser war als gar nichts. Darüber hinaus war er sich natürlich klar, daß jeder Gesetzestext Interpretationen zuließ. Für Poincaré könnte sich die Lage folgendermaßen dargestellt haben: Sowohl Deutschland, weil es seinen Reparations- und anderen Verpflichtungen aus dem Versailler Vertrag nicht nachgekommen war, als auch Großbritannien und die USA, weil sie beide schon vor dem Ruhrkampf eine Revision der Reparationsbestimmungen angedeutet hatten und den Beistandsverpflichtungen gegenüber Frankreich nicht nachgekommen waren, waren Frankreich gegenüber vertragsbrüchig. Es mußte also Ziel des französischen Ratspräsidenten sein, das Deutsche Reich wie auch die angelsächsischen Mächte wieder auf die Grundlage des Versailler Vertrags zu zwingen. Deutschland kam dieser Forderung erst mit der Note vom 24. Oktober 1923 nach - und nicht schon mit dem Abbruch des passiven Widerstandes -, in der es die Überprüfung der Zahlungsfähigkeit gemäß Artikel 234 des Versailler Vertrags durch die RepKo beantragte. Die USA und England ließen ihre Bereitschaft zur Rückkehr zum Versailler Vertrag erkennen, als sie erklärten, die Reparations- und Kriegsschuldenfrage zusammen zu diskutieren. Dies erklärt auch, daß Poincaré sich beständig weigerte, in Verhandlungen mit der Reichsregierung einzutreten, selbst als der passive Wider-

${ }^{235}$ Siehe ERdMANN, Alternativen, S. 33; BaRIÉTY, Ruhrkrise, S. 23.

${ }^{236}$ Zur Bedeutung der Legalität für Poincaré siehe Pierre MIQUEL, Poincaré, Paris 1984, S. 472. 
stand abgebrochen wurde ${ }^{237}$. Für Poincaré war er es nämlich mindestens bis zum 24. Oktober 1923 nicht. Es erklärt auch, weshalb er sich penibel an die Trennung zwischen den M.I.C.U.M.-Verhandlungen und den offiziellen Gesprächen hielt. Für ihn galt der Versailler Vertrag. Der Friedensvertrag war zwischen Staaten - und zwar zwischen allen ehemals alliierten und assoziierten Ländern und Deutschland - geschlossen worden, nicht zwischen Privatleuten. Wenn also die M.I.C.U.M. mit den Industriellen auf privater Basis verhandelte, so war das durchaus legitim und stand nicht im Widerspruch zum Versailler Vertrag. Deutsche Zugeständnisse, die auf diesem Wege zustande kamen, konnten so bedenkenlos genutzt werden, um die eigene Interpretation des Versailler Vertrags durchzusetzen oder auch um des eigenen Vorteils willen. Das französische Verhalten ist nur dann zu verstehen, wenn von diesen zwei Ebenen ausgegangen wird: Auf der Ebene der Regierungen fühlte sich Frankreich voll dem Versailler Vertrag verpflichtet. Auf dem Niveau von Privatverhandlungen galten diese Restriktionen zwar nicht, im Falle von Konflikten zwischen privaten Abmachungen und Regelungen, die auf Regierungsebene getroffen werden mußten, entschied sich die französische Führung jedoch stets zugunsten der geltenden internationalen Abmachungen. Die M.I.C.U.M.Verträge waren nicht deshalb zeitlich beschränkt, weil Frankreich seine Interessen gegenüber Deutschland nicht hätte durchsetzen können, sondern, um eine international abgesicherte Reparationsregelung nicht zu präjudizieren ${ }^{238}$, ohne allerdings den Druck, der durch die M.I.C.U.M.-Verträge zur Unterstützung der französischen Position ausgeübt werden konnte, aufzugeben.

Schwierig ist in diesem Zusammenhang allerdings die Interpretation der Unterstützung der rheinischen Separatisten durch die französische Regierung, zumindest in der Zeit unmittelbar nach dem Ausbruch der Unruhen. Hoffte Poincaré tatsächlich, in Unklarheit über den Rückhalt der Separatisten in der Bevölkerung, daß Deutschland dadurch in Gliedstaaten zerfallen würde und damit die deutsche Gefahr ausgeschaltet wäre ${ }^{239}$ ? War diese Option, die sich im Oktober $1923 \mathrm{zu}$ eröffnen schien, so verlockend, daß sich die französische Regierung davon hinreißen ließ, ihre bis dahin verfolgte Politik derart zu kompromittieren? Vielleicht ist es tatsächlich der Fall, daß diese unerwartete Chance der Geschichte kurzzeitig zu einer Abweichung des bis dahin verfolgten Kurses führte. Die Uneinheitlichkeit der französischen Reaktion spricht dafür, daß die Regierung in Paris nicht planvoll handelte ${ }^{240}$. Vielleicht haben erst die scharfen englischen Forderungen nach Erhaltung der Reichseinheit und die Gefahr drohender nationalistischer Putschversuche in Deutschland $\mathrm{Pa}$ -

\footnotetext{
${ }^{237}$ Siehe ARTAUD, Réparations, S. 99.

${ }^{238}$ Siehe BARIÉTY, Relations franco-allemandes, S. 304.

239 So sehen Bariéty und Jeannesson die Motivation Poincarés, siehe BARIÉTY, Relations franco-allemandes, S. 249; JEANNESSON, Poincaré, S. 303.

${ }^{240}$ Siehe JEANNESSON, Poincaré, S. 253, 332.
} 
ris dazu bewegt, auf die alte Linie der Politik zurückzukehren. Politik folgt eben nicht nur einem festgesetzten Plan, sondern ist eine Mischung aus bewußt verfolgten Zielen und der Reaktion auf mehr oder weniger unvorhersehbare externe Ereignisse. Vielleicht hat die französische Regierung in den separatistischen Unruhen nur ein weiteres Pfund gesehen, mit dem man gegenüber Deutschland und den vormals Alliierten wuchern konnte: Die M.I.C.U.M.-Verträge und das vermeintliche amerikanische Zugeständnis, Schulden und Reparationen gleich zu behandeln, kamen erst nach dem Aufstand im Rheinland zustande, der am 21. Oktober in Aachen losbrach.

Welche Konsequenzen ergeben sich nun aus dem Ruhrkampf und aus diesen Überlegungen für die Frage nach der Modernisierung der Außenpolitik? Ich denke, man kann zu zwei Interpretationen kommen, einer "schwachen« und einer »starken« Modernisierungswirkung des Ruhrkampfs.

Die »schwache" Modernisierungswirkung bestünde darin, daß der Ruhrkampf per se zunächst einen Rückschritt für die Modernisierung der Außenpolitik darstellte. Statt multilateraler Diplomatie kehrte Frankreich zum Bilateralismus zurück (in diesem Sinne wäre die Beteiligung Belgiens und Italiens am Ruhreinmarsch nichts weiter als ein diplomatisches Feigenblatt). Die friedliche Konfliktlösung wurde aufgegeben, statt dessen erfolgte die Rückkehr zur Machtpolitik. Folglich strebte Frankreich keine Politik des Interessenausgleichs, sondern die Durchsetzung von Maximalzielen an, wobei militärischpolitische Ziele, also vor allem die Rheingrenze, im Mittelpunkt standen. Dabei waren sowohl der Versailler Vertrag als auch das Rheinlandstatut verletzt worden. Folgt man dieser Interpretation, war die französische Politik des Ruhrkampfs also ein klarer Rückfall in die Machtpolitik der Zeit vor dem Ersten Weltkrieg. Die Modernisierungswirkung für die Außenpolitik ergab sich nun daraus, daß Frankreich sich nicht hatte durchsetzten können und deshalb gezwungen war, auf das von Briten und Amerikanern angebotene Modell der modernen Außenpolitik einzuschwenken. Somit wäre der Ausgang des Ruhrkampfs das Ereignis gewesen, welches die Pattsituation, die zwischen modernen und klassischen Konzeptionen der französischen Deutschlandpolitik vor dem Ruhrkampf bestanden hatte, zugunsten der modernen Ansätze aufgelöst hätte, weil die Machtpolitik scheiterte und diskreditiert wurde.

Auch in Deutschland führte die Existenzkrise des Ruhrkampfs zur bereits zitierten Erkenntnis Stresemanns, daß der Versailler Vertrag zwar schlecht sei, besser jedoch als ein vollkommen rechtloser Zustand, weil die Rechte aus dem Friedensvertrag wenigstens einklagbar seien ${ }^{241}$. Dies bedeutete, daß Deutschland den Versailler Vertrag nun als Grundlage seiner Beziehungen mit dem Westen anerkannte und zu einer Außenpolitik fand, die auf Einhaltung international festgesetzter Normen beruhte - im Sinne dieser Arbeit also eine mo-

${ }^{241}$ Siehe Besprechung mit den Vertretern der besetzten Gebiete (25.10.1923), AdR Stresemann I/II Bd. 2, Nr. 179. 
derne, weil an Recht gebundene Außenpolitik - und auf Obstruktionsversuche verzichtete. Im Rahmen dieser Interpretation war es also die Schwäche auf wirtschaftlichem wie auf politischem Gebiet, die sowohl Deutschland als auch Frankreich zur "Vernunft« brachten, sich dem liberalen Modell der Friedenssicherung, wie es von den USA und Großbritannien propagiert wurde, anzuschließen. Im Hinblick auf Frankreich läßt diese Interpretation aber außer acht, daß Paris während des gesamten Verlaufs der Ruhrkrise nie eine eindeutige Politik der Stärke betrieb und vielen, auch den vergleichsweise modernen, auBenpolitischen Prinzipien der Zeit vor der Ruhrbesetzung treu blieb.

Die "starke Interpretation der Modernisierungswirkung des Ruhrkampfs geht von der These aus, daß Frankreich - und vor allem Poincaré - mit der Ruhraktion gar nichts anderes bezweckte als den Versailler Vertrag endlich zur umfassenden Anwendung bzw. Durchsetzung zu bringen. Die Rückkehr zum Versailler Vertrag wäre also kein Nebenprodukt, weil sich Frankreich mit der Ruhraktion schlicht übernommen hatte, sondern von Anfang an Ziel des Unterfangens gewesen. Insofern wäre also der Ruhrkampf selbst ein überaus modernes Instrument der Außenpolitik gewesen, nämlich ein Mittel, um zu der völkerrechtlich legitimierten Grundlage von Außenpolitik, wie sie durch den Versailler Vertrag bestand, zurückzukehren.

Für diese Interpretation spricht einiges. Aus französischer Sicht bestand Ende des Jahres 1922 durchaus eine Notwehrsituation. Sowohl Deutschland wie auch England waren bereit, vom Versailler Vertrag, der die einzige dauerhafte Grundlage für Frankreichs Reparationsansprüche war, abzugehen. Poincaré konnte sich, wenn auch vielleicht nicht juristisch einwandfrei, doch immerhin moralisch zu einer Aktion legitimiert sehen. Auch war der Einmarsch durchaus keine blanke, unilaterale Aktion der Machtpolitik: Frankreich war stets um die zumindest stillschweigende Zustimmung Großbritanniens bemüht. Vielleicht wäre Frankreich nie ins Ruhrgebiet einmarschiert, hätte es nicht mit dieser wohlwollenden Neutralität Englands rechnen können ${ }^{242}$. Von französischem Unilateralismus konnte also keine Rede sein. Auch war es so, daß die Ruhraktion unter den Auspizien einer zivilen Behörde stattfand, der M.I.C.U.M. nämlich. Sie war also keine militärische Aktion im eigentlichen Sinne. Frankreich hätte, um den Vorwand zu entkräften, die M.I.C.U.M. sei nur legitimistisches Blendwerk gewesen, durchaus eine möglichst »unsichtbare« Form der Besetzung bevorzugt. Es war erst die Ausrufung des passiven Widerstands durch die Reichsregierung, mit dem am wenigstens die französischen Stellen gerechnet hatten, der die entsprechenden französischen Gegenreaktionen hervorrief. Auch im Moment des totalen Sieges über Deutschland

${ }^{242}$ In diesem Sinne Sally Marks, die Großbritannien für hauptverantwortlich für den Ruhrkampf hält, weil London nicht eindeutig gegen Paris Position bezogen habe, siehe Sally MARKS, The Myths of Reparations, in: Central European History 11 (1978), S. 231-255, hier S. 241-245. 
hatte Frankreich darüber hinaus keine Maßnahmen unternommen, um ambitioniertere politische Ziele $\mathrm{zu}$ verfolgen, z.B. weitere Gebiete $\mathrm{zu}$ besetzen, oder zu versuchen, Deutschland entlang der Mainlinie zu spalten. Weitergehende Sicherheits- und Wirtschaftsprogramme à la Tirard, Degoutte, Foch oder anderer standen bei der politischen Führung nicht auf der Agenda. Frankreich hatte Deutschland und die Alliierten zurück zum Versailler Vertrag gezwungen, und damit war das Ziel erreicht. In zwei Aufzeichnungen, vom August und Oktober $1923^{243}$, also in dem Zeitraum, als der französische Sieg im Ruhrkampf absehbar war, bzw. kurz nachdem er manifest geworden war, nahmen sich die französischen Forderungen moderat aus und bewegten sich durchaus im Rahmen des Versailler Vertrags, obwohl es sich sicherlich um französische Maximalforderungen handelte. Im einzelnen bestanden die französischen Forderungen darin, daß Deutschland den passiven Widerstand aufgeben müsse, der im Widerspruch zum Versailler Vertrag stehe und Deutschland selbst am meisten schade. Die Aufgabe des passiven Widerstands werde zu einer Entspannung führen und es der M.I.C.U.M. ermöglichen, ihre Arbeit wieder aufzunehmen und die Kohlensteuer und die Exportabgabe wieder zu erheben. Die Sachlieferungen sollten gemäß der Abkommen von Spa und Wiesbaden geleistet werden. Frankreich erkenne an, daß Deutschland momentan keine Reparationszahlungen tätigen könne. Die Währung, die von Deutschland bewußt in den letzten Jahren zerstört worden sei, müsse schnell wiederhergestellt werden. Die Währungsstabilisierung könne zügig geschehen, da die Substanz der deutschen Wirtschaft nicht angegriffen sei. Um sie zu erleichtern, solle ein Moratorium zugestanden werden. Auf Finanzkontrollen könne weitgehend verzichtet werden, es seien aber Pfänder dazu notwendig. Gedacht wurde vor allem an die Eisenbahnen in den besetzten Gebieten, die in eine Gesellschaft unter französischer, belgischer, englischer und rheinischer Beteiligung umgewandelt werden sollte. Auch die Saarbergwerke, Zölle und Deviseneinnahmen aus Exporten könnten als Sicherheit für ein Moratorium dienen. Als weiteres Pfand könne die Beteiligung alliierten Kapitals an deutschen Bergwerken dienen, um die französische Kohlenversorgung sicherzustellen. Im Gegenzug sollte Deutschland Erz und Halbwaren aus Lothringen zu Vorkriegskonditionen beziehen können. Zur Sicherheit solle das Ruhrgebiet nur in dem Umfang freigegeben werden, in dem Deutschland seine Reparationsleistungen zahlte. Allerdings stand für Frankreich die Höhe der Reparationen - die $132 \mathrm{Mrd}$. GM von Spa - außer Frage, nur im Falle einer Reduktion der französischen Kriegsschulden sei auch eine Verringerung der Reparationszahlungen möglich.

${ }^{243}$ Siehe Aufzeichnung ohne Unterschrift (14.8.1923), MAE PAAP 261, 3; Aufzeichnung ohne Unterschrift (22.10.1923), MAE PAAP 261, 3. 
In diesen beiden Aufzeichnungen, die auf einem französischen Gelbbuch ${ }^{244}$ basierten, in dem verschiedene Dokumente zur Reparationsfrage zusammengetragen worden waren und die den Dreh- und Angelpunkt der französischen Haltung bildeten, war nichts zu finden, was als langfristiges politisches Ziel französischer Politik im Rheinland hätte aufgefaßt werden können: keine Rede von einer militärischen Rheingrenze oder einem - in welcher konkreten Form auch immer - von Preußen oder gar vom Reich abgetrennten theinischen Staat. Poincaré selbst machte dies auch gegenüber MacDonald, der seit dem 22. Januar 1924 neuer britischer Premier war, deutlich. Vielmehr sollte die Lösung des Sicherheitsproblems im Rahmen des Völkerbunds gefunden wer$\operatorname{den}^{245}$. Es ist sicherlich kein Zufall, daß sich die französische Regierung im Sommer 1923 verstärkt für den Ausbau der kollektiven Sicherheitsstrukturen im Rahmen des Völkerbunds einsetzte ${ }^{246}$. Ganz in diesem Sinne stellte auch Seydoux im April 1924 fest, die Ruhrbesetzung sei ein Erfolg gewesen, weil dadurch die Reparationsfrage gelöst worden und durch den Zusammenbruch der deutschen Währung der währungspolitische Neuanfang geschaffen worden sei, durch den auf Dauer die deutschen Zahlungen an Frankreich sichergestellt würden ${ }^{247}$. Im Lichte dieser Interpretation wäre der Ruhrkampf also eine legitime Sanktion gewesen, die sowohl gegen Deutschland als auch gegen Großbritannien gerichtet war, um diejenigen Parteien, die sich immer mehr vom Versailler Vertrag zu entfernen drohten, wieder zu einer den im Friedensvertrag festgelegten Prinzipien entsprechenden Politik zu zwingen. Somit würde der Ausgang des Ruhrkampfs ziemlich genau dem entsprechen, was Frankreich davon erwartet hatte. Er würde auch nicht das Ende der französischen Vorherrschaft in Europa ${ }^{248}$ und den Sieg der "Dollardiplomatie $\ll^{249}$ bedeuten, die, nachdem Deutschland von Frankreich zu Boden gedrückt worden war und Frankreich sich an der Ruhr zu Tode gesiegt hatte, erfolgreich ihre eigenen reparations- und finanzpolitischen Vorstellungen durchgesetzt hätte ${ }^{250}$. Der Ruhrkampf würde in dieser Interpretation auch nicht das Scheitern kollektiver

\footnotetext{
${ }^{244}$ Die offiziell vom Quai d'Orsay herausgegebenen Dokumentensammlungen waren aufgrund ihres Einbandes allgemein als livre jaune (analog zu den Weißbüchern der deutschen und den Blaubüchern der englischen Regierung) bekannt. In den beiden Aufzeichnungen wird das Gelbbuch nicht weiter spezifiziert, es könnte sich jedoch um den Band: Documents relatifs aux réparations, hg. v. Ministère des affaires étrangères, Paris 1922, handeln.

${ }^{245}$ Siehe BARIÉTY, Relations franco-allemandes, S. 297.

${ }^{246}$ Siehe Antwort der franzősischen Regierung an den Völkerbund zum gegenseitigen Beistandspakt (15.6.1923), in: Documents diplomatiques. Documents relatifs aux négociations concernant les garanties de sécurité 1924, Nr. 44, Anhang 12. Zu Einzelheiten siehe Kap. 4.1.3.

${ }^{247}$ Aufzeichnung Seydoux (22.4.1924), MAE PAAP 261, 31.

${ }^{248}$ Siehe SCHUKER, French Predominance, S. 385.

${ }^{249}$ GIRAULT, Europe, S. 137.

${ }^{250}$ In diesem Sinne LINK, Ruhrkonflikt, S. 40f.; SCHULZE, Weimar, S. 25; KEIGER, Poincaré, S. 310-312; GIRALLT, Europe, S. 137.
} 
und friedlicher Konfliktlösungsmechanismen im Rahmen des Völkerbunds darstellen $^{251}$, sondern gerade den Versuch, die Mechanismen des Versailler Vertrags vor ihrer Aushöhlung zu bewahren. Insofern wurde Poincaré tatsächlich derjenige, der mit seiner Politik die deutsch-französische Verständigung ermöglichte und den Weg nach Locarno ebnete ${ }^{252}$, dies allerdings nicht unabsichtlich, indem er letztlich scheiterte, sondern in einer aktiven Art und Weise.

Wie gesagt, es spricht einiges für die letzte Interpretation, die Indizien dafür wurden benannt. Es wäre aber, so meine ich, falsch, dem Poincaré, der viel wagte und letztlich verior, den Poincaré entgegenzusetzen, der mit quasi seherischen Fähigkeiten nicht nur den Dawes-Plan, sondern auch die Möglichkeiten einer deutsch-französischen Verständigungspolitik der späteren 1920er Jahre vorhergesehen und zielstrebig darauf zugearbeitet hätte. Eine Ansicht, die im übrigen so gar nicht dem vielfach auch in der Forschung wiedergegebenen, eher negativen Bild Poincarés entspräche ${ }^{253}$. Auch wenn Poincarés Einflu $ß$ in dieser Phase der französischen Politikgestaltung sicherlich gro $\beta$ war, war er eben nicht der einzige, der auf die Rheinland- und Ruhrpolitik Einfluß nahm. Viele Widersprüche im französischen Handeln lassen sich daraus erklären, daß es in der französischen Politik die zwei genannten, grundsätzlich verschiedenen Ansätze der »Ökonomen«, zu denen Seydoux, Loucheur und vielleicht auch Poincaré gehörten, und der "Rheinländer" um Foch, Tirard und Degoutte gab. Allein auf die zweite Interpretation zu setzen hieße, in unzulässiger Weise die Dinge zu vereinfachen und zu verfälschen. Die Wahrheit - ohne sie genauer spezifizieren zu können oder auch nur zu wollen - dürfte irgendwo zwischen der "starken « und der "schwachen« Interpretation der Modernisierungswirkung des Ruhrkampfs liegen. Die beiden Optionen gegenüberzustellen und voneinander abzugrenzen, diente vor allem der analytischen Klarheit.

Bedeutend erscheint mir im Zusammenhang mit dem Ruhrkampf und dessen Einfluß auf die Modernisierung der Außenpolitik aber vor allem eines: Sowohl in Frankreich als auch in Deutschland bewirkte der Konflikt, sich eindeutiger auf die Spielregeln der modernen Außenpolitik, als dies in der Zeit unmittelbar nach dem Ersten Weltkrieg der Fall gewesen war, einzulassen, als verschiedene, moderne und klassische Politikkonzepte nebeneinanderstanden. Nach dem Ruhrkampf war für die Regierungen in Deutschland und Frankreich klar, daß

\footnotetext{
${ }^{251}$ Siehe LEE, German Foreign Policy, S. 47.

${ }^{252}$ Siehe KEIGER, Poincaré, S. 311.

253 "Poincaré had three defects: a cold, shy withdrawn manner; an inability to delegate and to listen to advice; thirdly a lack of judgement«, Anthony ADAMTHWAITE, France, Germany and the Treaty of Versailles: France's bid for Power in Europe, in: Karl Otmar Freiherr v. ARETIN u.a. (Hg.), Das deutsche Problem in der neueren Geschichte, München 1997, S. 7588, hier S. 82.
} 
im Rahmen multilateraler diplomatischer Anstrengungen innerhalb eines festgelegten Rechtssystems (dem Versailler Vertrag) eine für alle erträgliche Lösung für das Reparationsproblem (und die anderen offenen Fragen) gefunden werden sollte.

\subsection{Der Dawes-Plan und die Londoner Konferenz}

War der Ruhrkampf das reinigende Gewitter, das die deutsch-französischen Beziehungen, im weitesten Sinne aber auch das internationale System erfaßt hatte, so erfolgte mit dem Dawes-Plan das Aufräumen nach dem großen Sturm. Im folgenden wird es weniger darum gehen, die einzelnen Verhandlungsetappen des Dawes-Plans und der Londoner Konferenz nachzuzeichnen $^{254}$, sondern vor allem darum, welche Auswirkungen die Arbeit der Expertenkommission auf die Modernisierung der Außenpolitik hatte.

Hauptproblem Anfang des Jahres 1924 waren sicherlich die Reparationen ${ }^{255}$, zu dessen Lösung die beiden von der RepKo eingesetzten Expertenkommissionen beitragen sollten. Eng mit dieser Frage verknüpft war ein Komplex, der sich für Frankreich unter dem Stichwort der Sicherheit, für Deutschland unter dem Schlagwort Rheinlandfrage zusammenfassen läßt: Für Paris war das Rheinland ein wichtiges strategisches Glacis, das seine Verteidigungsfähigkeit gegenüber Deutschland erhöhen sollte, indem es das Reich militärisch und wirtschaftlich in seiner Bewegungsfreiheit einengte. Das Ziel der deutschen Politik war es, diese strategische Überlegenheit Frankreichs auf militärischem und wirtschaftlichem Gebiet im Rheinland zurückzudrängen und wieder »Herr im Haus« zu werden ${ }^{256}$. Andererseits war Frankreich an zuverlässigen, geregelten Reparationszahlungen von Deutschland interessiert, um so mehr, als es mit dem Franc immer bedrohlicher bergab ging ${ }^{257}$.

In dieser Situation eröffnete sich für die deutsche Politik die Möglichkeit, die wirtschaftliche Befreiung der besetzten Gebiete durch eine erträgliche Regelung der Reparationsfrage zu erreichen ${ }^{258}$. Die Reichsregierung bemühte

\footnotetext{
${ }^{254}$ Dazu liegen bereits umfangreiche Studien vor. An erster Stelle ist dabei natürlich die Darstellung Bariétys zu nennen (BARIÉTY, Relations franco-allemandes), aber auch andere Publikationen, siehe DAWES, Dawes-Plan; Die Londoner Konferenz Juli-August 1924. Amtliches deutsches Weißbuch über die gesamten Verhandlungen der Londoner Konferenz, Sitzungsprotokolle, Aktenstücke, Briefwechsel, hg. v. Auswärtiges Amt, Berlin 1925; Tagebuch der Reichskanzlei über die Londoner Konferenz (4.-18.8.1924), AdR Marx I/II Bd. 2, Anhang 1.

${ }^{255}$ Siehe KRÜGER, Versailles, S. 122.

${ }^{256}$ Siehe DERS., Außenpolitik, S. 232f.

${ }^{257}$ Siehe GIRAULT, Europe, S. 136.

${ }^{258}$ Zur Ausrichtung der deutschen Politik siehe KRÜGER, Außenpolitik, S. 233-236.
} 
sich deshalb, guten Willen zu zeigen, und suchte besonders die Nähe zu Großbritannien und den USA, bei denen man in Berlin richtigerweise vermutete, daß sie den deutschen Forderungen nach Wiederherstellung der wirtschaftlichen Einheit des Reiches - aus Furcht vor einer französischen Wirtschaftshegemonie auf dem Kontinent - wohlgesonnen waren.

In Paris stellte man sich unterdessen die Frage, wie man in der Deutschlandpolitik fortfahren sollte. Die Reparationsfrage lag wegen der Überweisung an die Experten zunächst auf Eis. Hier blieb wenig übrig, als den begrenzten Einfluß auf die Sachverständigen zu nutzen und ansonsten der Dinge zu harren, die da kommen mochten. Gewiß, Frankreich hatte seine Armee fest im Ruhrgebiet etabliert, die Eisenbahnregie arbeitete und die M.I.C.U.M.-Verträge lieferten Ergebnisse. Wie sollte es aber weitergehen? Eine Regelung für die Bezahlung der Kriegsschulden bei den USA und England war nicht in Sicht, und langfristig würde es ohne die Unterstützung der USA und Großbritanniens weder bei den wirtschaftlichen Problemen noch bei der Sicherheitsfrage zu Fortschritten kommen. Außerdem bereitete der Wertverfall des Franc der französischen Führung zunehmend Kopfzerbrechen. Die Pariser Presse argwöhnte, eine konzertierte Aktion deutscher und englischer Banken stände hinter dem rasanten Verfall der französischen Währung, um Druck auf die französische Regierung auszuüben ${ }^{259}$. Allerdings wurde bald klar, daß die Spekulation gegen den Franc vor allem von französischen Industriellen ausgelöst wurde ${ }^{260}$. Allerdings gelang es der französischen Regierung, einen 100 Mio. Dollar Kredit des amerikanischen Bankhauses Morgan zu erhalten und so einerseits die Spekulationswelle zu stoppen und andererseits den eigenen politischen Spielraum wieder zu vergrößern ${ }^{261}$. Poincaré mußte aber im Gegenzug für die Anleihe zustimmen, „daß die Französische Regierung im Falle der Durchführung der Stützungsaktion die [Dawes-, R.B.] Gutachten anzunehmen und auszuführen sich verpflichte ${ }^{262}$.

Angesichts der vor allem wirtschaftlichen Probleme einerseits und der immer noch intakten politischen Druckmittel andererseits galt es also, die Karten, die man in der Hand hielt, im Sinne einer langfristigen, für Frankreich vorteilhaften Politik auszuspielen. Als erster erkannte wieder einmal Seydoux die Notwendigkeiten der Neuorientierung der französischen Außenpolitik und legte seine Gedanken Anfang Februar 1924 in einer Aufzeichnung nieder, die

\footnotetext{
${ }^{259}$ Siehe Hoesch an AA (5.1.1924), PAAA R, 28234.

${ }^{260}$ Siehe Bendix an AA (14.1.1924), BArch R 3101, 14553, vgl. auch JEANNENEY, L'argent caché, S. 169-199; Jean-Claude DEBEIR, La crise du franc de 1924. Un exemple de spéculation winternationale $\ll$, in: Relations internationales 13 (1978), S. 29-49. Anders Roth, der holländische und österreichische Bankhäuser für die Spekulation verantwortlich macht, siehe ROTH, Poincaré, S. 453.

${ }^{261}$ Siehe LefFler, Quest, S. 100.

${ }^{262}$ Sthamer an AA (3.5.1925), BArch R 3101, 14554.
} 
im großen und ganzen auch auf die Zustimmung Poincarés stie $\beta^{263}$. Zunächst betonte Seydoux den Wert der Ruhrbesetzung, deren eigentlicher Nutzen vor allem darin bestehe, daß sie Großbritannien zur Zusammenarbeit mit Frankreich gedrängt habe. Allerdings sei die direkte wirtschaftliche Ausbeutung des Ruhrpfandes weniger ertragreich als eine gütliche Lösung mit Deutschland, was die Wiederherstellung der wirtschaftlichen Einheit mit einschließe. Um die französischen Forderungen bezüglich der Reparationen und der Sicherheit durchzusetzen, müsse versucht werden, zu einer Annäherung an Großbritannien zu kommen und den Völkerbund auszubauen, denn letztlich sei es nur durch England und die USA möglich, Europa zu befrieden, indem die Wirtschaft wiederaufgebaut werde. Was die französische Regierung also hier versuchte, war, das Ruhrpfand für langfristige wirtschafts- und sicherheitspolitische Zwecke einzusetzen. Die Verbesserung der Beziehungen gegenüber Großbritannien stand dabei im Mittelpunkt der Bemühungen, und es kam Anfang des Jahres $1924 \mathrm{zu}$ einer deutlichen Annäherung zwischen London und Paris: Die Abkehr Frankreichs von der Unterstützung der pfälzischen Separatisten und insgesamt die Aufgabe einer prononcierten Rheinlandpolitik, eine nachgiebigere Haltung Frankreichs in der Frage der Wiederaufnahme der Militärkontrolle durch die IMKK und der anglo-französische Kompromiß über die gemeinsame Ausbeutung der Erdölvorkommen im Irak trugen Früchte ${ }^{264}$. Auch in der Ruhrfrage ging man aufeinander zu. Frankreich stellte zwar nicht die militärische Räumung in Aussicht, kündigte aber an, auf wirtschaftliche Pressionen zu verzichten und die Besetzung für die Deutschen so »unsichtbar" wie möglich zu gestalten ${ }^{265}$.

Neben der Verbesserung der Beziehungen zu Großbritannien mußte Frankreich aber auch versuchen, die politisch-militärischen und wirtschaftlichen Druckmittel gegenüber Deutschland aufrechtzuerhalten. Die Annäherung an England konnte also in dieser Phase, wo weder über die Zukunft der Reparationen und Kriegsschulden noch die der Sicherheit und der anderen schwebenden Probleme entschieden worden war, nicht soweit gehen, daß französischerseits die militärische Ruhrräumung oder die M.I.C.U.M.-Verträge zur Disposition gestellt werden durften.

Die Frage der militärischen Besetzung war zunächst nicht akut. Sie war ausdrücklich aus dem Programm der Expertenkommission ausgeklammert worden. Drängender war hingegen das Problem der M.I.C.U.M.-Absprachen. Sie waren zunächst bis zum 15. April 1924 befristet, einem Zeitpunkt also, zu dem eine endgültige Regelung der Reparationsfrage noch nicht zu erwarten war. In bezug auf die Frage nach der Verzahnung von wirtschaftlichen und politischen

${ }^{263} \mathrm{Zu}$ dieser Aufzeichnung siehe BARIÉTY, Relations franco-allemandes, S. 293-295; JEANNESSON, Poincaré, S. 391-393.

${ }^{264}$ Siehe BARIÉTY, Relations franco-allemandes, S. 298f., 307.

${ }^{265}$ Siehe JEANNESSON, Poincaré, S. 393f. 
Problemen lohnt es sich, auf die Frage der Verlängerung der M.I.C.U.M.Verträge etwas genauer einzugehen, denn hier trafen die unterschiedlichen Interessen von deutscher und französischer Außenpolitik sowie die der Wirtschaft beider Länder zusammen. Was also verbanden diese verschiedenen Akteure mit den M.I.C.U.M.-Verträgen?

Die deutsche Wirtschaft wollte eine Änderung des gegenwärtigen Wirtschaftsregimes in den besetzten Gebieten. Die Belastungen, die der Industrie durch die Abkommen mit der M.I.C.U.M. auferlegt wurden, seien auf Dauer nicht zu verkraften, außerdem strömten durch die offene Zollgrenze im Westen ungebremst und durch den Francverfall verbilligte französische Waren in das Rheinland ${ }^{266}$. Für eine Verringerung der Lasten aus den M.I.C.U.M.Verträgen war man deshalb bereit, langfristige Verträge mit der französischen Industrie z.B. in bezug auf die Koksversorgung abzuschließen ${ }^{267}$. Mit diesem Ziel verhandelten Vertreter Stinnes' im Januar und Februar 1924 mit Pinot, dem Chef des Comité des forges, und mit Seydoux.

Die Haltung der rheinisch-westfälischen Schwerindustrie korrespondierte, gelinde gesagt, kaum mit der Stresemanns:

Der Minister Ritter und der Botschaftsrat von Hoesch hätten darauf in seinem, des Ministers Auftrage Herm Stinnes um die Mitteilung seines Reparationsplanes gebeten. Hierbei habe sich wenig Positives ergeben; der Gedanke der Stinnesgruppe laufe im wesentlichen auf eine Fortsetzung der Micum-Verträge unter Zuhilfenahme einer internationalen Anleihe hinaus.

Dieser Gedanke sei unbedingt zu verurteilen, denn er nehme den gegenwärtigen Zustand an Rhein und Ruhr zum Ausgangspunkt und bedeute hierdurch gewissermaßen eine Anerkennung des französisch-belgischen Regimes in seiner heutigen Gestalt. Er stehe somit im unmittelbaren Widerspruch $\mathrm{zu}$ der Generalpfandidee der Reichsregierung und bedeute eine Sabotierung dieser Idee und somit auch der Arbeiten des Sachverständigenkomitees, das nach den vorliegenden Orientierungen ebenfalls eine Lösung im Sinne des Generalpfandes anstrebe. Er halte es daher für erforderlich, die Gedankengänge der Stinnes-Gruppe seitens der Reichsregierung zurückzuweisen ${ }^{268}$.

Es war also im Interesse der Reichsregierung, die M.I.C.U.M.-Frage offenzuhalten bzw. diese von der Ebene der quasi privaten Absprachen zwischen deutscher Wirtschaft einerseits und M.I.C.U.M. andererseits auf die Regierungsebene zu heben. Kämen Deutsche und Franzosen zu langfristigen wirtschaftlichen Verträgen bezüglich der wirtschaftlichen Kooperation, würde es unendlich viel schwieriger für die deutsche Regierung werden, den Abzug der französischen Besatzungstruppen aus dem Ruhrgebiet zu erreichen. Deshalb forderte Stresemann Hoesch auf, statt über eine Verlängerung der M.I.C.U.M.Verträge über ein provisorisches Abkommen zwischen den Regierungen zu

${ }^{266}$ Siehe Vögler an Ritter (24.1.1924), BArch R 3101, 14767.

${ }^{267}$ Siehe BARIÉTY, Relations franco-allemandes, S. 302.

${ }^{268}$ Kabinettssitzung (29.1.1924), AdR Marx I/II Bd. 1, Nr. 79 
verhandeln, um die Zeit bis zum Inkrafttreten der neuen Reparationsregelungen zu überbrücken ${ }^{269}$.

Die Franzosen hingegen lehnten dies ab. Als sich abzeichnete, daß sie im Falle einer Nichtverlängerung der M.I.C.U.M.-Absprachen zu den Repressalien der Vor-M.I.C.U.M.-Zeit zurückkehren würden ${ }^{270}$, gab die Reichsregierung schließlich doch nach, weil sonst das wirtschaftliche Chaos gedroht hätte ${ }^{271}$. Außerdem war für Deutschland die befristete Verlängerung der M.I.C.U.M.Verträge immer noch erträglicher als dauerhafte Abkommen zwischen den Industriellen, die den deutschen Spielraum in der Frage der militärischen Räumung langfristig eingeengt hätten. Die dringende Bitte Englands, durch die drohende Nichtverlängerung der Verträge mit der M.I.C.U.M. die Lösung des Reparationsproblems nicht zu gefährden, tat ihr übriges, um die Reichsregierung zum Nachgeben zu bewegen. Am 14. April 1924, also einen Tag vor ihrem Ablauf, einigten sich die Sechserkommission und die M.I.C.U.M. auf die Verlängerung der Absprachen bis zum 15. Juni 1924. Frankreich hatte so zwar noch alle Druckmittel in der Hand, als über den Dawes-Plan verhandelt wurde, allerdings hatte Deutschland auch vermeiden können, daß die Verträge unbefristet verlängert worden waren ${ }^{272}$.

Frankreich wollte also die Verlängerung der M.I.C.U.M.-Verträge. Zu welchem Zweck? Wäre es für Frankreich nicht besser gewesen, jetzt, im Moment der Stärke, mit den deutschen Industriellen zu langfristigen Absprachen zu kommen, um dauerhaft den französischen Einfluß auf die rheinischwestfälische Schwerindustrie zu sichem? Ein Problem in diesem Zusammenhang waren die Konflikte innerhalb der französischen Schwerindustrie. Der Comité des forges war zwar an einer teilweisen oder vollständigen Besitzübertragung von Bergwerken im Ruhrrevier auf die französische Eisenindustrie interessiert, stieß damit aber auf den Widerstand des Kohlenverbandes, dem Comité central des houillères de France (C.C.H.F.) ${ }^{273}$. In dieser innerwirtschaftlichen Auseinandersetzung boten die M.I.C.U.M.-Verträge eine sowohl für den Comité des forges wie auch für den C.C.H.F. erträgliche Übergangslösung, wähnte man doch die deutsche Konkurrenz wirksam ausgeschaltet ${ }^{274}$.

Allerdings entspann sich innerhalb der französischen Regierung bald ein Konflikt über die Vorgehensweise. Seydoux war zwar auch der Meinung, daß eine endgültige Regelung für die langfristige Zusammenarbeit zwischen deutscher und französischer Schwerindustrie erst dann zustande kommen könne,

\footnotetext{
${ }^{269}$ Siehe Stresemann an Paris und Brüssel (2.4.1924), ADAP A IX, Nr. 243.

${ }^{270}$ Siehe Vögler an Ritter (3.4.1924), BArch R 3101, 14769.

$271 \mathrm{Zu}$ den Motiven der deutschen Regierung, der Verlängerung der M.I.C.U.M.-Verträge zuzustimmen, siehe BARIÉTY, Relations franco-allemandes, S. 306.

${ }^{272}$ Siehe Runderlaß Ritter (30.4.1924), ADAP A X, Nr. 52.

${ }^{273}$ Siehe Aufzeichnung Seydoux [?] (8.1.1924), MAE PAAP 261, 30.

${ }^{274}$ Siehe Hoesch an Schubert (1.3.1924), ADAP A IX, Nr. 177.
} 
den Deutschen, um in dem Moment, in dem die Experten ihr Ergebnis vorlegten, zügig zu einem Abschluß mit den deutschen Industriellen kommen zu können. Er wollte außerdem den Deutschen eine Perspektive aufzeigen, damit sie ihren Widerstand gegen die Verlängerung der M.I.C.U.M.-Verträge aufgäben $^{275}$. Gleichzeitig sollte das Thema mit London erörtert werden, um die englische Zustimmung für diese Pläne zu sichern ${ }^{276}$. Staatspräsident Millerand und der Minister für öffentliche Arbeiten, Le Trocquer unterstützten den Vorstoß Seydoux', nicht aber Poincaré, der Pinot lediglich erlaubte, dilatorisch mit den deutschen Industriellen zu verhandeln, und Gespräche mit Hoesch über dieses Thema ablehnte ${ }^{277}$. Über die Haltung Poincarés in dieser Frage läßt sich nur spekulieren. Wollte er vermeiden, daß das gerade wieder mühsam verbesserte Verhältnis zu England durch deutsch-französische Sonderverhandlungen Schaden nahm? Vielleicht steht seine Weigerung im Zusammenhang mit der Sicherheitsfrage, die Anfang März 1924 wieder stärker die französische Politik bestimmte ${ }^{278}$. Käme man jetzt auf wirtschaftlicher Ebene mit Deutschland zu einer Regelung, würde das Ruhrpfand für die Sicherheitsfrage wertlos. Vielleicht stand seine Haltung aber auch im Zusammenhang mit den Verhandlungen für den 100 Mio. Dollar Kredit von Morgan, der bereits erwähnt wurde. Dabei hatte sich die französische Regierung verpflichtet, den neuen Reparationsplan zu unterstützen, und Poincaré wollte vielleicht verhindern, daß das von den Experten erarbeitete Reparationsschema durch deutschfranzösische Sonderabsprachen kompromittiert wurde.

Bezüglich der M.I.C.U.M.-Verhandlungen und des Einflusses der Wirtschaftskräfte auf deren Ausgang läßt sich feststellen, daß die deutsche Industrie ihre Vorstellungen nicht hatte durchsetzen können. Sie war auf nur mäßiges Interesse bei ihren französischen Partnern gestoßen und sah sich der Opposition der deutschen wie der französischen Politik ausgesetzt. Obwohl zwar beide Regierungen bezüglich der M.I.C.U.M. »diametral entgegengesetzte ${ }^{279}$ Zielsetzungen verfolgten, war keine der beiden Seiten zu diesem Zeitpunkt an einer langfristigen Bindung der französischen und deutschen Industrie interessiert: Die Reichsregierung wollte die Lage offenhalten, um auch die militärische Besetzung in einem günstigen Augenblick abzuschütteln, Frankreich war an einer Regelung der Frage im Gesamtzusammenhang mit den Reparationen und der Sicherheitsfrage interessiert. So entsprach die befristete Verlängerung der M.I.C.U.M.-Verträge den Zielen der französischen Politik. Verglichen mit

\footnotetext{
${ }^{275}$ Siehe Aufzeichnung Seydoux (3.3.1924), MAE PAAP 261, 40.

${ }^{276}$ Seydoux zog hier offensichtlich die Konsequenz aus dem Mißerfolg seines Reparationsplans von 1920, der vor allem am englischen Widerstand gescheitert war.

${ }^{277}$ Siehe Aufzeichnung Seydoux (3.3.1924), MAE PAAP 261, 40.

${ }^{278}$ Hoesch an AA (4.3.1924), PAAA R, 70096.

${ }^{279}$ BARIETY, Relations franco-allemandes, S. 305.
} 
der Alternative langfristiger deutsch-französischer Wirtschaftsabkommen war sie für Deutschland das kleinere Übel.

In diesem Umfeld begannen die Dawes-Plan Verhandlungen, nachdem die RepKo am 30. November 1923 beschlossen hatte, zwei Expertenkommissionen zur Lösung der Reparationsfrage einzusetzen. Die erste Kommission sollte Maßnahmen erarbeiten, wie das deutsche Budget ins Gleichgewicht gebracht und die neue deutsche Währung langfristig stabil gehalten werden konnte. Die zweite sollte Ausmaß und Bedeutung der Kapitalflucht aus Deutschland während der Inflationszeit untersuchen ${ }^{280}$. Die erste Kommission - betreffend das deutsche Budget und die Währungsstabilisierung - unter Vorsitz des Amerikaners Charles G. Dawes bestand aus zehn Mitgliedern (je zwei aus den USA, Großbritannien, Frankreich, Belgien und Italien). Sie war die bei weitem wichtigere der beiden Arbeitsgruppen: Ihr oblag es letztendlich zu bestimmen, welche Reparationsbelastung sowohl mit dem budgetären Gleichgewicht als auch der Stabilität der deutschen Währung zu vereinbaren war. Die zweite Kommission, unter Vorsitz des britischen Bankiers McKenna, bestand aus fünf Mitgliedern (je einem aus den genannten Ländern) und war vor allem wein sachlich belangloses Lockmittel für die französische Seite, das der britische Reparationsbeauftragte Bradbury erdacht hatte, um Frankreich die Zustimmung zum ersten Mandat zu erleichtern ${ }^{281}$.

Wie bereits im vorherigen Kapitel zu sehen war, hatte sich Frankreich bemüht, die Rolle der Expertenkommissionen möglichst stark auf die technischen Aspekte des Reparationsproblems zu beschränken und konnte immerhin durchsetzen, daß weder die Ruhrbesetzung noch die M.I.C.U.M.-Verträge Bestandteil der Erörterungen der Experten sein durften. Auch das 1921 in Spa festgelegte Gesamtvolumen der deutschen Reparationsschuld von 132 Mrd. GM stand nicht zur Disposition ${ }^{282}$. Allerdings konnte Frankreich sich nicht mit seinen Forderungen durchsetzen, die Fragen der Eisenbahnregie und der innerdeutschen Zollgrenze aus den Expertendiskussionen herauszuhalten ${ }^{283}$.

Die Ergebnisse, zu denen die Experten in ihrem Abschlußbericht vom 9. April 1924 kamen, sind schnell zusammengefaßt ${ }^{284}$. Voraussetzung für das Funktionieren des Planes, so die Fachleute, sei die Wiederherstellung der wirt-

${ }^{280}$ Zur Organisation der Arbeit der Sachverstăndigenkommissionen vgl. SCHWABE, Ruhrkrise, S. 70; JEANNESSON, Poincaré, S. 389f.; BARIÉTY, Relations franco-allemandes, S. 275, 301.

${ }^{281}$ SCHWABE, Ruhrkrise, S. 70.

${ }^{282}$ Siehe JEANNESSON, Poincaré, S. 389.

${ }^{283}$ Siehe ibid. Zur Entwicklung des Auftrages des Expertenkomitees, der sogenannten terms of reference, siehe auch DAWES, Dawes Plan, S. 285-296.

${ }^{284}$ Der Text des Expertenberichts ist u.a. abgedruckt in: DAWES, Dawes Plan, S. 299-509. Die folgende Zusammenfassung der Ergebnisse des Dawes-Plans beruht auf WEILLRAYNAL, Réparations, Bd. 2, S. 562f. 
schaftlichen und fiskalischen Einheit Deutschlands ${ }^{285}$ und die Unteilbarkeit des gesamten Gutachtens. Der Plan sah vor, daß die deutschen Reparationszahlungen stufenweise von $1 \mathrm{Mrd}$. GM pro Jahr im ersten auf 2,5 Mrd. GM im füften Jahr steigen sollten, um dann auf diesem Niveau zu bleiben. Die Laufzeit der deutschen Zahlungen wurde nicht festgelegt. Die weitere Erhöhung der Annuitäten war aufgrund eines Wohlstandsindex' möglich, eine Revision der Zahlungen in dem Fall, daß sich der Goldwert dramatisch verändern würde. Als Pfänder für die deutschen Reparationszahlungen wurden Hypotheken auf die Reichsbahn und die deutsche Industrie vorgesehen, außerdem wurden bestimmte Staatseinnahmen verpfändet. Das betraf vor allem Zölle sowie die Monopolgewinne und Steuereinnahmen auf Alkohol, Bier, Tabak und Zucker. Die Pfänder wurden durch je einen Kommissar für die Reichsbahn und die verpfändeten Staatseinnahmen überwacht, außerdem durch den Generalagenten. Der Generalagent hatte auch dafür zu sorgen, daß der Wechselkurs der neuen deutschen Währung durch die Transferierung großer Geldwerte ins Ausland nicht $\mathrm{zu}$ stark belastet wurde und konnte unter Umständen Überweisungen in das Ausland verzögern. Durch die Anrechnung von Sachlieferungen und die Einführung des Recovery $\mathrm{Act}^{286}$ sollte darüber hinaus der Transfer von Devisen verringert werden. Um neben dem Transferschutz die Stabilität der neuen deutschen Währung zu gewährleisten, wurde die Golddeckung wieder eingeführt ${ }^{287}$. Der Reichsbank wurde verboten, dem Reich Kredite zu gewähren, und sie wurde einer internationalen Kontrolle unterworfen. Um der deutschen Wirtschaft nach dem Ruhrkampf und der völligen Entwertung der Mark unter die Arme zu greifen, erhielt das Deutsche Reich darüber hinaus einen Kredit von 800 Mio. GM.

Eine wesentliche Frage ist, warum die Experten mit ihrem Gutachten den Erfolg hatten, der den verschiedenen Reparationskonferenzen zuvor versagt geblieben war, obwohl vieles, was die Experten zu Papier gebracht hatten -

${ }^{285}$ Nach deutscher Auffassung bedeutete das: Aufhebung der Binnenzollinie und der Derogationsämter, die den Austausch zwischen besetztem und unbesetztem Gebiet regelten, Wiederherstellung der deutschen Zollhoheit auch an der Westgrenze, Abschaffung des Lizenzsystems für die deutsche Ausfuhr an der Westgrenze, Aufhebung der Eisenbahnregie, freier Personenverkehr zwischen besetztem und unbesetztem Gebiet, Freiheit der Schiffahrt und des Kfz-Verkehrs, Zulassung von Rundfunk und Luftverkehr, Reduzierung der Besatzungstruppen, Rückgabe aller enteigneten Pfänder, Ende der Beschlagnahmungen, Ende der Unterstützung der Separatisten, Ende der Eingriffe in das Steuerwesen, Aufhebung der M.I.C.U.M.-Verträge und Wiederherstellung der deutschen Verwaltungshoheit. Außerdem mußte gewährleistet sein, daß im besetzten Gebiet Gesetze gleichzeitig wie im Rest Deutschlands in Kraft treten konnten, siehe Miller an AA (6.5.1924), ADAP A X, Nr. 69.

${ }^{286}$ Der Recovery Act war eine 26prozentige Abgabe, die auf den deutschen Export in die Reparationsgläubigerländer erhoben wurde. Die so abgeführten Devisen wurden den deutschen Exporteuren in Markbeständen erstattet.

${ }^{287}$ Die Deckungsquote betrug $40 \%$, von denen $3 / 4$ durch Gold aufgebracht werden mußten. 
wie beispielsweise die Idee einer internationalen Anleihe zur Stabilisierung der deutschen Währung -, bereits zuvor erörtert worden war.

Was das Dawes-Komitee von seinen Vorgängern, seien es nun Expertenoder Regierungsgremien, unterschied, war, daß sein Auftrag einerseits nicht zu eng gefaßt - die Verhandlungen der Bankiers über die Anleihe zur Währungssanierung in Deutschland waren bekanntlich an der Pfandfrage gescheitert, die jedoch nicht Inhalt der Bankiersverhandlungen gewesen war -, andererseits aber auch nicht zu weit gefaßt war, weil andere Problembereiche, wie die der Sicherheit Frankreichs, ausgeklammert blieben. Die Reduzierung der Agenda auf den rein wirtschaftlichen Aspekt machte es möglich, daß ein gemeinsamer Standpunkt leichter gefunden werden konnte. Alle Staaten, einschließlich der USA, hatten letztlich ein Interesse daran, die Reparationsfrage zu lösen, während in der Beurteilung der Sicherheitslage doch erhebliche Differenzen bestanden. Die vorangegangenen Versuche zur Lösung des Reparationsproblems waren dagegen vor allem an der unseligen Verkopplung von Reparations- und Sicherheitsfrage gescheitert, wie besonders der Mißerfolg der Weltwirtschaftskonferenz von Genua gezeigt hatte. Stresemanns Einschätzung, die Einsetzung des Dawes-Komitees sei ein Sieg der französischen Regierung gewesen, durch den es Paris gelungen sei, „den englischen Versuch der Einberufung einer Weltkonferenz zum Zwecke der Gesamtlösung der Reparationsfrage und der Rhein- und Ruhrfrage wenigstens vorläufig zu para-

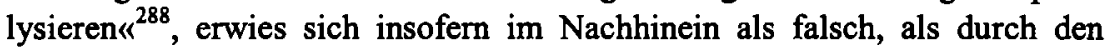
Versuch, eine "Gesamtlösung" anzustreben, sich das ganze Spiel der Vorruhrkampfzeit mit seinen erfolglosen Regierungskonferenzen vermutlich wiederholt hätte.

Die Nichtbeteiligung Deutschlands an den Expertengesprächen erwies sich als weiterer außerordentlicher Glücksfall. In der Konstellation, in der verhandelt wurde, bestanden ausreichend Gemeinsamkeiten zwischen den Experten, um zu einem konstruktiven Ergebnis zu gelangen. Trotzdem waren aber auch die deutschen Interessen indirekt vertreten, weil diese sich vielfach mit denen der USA und Großbritanniens deckten, und es gab informelle Kontakte zwischen deutschen Wirtschaftsvertretern und den britischen und amerikanischen Sachverständigen ${ }^{289}$. Im Grunde genommen waren die angelsächsischen Mächte bessere Anwälte der deutschen Sache als es die Deutschen selbst je hätten sein können. Wie schwierig die Regelung des Problems der Reparationen unter deutscher Einbeziehung hätte sein können, läßt sich an den Verhandlungen zum Young-Plan erahnen, die vor allem an der Haltung Schachts fast gescheitert wären.

Die Beteiligung der Vereinigten Staaten an der Expertenkommission war ein weiterer zusätzlicher Faktor, der letztlich zum Erfolg des Dawes-Gutachtens

\footnotetext{
${ }^{288}$ Stresemann an Sthamer (21.1.1924), ADAP A IX, Nr. 106.

${ }^{289}$ Siehe BAECHLER, Stresemann, S. 501f.
} 
führte, denn nur sie verfügten über die finanzielle Manövriermasse und saßen an der entscheidenden Stelle im Gesamtkomplex aus Reparationen und interalliierten Kriegsschulden, um den Plan zum Erfolg zu führen.

Auch die Auswahl der Experten sollte sich als außerordentlich günstig erweisen. Betrachtet man deren Biographien, so fällt auf, daß sie vielfach eben keine unabhängigen Wirtschaftsfachleute waren, sondern oftmals einer »Grauzone « zwischen Wirtschaft und Politik entstammten und mit beiden Sphären vertraut waren. Der Vorsitzende und Namensgeber der Expertenkommission, Charles Gates Dawes, war nicht nur Bankier, sondern auch Jurist und »one of the nation's most able statesmen ${ }^{290}$. Er organisierte teilweise den Präsidentschaftswahlkampf McKinleys, in dessen Administration er tätig war, und war als General im Ersten Weltkrieg für die gesamte Materialversorgung der Alliierten zuständig gewesen. Er war später außerdem Vizepräsident unter Coolidge und Botschafter seines Landes in Großbritannien. Auch Owen D. Young als weiterer amerikanischer Fachmann und einflußreiches Mitglied der Expertenkommission war keinesfalls nur in der Welt der Wirtschaft zu Hause: Neben seiner Tätigkeit als Chairman of the Board für General Electric war er unter anderem Direktor der Federal Reserve Bank of New York, Mitglied diverser Delegationen auf vielen internationalen Wirtschaftskonferenzen und Experte in verschiedenen Gremien, die den US-Präsidenten in Wirtschaftsund Sozialfragen berieten ${ }^{291}$. Die französischen Experten waren ebenfalls keineswegs reine Wirtschaftsfachleute: Der französische Hauptdelegierte, Jean Parmentier, war als Directeur du mouvement général des fonds einer der höchsten Beamten im französischen Finanzministerium ${ }^{292}$. Ähnliches galt für den zweiten französischen Delegierten, Edgar Allix. Als Professor für Finanzwissenschaft an der Sorbonne galt er mals Größe auf dem Gebiet des Verwaltungsrechts und der Nationalökonomie $\ll^{293}$ und sammelte politische Erfahrungen als chef du cabinet von Paul Doumer, dem Finanzminister im vierten Kabinett Briand $^{294}$. Für die Experten aus den übrigen Ländern läßt sich Analoges sagen: Émile Francqui, einer der belgischen Delegierten, machte in der Société générale Karriere, war aber auch Minister unter Jaspar und einer der Hauptverantwortlichen für die Währungssanierung in Belgien im Jahre $1926^{295}$. Sein

${ }^{290}$ Steven G. O'BRIEN, American Political Leaders. From Colonial Times to Present, Santa Barbara, Denver, Oxford 1991, S. 102.

${ }^{291}$ Siehe O.V., Who was Who in America, Bd. 4, Chicago 1968, S. 1043. Zur Rolle Youngs bei den Dawes-Plan-Verhandlungen siehe CostigliolA, Awkward Dominion, S. 116-118.

${ }^{292}$ Siehe Robert BURNAUD, Qui êtes-vous? Annuaire des contemporains, notices biographiques, Paris 1924, S. 587.

${ }^{293}$ Siehe Aufzeichnung ohne Datum und Unterschrift, BArch R 3101, 20436.

${ }^{294}$ Das vierte Kabinett Briand war vom 16.1.1921 bis 15.1.1922 im Amt.

${ }^{295}$ Siehe Fernand BAUDHUIN, art. "Francqui «, in: Biographie Nationale, hg. v. Académie royale des sciences, des lettres et des beaux-arts de Belgique, Bd. 31, Brüssel 1962, Sp. 362-370. 
Mitdelegierter Albert Janssen war Präsident der belgischen Nationalbank ${ }^{296}$. Der britische Vertreter Robert Kindersley war neben seinen Aufgaben bei der Bank Lazard Brothers auch Präsident des War Savings Committee und des National Savings Committee ${ }^{297}$. Sein Kollege im Dawes-Komitee, Josiah Stamp, begann seine Karriere in der britischen Finanzverwaltung und wechselte später in die Privatwirtschaft ${ }^{298}$. Die Liste ließe sich fortsetzen, auch wenn bei einigen Delegierten das privatwirtschaftliche Element stärker ausgeprägt zu sein schien, so z.B. bei dem dritten französischen Delegierten, André Laurent-Atthalin, Generaldirektor der Banque de Paris et des Pays-Bas, deren Präsident er später werden sollte ${ }^{299}$, oder bei den italienischen Delegierten Alberto Pirelli und Mario Alberti ${ }^{300}$, die in der Industrie bzw. dem Bankwesen tätig waren. Der Erfolg der Experten dürfte also einerseits darin begründet liegen, $\mathrm{da} ß$ sie ausgewiesene Wirtschaftsexperten waren und somit den nötigen Sachverstand für ihre Aufgabe mitbrachten und trotzdem weitgehend unabhängig vom politischen Prozeß waren. Andererseits waren sie aber auch soweit in das politische System ihrer Länder integriert, daß sie dort den notwendigen Einfluß hatten, um dem Expertengutachten das notwendige Gewicht zu verleihen. Ein weiterer, schwer zu bestimmender, nichtsdestotrotz aber nicht zu unterschätzender Faktor dürfte gewesen sein, daß sich gewisse Gemeinsamkeiten in den Biographien ergaben, die dem Erfolg der Arbeit dienlich gewesen sein dürften: Es handelte sich eben in der Tat um Männer, die in der Politik ebenso beheimatet waren wie in der Wirtschaft, mit zum Teil sehr ähnlichen Karrieren, so daß folglich Wert- und Zielvorstellungen und die Art des Denkens einen hohen Grad an Übereinstimmung gezeigt haben dürften.

Das letztlich entscheidende Kriterium dafür, daß für das Reparationsproblem - nach den Imungen und Wirrungen der Jahre unmittelbar nach dem Krieg vielleicht uberraschend - eine für alle erträgliche Lösung gefunden wurde, war die Bereitschaft aller Beteiligten aus Regierungen oder der Wirtschaft, überhaupt zu einer Lösung kommen za wollen. Diese Bereitschaft war vor dem Ruhrkampf nicht vorhanden gewesen, sei es, weil die Reparationen als solche abgelehnt wurden oder die Reparationsfrage lediglich als Mittel zur Lösung anderer Probleme gesehen wurde. Der Ruhrkampf hatte jedoch bei

\footnotetext{
${ }^{296}$ Siehe Aufzeichnung ohne Datum und Unterschrift, BPPB 1 Cabet 1, 187.

${ }^{297}$ Siehe Robert H. BRAND, art. "Kindersley, Robert Molesworth«, in: L. G. WICKHAM LEGG, E. T. Williams (Hg.), The Dictionary of National Biography, 1941-1950, Oxford u.a. 1959, S. 585.

${ }^{298}$ Siehe William H. BEVERIDGE, art. "Stamp, Josiah Charles«, in: ibid. S. 817-820.

${ }^{299}$ Siehe BuRNAUD, Qui êtes-vous 1924, S. 21; Eric Bussiére, Paribas 1872-1992, l'Europe et le monde, Antwerpen 1992, S. 310.

${ }^{300}$ Alberti war stellvertretender Generaldirektor bei Credito Italiano, siehe Aufzeichnung ohne Datum und Unterschrift, BPPB 1 Cabet 1, 187, Pirelli Direktor eines Industriekonzerns, in dem nicht nur die besagten Pirelli-Reifen produziert wurden, Aufzeichnung ohne Unterschrift und Datum, BArch R 3101, 20436.
} 
jedermann die Erkenntnis zutage gefördert, daß eine schnelle, erträgliche Lösung für das Reparationsproblem gefunden werden mußte, um aus der Sackgasse, in der sich die Politik seit dem Ende des Ersten Weltkriegs befunden hatte, herauszukommen, oder, wie Seydoux gegenüber Hoesch erklärt hatte: "Sachverständigengutachten gefalle ihm zwar in vielen Punkten nicht. Er halte es aber für einzig möglichen Ausweg. [...] Gutachten vorkomme ihm wie vorbeifahrendes Schiff, in das alle einsteigen müßten, wenn nicht jede Hoffnung auf Weiterkommen verloren sein solle ${ }^{301}$.

Der Ruhrkampf hatte außerdem zu einer inhaltlichen Annäherung zwischen den Konfliktparteien geführt. Vergleicht man die Positionen der deutschen ${ }^{302}$ und französischen ${ }^{303}$ Regierung Anfang des Jahres 1924 mit den Ergebnissen des Dawes-Plans, so ergibt sich eine erstaunliche Nähe der Vorstellungen. Gegensätze bestanden zwischen Deutschland und Frankreich allerdings noch in der Währungs- und Eisenbahnfrage. Frankreich forderte die Schaffung nicht einer, sondern mehrerer Länder-Notenbanken und die Errichtung mehrerer Landeseisenbahngesellschaften, die nur locker koordiniert werden sollten, während Deutschland auf eine zentrale Lenkung sowohl des Geld- wie des Eisenbahnwesens bestand. Frankreich wich jedoch nach und nach von seinen Forderungen in diesen beiden Bereichen zurück ${ }^{304}$. Aus deutschlandpolitischer Sicht ist an diesen Überlegungen bemerkenswert, daß zumindest Teile der französischen Führung Anfang des Jahres zwar eine weitreichende Föderalisierung des Reiches anstrebten, aber von den Plänen zur Zerstückelung des Reiches Abschied genommen hatten. Auch bezüglich der Beteiligung französischer Unternehmen an der deutschen Industrie herrschte weiterhin Dissens. Während die Reichsregierung dies noch immer ablehnte ${ }^{305}$, hielt Frankreich daran fest. Allerdings sah man in Paris diese Frage weniger als ein Reparationsproblem, sondern vielmehr als einen Teil der notwendigen Neuordnung der deutsch-französischen Wirtschaftsbeziehungen, die durch langfristige Verträge zwischen der deutschen und französischen Montan- und chemischen Industrie und durch einen Handelsvertrag abgesichert werden sollten ${ }^{306}$.

Nach dem bereits Gesagten ist es wenig verwunderlich, daß die Reichsregierung am 16. April 1924 trotz der hohen finanziellen Belastungen und des erheblichen innenpolitischen Widerstandes von rechts dem Dawes-Plan ihre $\mathrm{Zu}$ stimmung $\mathrm{gab}^{307}$. Für die Annahme sprachen vor allem folgende Gründe ${ }^{308}$ :

\footnotetext{
${ }^{301}$ Hoesch an AA (6.5.1924), ADAP A X, Nr. 68.

${ }^{302}$ Siehe "Richtlinien für die Verhandlungen mit dem Sachverständigen-Komitee [25.1.

1924] « (ohne Unterschrift), AdR Marx I/II Bd. 1, Nr. 72.

${ }^{303}$ Siehe Aufzeichnung Seydoux (4.1.1924), MAE PAAP 261, 30.

${ }^{304}$ Siehe BARIÉTY, Relations franco-allemandes, S. 308.

${ }^{305}$ Siehe KRÜGER, Außenpolitik, S. 237.

${ }^{306}$ Siehe Aufzeichnung Seydoux (4.1.1924), MAE PAAP 261, 30.

${ }^{307}$ Siehe DUROSELLE, Histoire, S. 68.

${ }^{308}$ Siehe KRÜGER, Außenpolitik, S. 238; Hoesch an AA (25.4.1924), ADAP A X, Nr. 42.
} 
Der Expertenplan machte die Reparationszahlungen kalkulierbar und ermöglichte dadurch den wirtschaftlichen Wiederaufbau Deutschlands. Durch die Eröffnung einer wirtschaftlichen Perspektive für Deutschland und den Transferschutz würde zukünftig eine Überlastung der deutschen Wirtschaft vermieden und damit endlich die Stabilität geschaffen, die die Voraussetzung für die dringend benötigten Kredite aus den USA bildete. Es ist deshalb wenig erstaunlich, daß vor allem die Wirtschaft nachdrücklich auf die Annahme des Expertenplans drängte ${ }^{309}$.

Doch nicht nur wirtschaftlich, auch politisch hatte der Plan Vorteile für Deutschland. Die Experten forderten nämlich ausdrücklich die Wiederherstellung der wirtschaftlichen und fiskalischen Einheit Deutschlands, was langfristig auch die Grundlage für die militärische Besetzung des Ruhrgebiets unterminieren mußte. $\mathrm{Da}$ die Sachverständigen außerdem vorgeschlagen hatten, daß die Kosten für die Besetzung des Ruhrgebiets aus dem französisch-belgischen Reparationsanteil bezahlt werden sollte, ergab sich hier ein weiteres Druckmittel, Paris zur militärischen Räumung des Ruhrgebiets zu bewegen.

Frankreich tat sich etwas schwerer mit der Zustimmung, erklärte als letzter der beteiligten Staaten am 25. April 1924 seine grundsätzliche Zustimmung zum Dawes-Gutachten ${ }^{310}$ und machte die endgültige Inkraftsetzung des Expertenplans von diversen Bedingungen abhängig ${ }^{311}$. Sie sollte erst erfolgen, wenn Deutschland alle notwendigen Vorbedingungen erfullt haben würde, also beispielsweise die Gesetze verabschiedet sein würden, die notwendig waren, um die Reichsbahn und die Reichsbank im Sinne der Dawes-Plans umzugestalten. Auch forderte Poincaré die Aufrechterhaltung der militärischen Ruhrbesetzung bis zu dem Zeitpunkt, an dem Deutschland seine Reparationsschulden vollständig bezahlt haben würde. Für den Fall, daß Berlin seinen Verpflichtungen nicht nachkäme, sollten wieder wirtschaftliche Zwangsmaßnahmen in Kraft treten, und diesmal sollte sich Großbritannien daran beteiligen. Zwar wollte Frankreich auf die wirtschaftlichen Pfänder und Druckmittel, die es seit der Ruhrbesetzung hatte, verzichten, jedoch sollte französisches und belgisches Personal die Ausführung der Bestimmungen des Dawes-Plans kontrollieren. Abgerundet wurde das Programm Poincarés durch Forderungen, die die Kohlenversorgung Frankreichs und die Kontrolle der Eisenbahnen im Rheinland, oder zumindest einiger wichtiger Linien, sicher stellen sollten.

Es ist viel darüber spekuliert worden, ob Poincaré unter dem Druck der immensen Besatzungskosten, der Franc-Krise, der wachsenden Kritik der Öffent-

309 Zur Zustimmung der Wirtschaft siehe Aufzeichnung ohne Unterschrift (10.4.1924), PAAA R, 28939, Resolution des Wirtschaftsausschusses fir die besetzten Gebiete (1.5.1924), BArch R 3101, 14913, Resolution der Industrie- und Handelskammer Berlin (2.5.1924) BArch R 3101, 14913.

${ }_{310}$ Siehe Poincaré an Barthou (25.4.1924), BArch R 3101, 14913.

${ }^{311}$ Siehe JEANNESSON, Poincaré, S. 398. 
lichkeit oder des französischen Delegierten in der RepKo, Barthou, dem Sachverständigengutachten seine Zustimmung hat geben müssen ${ }^{312}$. Übereinstimmend mit Bariéty ${ }^{313}$ bin ich nicht der Ansicht, daß Poincaré nachgegeben hat. Wie bereits oben zu sehen war, lag die französische Linie in der Reparationspolitik nicht allzu weit von dem entfernt, was die Experten letztendlich vorgeschlagen hatten. Dies deckt sich auch mit den Beobachtungen zu den Absichten, die Poincaré vor und während des Ruhrkampfs verfolgt hat. Klar ist allerdings auch, daß er versuchte, den Atout, den er mit der Ruhr gegenüber Deutschland und den westlichen Mächten in der Hand hielt, möglichst lange zu behalten und für seine Politik, die ja nicht nur die Reparationen, sondern auch die Sicherheit Frankreichs betraf, zu nutzen ${ }^{314}$. Für Poincaré kam es nun darauf an, seine Bedingungen, die er mit der Inkraftsetzung des Dawes-Plans verknupfte, durchzusetzen. Hauptadressat dafür war aber nicht Berlin, sondern vor allem London.

Nachdem sich alle beteiligten Regierungen zur prinzipiellen Annahme des Dawes-Gutachtens bereit erklärt hatten, traten in Deutschland wie in Frankreich die außenpolitischen Fragen wegen der stattfindenden Wahlen zunächst ein wenig in den Hintergrund.

Die Reichstagswahlen vom 4. Mai 1924 führten zu einer Schwächung der bürgerlichen Regierungsparteien und der Sozialdemokraten, also der Parteien der sogenannten Weimarer Koalition und der DVP, während die Rechte - die DNVP und die erstmals im Reichstag vertretene Nationalsozialistische Freiheitsbewegung - deutliche Zugewinne erzielen konnten ${ }^{315}$. Angesichts der prekären Mehrheitsverhältnisse wuchs also der Einfluß der DNVP, die hinter der SPD knapp zweitstärkste Partei geworden war ${ }^{316}$. Marx bildete erneut ein Minderheitskabinett, da weder eine große Koalition (unter Einschluß der SPD) noch eine bürgerliche Rechtskoalition (mit Beteiligung der DNVP) zustande kam. Allerdings scheiterten die Koalitionsverhandlungen mit der DNVP nicht, wie man annehmen könnte ${ }^{317}$, an außenpolitischen Differenzen, sondern an der Forderung der Deutschnationalen, daß die bürgerlichen Parteien die große Koalition in Preußen verlassen sollten ${ }^{318}$. Die DNVP, so war sich Stresemann

\footnotetext{
${ }^{312}$ Siehe GiRAULT, Europe, S. 137; WeILL-RAYNAL, Réparations, Bd. 2, S. 598-603.

${ }^{313}$ Siehe BARIÉTY, Relations franco-allemandes, S. 313.

${ }^{314}$ Siehe Hoesch an AA (18.4.1924), ADAP A X, Nr. 18.

${ }^{315} \mathrm{Zu}$ Einzelheiten siehe Statistisches Jahrbuch für das Deutsche Reich 1924/25, hg. v. Statistisches Reichsamt, Berlin 1926, S. 389; BAECHLER, Stresemann, S. 514.

${ }_{316} \mathrm{Zu}$ Anfang der Legislaturperiode hatte die SPD 100, die DNVP 95 Sitze, aufgrund von Fraktionsaus- und Öbertritten erhöhte sich die Zahl der DNVP-Abgeordneten bis zum Ende der Legislaturperiode auf 106, die der SPD-Abgeordneten blieb bei 100, siehe Statistisches Jahrbuch 1924/25, S. 389.

${ }^{317}$ Siehe z.B. BARIÉTY, Relations franco-allemandes, S. 319.

${ }^{318}$ Siehe Runderlaß Maltzan (4.6.1924), ADAP A X, Nr. 123.
} 
sicher, werde seine Außenpolitik und den Dawes-Plan dennoch stützen müssen:

Die finanziellen und wirtschaftlichen Bestimmungen des Sachverständigengutachtens würden nach meiner Auffassung im Reichstage eine Mehrheit finden, da die Deutschnationalen es kaum wagen könnten, den Bericht abzulehnen, ohne die weitesten Kreise der Industrie und der Landwirtschaft, von denen sie doch wesentlich unterstützt würden, vor den Kopf zu stoßen ${ }^{319}$.

Trotz der Schwächung der bestehenden Regierung drohte also für die Außenpolitik von rechts, zumindest für den Augenblick, wenig Gefahr, so daß die unmittelbaren Auswirkungen der Reichstagswahlen für die deutsche Außenpolitik relativ gering waren.

Die Wahlen zur französischen Kammer führten zur Abwahl des Nationalen Blocks und der Regierung Poincaré und zum Sieg des Linkskartells unter Führung von Édouard Herriot. Der Wahlsieg des Linkskartells hatte jedoch einige Schönheitsfehler. Es gewann zwar - aufgrund des Wahlrechts, das Wahlbündnisse bevorzugte ${ }^{320}$ - die Mehrheit der Sitze im Parlament, nicht jedoch die Mehrheit der Stimmen ${ }^{321}$. Für die parlamentarische Arbeit mochte das unmittelbar kaum von Bedeutung sein, es machte aber deutlich, daß der Rückhalt des Kartells in der Öffentlichkeit weniger groß war als die Sitzverteilung vermuten ließ: »The election result was more a protest vote about taxes and the financial situation than an expression of confidence in the cartel $\aleph^{322}$. Zudem hatten die Linksparteien zwar die Mehrheit in der Kammer, nicht jedoch im Senat. Nachdem die Linke zwar erfolgreich Millerand aus dem Präsidentenamt hatte vertreiben können, gelang es ihr nicht, ihren Wunschkandidaten, Paul Painlevé, durch den Senat zu bringen, so daß als Kompromißkandidat Gaston Doumergue zum französischen Staatsoberhaupt gewählt wurde ${ }^{323}$. Als eigentliche Achillesferse für die neue Regierung sollte sich jedoch erweisen, daß das Wahlbündnis zwischen den Sozialisten, der Section française de l'internationale ouvrière (S.F.I.O.), und Herriots Radicaux nicht in eine Regierungskoalition umgewandelt werden konnte: Die S.F.I.O. erklärte zwar, sie wolle Herriot tolerieren, verweigerte aber die Mitarbeit in der Regierung ${ }^{324}$. Dies zeigt, $\mathrm{da} ß$ das Linkskartell weniger homogen war, als es sein Name vermuten ließ: Zwischen dem rechten Rand des Kartells, den die républicains socialistes bil-

\footnotetext{
${ }^{319}$ Aufzeichnung Stresemann (4.6.1924), ADAP A X, Nr. 122.

${ }^{320}$ Nach dem Wahlgesetz von 1919 gewann die Partei bzw. das Wahlbündnis alle Sitze eines Departments, welches die absolute Mehrheit in einem Departement erhielt. Konnte kein Bündnis die absolute Mehrheit erzielen, wurden die Sitze proportional zum Wahlergebnis vergeben, siehe RÉMOND, République souveraine, S. $72 \mathrm{f}$.

${ }^{321}$ Siehe KEIGER, Poincaré, S. 309.

${ }^{322}$ Ibid.

${ }^{323}$ Siehe RÉMOND, Frankreich, S. 103.

${ }^{324}$ Siehe Jean Denis BREDIN, Joseph Caillaux, Paris 1980, S. 315.
} 
deten, und dem äußersten linken Rand der Sozialisten lagen - ideologisch gesehen - Welten, vor allem in der Sozial- und Wirtschaftspolitik ${ }^{325}$. Selbst innerhalb der wichtigsten Gruppierung des Kartells, den Radicaux, war die Spannbreite der politischen Ansichten enorm. In der Außenpolitik beispielsweise stand der verständigungsbereiten Haltung Caillaux ${ }^{326}$, der den Ausgleich mit Deutschland suchte, der Chauvinismus Franklin-Bouillons gegenüber ${ }^{327}$.

Bleiben wir zunächst bei der Frage nach der außenpolitischen Position des Linkskartells. Während des Wahlkampfs hatten sich die Radikalen und die Sozialisten lediglich zu Allgemeinplätzen wie Frieden, Entspannung, Gerechtigkeit und Kooperation bekannt, ein gemeinsames außenpolitisches Programm war aber nicht zustande gekommen ${ }^{328}$. Das Bekenntnis zu den gemeinsamen Idealen verdeckte nur mühsam den tiefen Widerspruch zwischen den Positionen der beiden Parteien. Während die S.F.I.O. den Versailler Vertrag und die Ruhrpolitik Poincarés grundsätzlich ablehnte, fand beides in den Reihen der Radikalen Zustimmung ${ }^{329}$. Der Dissens zwischen den beiden Parteien in außenpolitischen Fragen wird an einer kleinen Episode deutlich, die sich Ende Juni 1924 in der Kammer abspielte. Anläßlich einer Debatte zur Verlängerung der Kredite zur Finanzierung der Besatzungstruppen im Ruhrgebiet geriet Herriot in eine $"$ peinliche Lage ${ }^{330}$, weil die S.F.I.O. ihm nicht folgte. Letztlich konnte er nur mit Hilfe der Opposition eine Verlängerung der Kredite erreichen. Herriots Lage war also selbst für die Verhältnisse der Dritten Republik recht schwierig.

Was waren nun aber die außenpolitischen Ziele der neuen französischen Regierung? In einem Schreiben an Léon Blum erläuterte Herriot die Ziele seiner Außenpolitik ${ }^{331}$ : Langfristig sei der Frieden nur durch die Kooperation der Völker zu erreichen. Gewährleistet werden könne dies durch den Ausbau und die Verstärkung der internationalen Institutionen, wie den Völkerbund, den Internationalen Gerichtshof in Den Haag oder das Internationale Arbeitsamt. Er bekannte sich weiterhin zur Aufnahme von Beziehungen zur Sowjetunion und zur Annahme des Expertengutachtens "sans aucune arrière pensée « ${ }^{332}$. Bezüglich Deutschlands stellte er jedoch fest, daß als Schutz vor dem "pan-

\footnotetext{
${ }^{325}$ Siehe WURM, Sicherheitspolitik, S. 134-136.

${ }^{326}$ Caillaux war sogar unter Clemenceau am 15.10.1918 wegen angeblicher Kollaboration mit den Deutschen während des Kriegs angeklagt und am 23.4.1920 wegen Hochverrats zu drei Jahren Haft verurteilt worden. Erst Anfang 1925 wurde Caillaux rehabilitiert, siehe BREDIN, Caillaux, S. 270, 304f., 315-319.

${ }^{327}$ Siehe BARIÉTY, Relations franco-allemandes, S. 330.

${ }^{328}$ Siehe ibid. S. 324.

${ }^{329}$ Siehe Michel SOULIÉ, La vie politique d'Édouard Herriot, Paris 1962, S. 126-128.

${ }^{330}$ Hoesch an AA (29.6.1924), PAAA R, 28235.

${ }^{331}$ Der Brief ist teilweise zitiert in: Köpke an RWiM (7.6.1924), BArch R 3101, 14913.

332 Ibid.
} 
germanisme nationaliste ${ }^{333}$ die Ruhr erst dann evakuiert werden könne, wenn entsprechende Pfänder und die Institutionen zu deren Umsetzung geschaffen worden seien. Die Sicherheitsfrage könne nur durch Sicherheitsabkommen im Rahmen des Völkerbunds gelöst werden.

Es wird also deutlich, daß Herriot die außenpolitischen Alleingänge Poincarés zwar ablehnte und eine internationale Lösung anstrebte, die Berechtigung des französischen Sicherheitsinteresses sah er aber für voll und ganz gegeben. Diese Überlegung stand in engem Zusammenhang mit seinem Deutschlandbild, in dem sich das in Frankreich weit verbreitete Bild der »deux Allemagnes « widerspiegelte: das eine, geprägt durch den "nationalistischen Pangermanismus « der Militärs, der Junker und der Schwerindustrie und das "gute« Deutschland der Republikaner und Demokraten ${ }^{334}$. Erst wenn das nationalistische Deutschland endgültig der Vergangenheit angehören würde, sei Frankreich sicher, und so. lange seien die französischen Sicherheitsmaßnahmen gegenüber Deutschland durchaus gerechtfertigt.

In seiner Regierungserklärung vor der Kammer am 17. Juni 1924 wiederholte Herriot nochmals seine Position ${ }^{335}$ : Internationale Zusammenarbeit, Ausbau des Völkerbunds, Garantien und Überwachung Deutschlands. Gegenüber Margerie machte er deutlich: "Je constate avec satisfaction l'impression causé à Berlin par la constitution du nouveau Gouvernement [...] Mais on ne doit en effet pas se méprendre sur notre résolution de maintenir les droits de la France $\varkappa^{336}$.

Verglichen mit der Politik Poincarés, besonders, wenn man von der Interpretation ausgeht, daß er mit der Ruhraktion vor allem bezweckte, sowohl Deutschland als auch die ehemals Verbündeten wieder in das Versailler System zurück zu zwingen, ist der Unterschied zu Herriots Politik relativ gering. Ein größerer Unterschied scheint mir jedoch zu sein, daß der Völkerbund in Herriots Konzept einen größeren Raum einnahm als bei Poincaré und Deutschland dabei gleichberechtigt mit einbezogen werden sollte. Hoesch gegenüber machte der neue französische Ratspräsident deutlich, "ganze Tendenz seiner Politik in Reparations- und sécurité-Frage hinausgehe auf schließliche Einschaltung Völkerbunds. Bis dahin schienen ihm die französischen Interessen nicht recht gesichert ${ }^{337}$.

Außerdem forderte er die Aufnahme Deutschlands in den Völkerbund, da der "Völkerbund erst nach Aufnahme Deutschlands wahren Bund darstelle ${ }^{338}$. In Deutschland wurde, wie wir gesehen haben, die Wahl Herriots über-

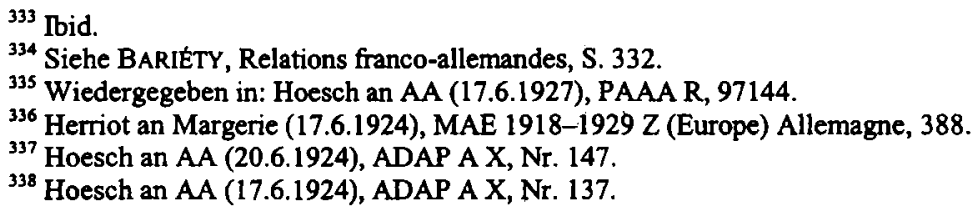


wiegend positiv, ja vielleicht zu positiv aufgenommen, wenngleich Hoesch vor zuviel Optimismus warnte ${ }^{339}$. Der Wahlsieg der Linken ließe die Wiederherstellung der wirtschaftlichen und fiskalischen Einheit Deutschlands wahrscheinlicher werden und die Chancen für die Räumung des Ruhrgebiets und des Rheinlands steigen. Auch ergäben sich »Möglichkeiten, Sicherheitsfrage unter Heranziehung Völkerbunds vielleicht in für uns tragbarer Weise zu lösen $\aleph^{340}$, wobei deutscherseits durchaus erkannt wurde, daß dies ein für Frankreich wesentliches Problem war ${ }^{341}$.

Wie Poincaré auch mußte Herriot, um seine Politik durchzusetzen, den Schulterschluß mit England suchen. In Whitehall, nicht in der Wilhelmstraße, lag der Schlüssel zur Erfüllung der französischen Forderungen nach Sicherheit, nach Reparationen und nach einer Regelung der interalliierten Schuldenfrage $^{342}$. Die Bedeutung Londons für die französische Politik wurde dadurch deutlich, daß Herriot gleich nach seinem Regierungsantritt den Kontakt mit der englischen Regierung suchte. Das Ergebnis dieser Bemühungen waren die französisch-britischen Gespräche, die am 21. und 22. Juni 1924 auf dem Landsitz des britischen Premierministers in Chequers stattfanden. Chequers, das ist in der Geschichtsschreibung zum Synonym für den Sündenfall des Linkskartells in der Außenpolitik geworden. Herriot erscheint dabei als außenpolitischer Amateur ohne genaue Kenntnis der Akten und von schwacher Durchsetzungskraft, der sich von einem gewieften MacDonald in allen wesentlichen Punkten hat über den Tisch ziehen lassen ${ }^{343}$.

War Herriots Außenpolitik tatsächlich so unrealistisch und dumm? $\mathrm{Zu}-$ nächst: Herriot war kein Greenhorn. Seit 1905 Bürgermeister von Lyon, der drittgrößten Stadt Frankreichs, war er Senator, Deputierter und Minister, bevor er 1924 Ratspräsident wurde ${ }^{344}$. In einer geschickten Wahlkampagne ${ }^{345}$ hatte er es nicht nur geschafft, die widerwilligen Sozialisten hinter sich zu vereinen, sondern auch Poincaré - den man schwerlich als politisches Leichtgewicht bezeichnen kann - zu besiegen. Unterschätzt wird vor allem seine schwierige parlamentarische Situation. Er mußte stets taktieren, um die eigene Partei aber auch die Sozialisten und andere Gruppen, deren Unterstützung er für seine Politik benötigte - hinter sich zu vereinigen. Selbst in seiner Regierung war der Kurs der Deutschlandpolitik nicht unumstritten, standen doch die Positio-

\footnotetext{
${ }^{339}$ Zum folgenden siehe Hoesch an AA (14.5.1924), ADAP A X, Nr. 81.

${ }^{340}$ Ibid.

${ }^{341}$ Siehe Hoesch an AA (17.6.1924), ADAP A X, Nr. 137.

${ }^{342}$ Siehe ARTAUD, Dettes interalliées, S. 638.

${ }^{343}$ Siehe BARIETY, Relations franco-allemandes, S. 379; ARTAUD, Dettes interalliées, S. 646; MONIER, Années 20, S. 123; ADAMTHWAITE, Grandeur, S. 104.

${ }^{344}$ Siehe L. TRENARD, art. "Herriot, Marie-Édouard«, in: biographie française, Bd. 17, Sp. 1125-1127.

${ }^{345}$ Vgl. Serge BERSTEN, Édouard Herriot ou la République en personne, Paris 1985, S. 96-102.
} 
nen von Kriegsminister Nollet, der unbedingt die militärische Besetzung der Ruhr aufrechterhalten wollte, und die von Herriots Kabinettschef Bergery, der die Abkehr von der militärischen Besetzung forderte, einander unversöhnlich gegenüber $^{346}$.

Auch hatte Herriot durchaus ein außenpolitisches Konzept, wie selbst Bariéty einräumt: »le plan est structuré, logique, et il pose tous les problèmes qui se posent à la politique étrangère de la France d'alors ${ }^{347}$. Dieser Plan sah im einzelnen vor ${ }^{348}$ : die Gewährung gewisser Garantien für die Ausführung des Dawes-Plans, namentlich die Kontrolle der deutschen Eisenbahnen, die militärische Räumung nur in dem $\mathrm{Maße}$, in dem die deutsche Reparationsschuld kommerzialisiert wurde, und eine Schlichtung durch die USA, falls es zu Streitigkeiten darüber kommen sollte, ob Deutschland seinen Verpflichtungen willentlich nicht nachkommt. Auf dem Gebiet der Sicherheitspolitik sah der Plan Herriots die Aufrechterhaltung der militärischen Besetzung des Ruhrgebiets vor, ebenso die Fortsetzung der Besetzung der sogenannten »Kölner Zone« und der rechtsrheinischen Brückenköpfe sowie die Fortführung der Militärkontrollen durch die IMKK, bis durch den Völkerbund ein geeignetes Gremium zur Überwachung der deutschen Entwaffnung geschaffen würde. Außerdem forderte er einen Sicherheitspakt im Rahmen des Völkerbunds, der später auch auf Deutschland ausgeweitet werden sollte. Untergeordnete Probleme bildeten für Herriot dagegen die interalliierten Schulden, die Verteilung der Einnahmen, die durch die Ruhrbesetzung erzielt worden waren und die Frage der Kohlenversorgung. Die Grundideen dieses Plans tauchten bereits in dem angesprochenen Schreiben Herriots an Blum auf. Auch in fünf Aufzeichnungen Seydoux' vom 19. Juni 1924 wurden Grundgedanken des »HerriotPlans « niedergelegt ${ }^{349}$, die wiederum die seit Anfang des Jahres festgelegte französische Politik widerspiegelten. Im Verlauf des Sommers und des Herbstes 1924 blieb Herriot diesem Programm durchaus treu, und die Ursachen für sein Scheitern lagen, wie weiter unten zu sehen sein wird, nicht ausschließlich bei ihm.

Vergleichen wir die Position Herriots nun mit der MacDonalds: Für MacDonald stand der Völkerbund im Zentrum der neuen internationalen Ordnung ${ }^{350}$. Die Außenpolitik des britischen Premiers ließ sich zusammenfassen mit »Völkerbund, Abrüstung, internationale Konferenz « ${ }^{351}$, während er von bilateralen Abkommen, also auch von einem englisch-französischen Bündnis,

\footnotetext{
${ }^{346}$ Siehe BARIÉTY, Relations franco-allemandes, S. 374.

${ }^{347}$ Ibid. S. 378.

${ }^{348}$ Das Dokument ist abgedruckt ibid. S. 377.

${ }^{349}$ Die Aufzeichnungen Seydoux' - alle datiert vom 19.6.1924 - finden sich in MAE PAAP 261,31 .

${ }^{350}$ Siehe Sthamer an AA (24.1.1924), ADAP A DX, Nr. 110.

${ }^{351}$ Hoesch an AA (14.2.1924), ADAP A IX, Nr. 154; zusammenfassend zur Außenpolitik MacDonalds siehe COHRS, Peace Settlements, S. 12-14.
} 
wenig hielt, da er gerade solche Bündnisse für den Ausbruch des Krieges verantwortlich machte ${ }^{352}$.

Ein echter Unterschied zwischen den Positionen Herriots und MacDonalds, was das Fernziel der angestrebten internationalen Ordnung angeht, war dabei nicht auszumachen. Für beide stand der Völkerbund, und zwar in einer erweiterten und verstärkten Form, im Zentrum des zukünftigen Systems der europäischen Sicherheit. Der große Unterschied bestand aber darin, wie dieses Ziel zu erreichen sei: Frankreich versuchte, den Weg dorthin durch ein System wirtschaftlicher und militärischer Garantien abzusichern, wie sie im HerriotPlan festgelegt wurden. Eine Abschwächung der bilateralen Sicherheitsgarantien für Frankreich konnte also nur in dem Maße erfolgen, in dem die multilateralen Garantien im Rahmen des Völkerbunds ausgebaut wurden. England hingegen versuchte, durch einen Vertrauensvorschuß an Deutschland - durch eine zügige Umsetzung des Dawes-Plans und das Dringen auch auf die militärische Räumung des Ruhrgebiets - die Stärkung des Völkerbunds zu erreichen.

Nach diesen allgemeineren Überlegungen und Positionsbestimmungen wollen wir uns nun konkret dem zuwenden, was in Chequers besprochen und beschlossen wurde und welche Bedeutung diese Gespräche hatten ${ }^{353}$.

Am ersten Tag der Unterredungen (am 21. Juni 1924) standen vor allem die Umsetzung des Dawes-Plans und die notwendigen Garantien hierfür auf dem Programm. MacDonald forderte, daß ein verbindlicher Zeitplan für die wirtschaftliche und die militärische Räumung des Ruhrgebiets festgelegt werden müsse, während Herriot darauf beharrte, die Implementierung des Plans davon abhängig zu machen, welche konkreten Maßnahmen Deutschland einleite. Dissens bestand auch in der Frage der militärischen Räumung: Herriot verlangte, sie zumindest von der teilweisen Kommerzialisierung der Reparationsschuld abhängig zu machen. MacDonald dagegen argumentierte, daß die wirtschaftliche und militärische Räumung des Ruhrgebiets schon deshalb zeitgleich erfolgen müßte, weil die amerikanischen und englischen Bankiers andernfalls die Sicherheit ihrer Anleihe an Deutschland gefährdet sähen. Auch den französischen Vorschlag, konkrete Maßnahmen für den Fall festzuschreiben, daß Deutschland seinen Verpflichtungen aus dem Dawes-Plan nicht nachkäme, lehnte die englische Seite ab.

Am zweiten Tag der Konsultationen ging es wiederum um Reparationsfragen, aber auch um die Sicherheitsproblematik. Die Engländer forderten die

${ }^{352}$ Siehe WURM, Sicherheitspolitik, S. 61.

${ }^{353}$ Die zwei offiziellen Gespräche zwischen der französischen und der englischen Delegation am 21. und 22.6.1924 sind abgedruckt bei: Georges SUAREZ, Une nuit chez Cromwell. Précédé d'un important récit historique de Raymond Poincaré, Paris 1930, S. 34-84, 99-174. Ein Gesprächsprotokoll (ohne Unterschrift) vom 22.6.1924 findet sich u.a. in: MAE PAAP 217, 105. Herriot hat in seinen Memoiren ebenfalls wörtlich die Gespräche wiedergegeben: Édouard HERRIOT, Jadis, Bd. 2: D'une guerre à l'autre 1914-1939, Paris 1952, S. 139-145. 
Aufgabe der Eisenbahnregie, die im Widerspruch zu den Schlußfolgerungen der Experten stehe, während die Franzosen diese, vor allem aus Sicherheitsgründen, weiterhin für notwendig erachteten. Bezüglich des Modus, wie der Dawes-Plan umgesetzt werden könnte, schlug MacDonald eine Regierungskonferenz vor, wobei sich die Frage stellte, ob und wie Deutschland an der Konferenz beteiligt werden sollte. Großbritannien wünschte die gleichberechtigte Teilnahme Deutschlands, Herriot dagegen schlug eine Zweiteilung der Konferenz vor: Im ersten Abschnitt sollten die Alliierten unter Ausschluß Deutschlands über die grundsätzlichen Rahmenbedingungen für die Inkraftsetzung des Plans entscheiden, also beispielsweise festlegen, welche Vorleistungen Deutschland zu erbringen hätte, die Modalitäten der Räumung und eventuelle Sanktionsmaßnahmen. Im zweiten Teil der Konferenz sollte mit Deutschland nur noch die Umsetzung der Maßnahmen besprochen werden. Der französischen Delegation ging es also hauptsächlich um die Festlegung von Sicherheiten für den Fall der deutschen Nichterfüllung, was Großbritannien jedoch ablehnte.

Ein weiteres Gesprächsthema war die Verknüpfung von interalliierten Schulden und Reparationen. MacDonald konnte sich mit seiner Auffassung durchsetzen, die Schuldenfrage erst nach der Inkraftsetzung des Dawes-Plans zu besprechen.

In der Sicherheitsfrage drängte Herriot erneut auf einen europäischen Sicherheitspakt, dem MacDonald - unter Hinweis auf die kritische Haltung der Dominions, innenpolitische Widerstände und die ablehnende Haltung der neutralen Länder - allerdings wenig Chancen einräumte. Der englische Premier befürwortete statt dessen eine Regelung der Sicherheitsfrage im Rahmen des Völkerbunds durch allgemeine Abrüstung und Entspannung und schlug eine Reihenfolge der zu lösenden Probleme vor: Dawes-Plan, Schulden, Sicherheit.

Es bestanden also große Differenzen zwischen der britischen und der französischen Position. Die einzig greifbare Entscheidung der beiden Regierungschefs war eine an Deutschland gerichtete Note mit der Forderung, die Militärkontrolle wieder zuzulassen ${ }^{354}$. Das gemeinsame Kommuniqué ${ }^{355}$ enthielt darüber hinaus wenig Konkretes: Den Verweis auf die Entwaffnungsnote an die deutsche Regierung, die Einberufung einer Regierungskonferenz zur Inkraftsetzung des Dawes-Plans und die Zweiteilung dieser Konferenz, wobei der erste Teil der Diskussion der Siegermächte untereinander dienen und die deutsche Seite erst im zweiten Teil hinzugezogen werden sollte. Außerdem enthielt die Erklärung der beiden Regierungschefs ein Bekenntnis zu einem "pacte moral de coopération continue ${ }^{356}$.

\footnotetext{
${ }^{354}$ Text der Note in: DBFP 1 XXVI, Nr. 670f.

${ }^{355}$ Siehe Aufzeichnung ohne Unterschrift (22.6.1924), MAE PAAP 217, 105.

${ }^{356}$ Ibid.
} 
Wie sind die Gespräche von Chequers und deren Ergebnisse zu deuten? Bariéty hält sie für eine wichtige Vorentscheidung bezüglich der Londoner Konferenz $z^{357}$, wobei sich die englische Auffassung hinsichtlich der anzustrebenden internationalen Ordnung weitgehend durchgesetzt habe. MacDonald habe sich mit seinen Forderungen nach einer internationalen Konferenz unter Beteiligung Deutschlands, der Trennung von Schulden- und Reparationsfrage sowie einer Ausklammerung der Sicherheitsfrage behaupten können, während Herriot mit seinen Vorschlägen zu einem Sicherheits- und Garantiepakt gescheitert sei. Die prinzipielle Zustimmung Herriots zur ökonomischen Räumung enthalte implizit den Verzicht auf die M.I.C.U.M.-Verträge und die wirtschaftlichen Pfänder. Mit der Ausklammerung der Sicherheitsfrage »Herriot a accepté une négociation où l'on ne traitera que d'un domaine où la France a à donner et où l'on ne traitera pas de domaines où la France a à demander ${ }^{358}$, weshalb die Londoner Konferenz von vornherein richtige Verhandlungen im Sinne eines Interessensausgleichs ausgeschlossen habe. Dies wiederum habe die Aufgabe einer unabhängigen französischen Außenpolitik zur Folge gehabt, wobei Großbritannien nun die Maßstäbe setzte. Chequers war demnach die Konfrontation "entre la conception de la paix par l'apaisement général et international et celle de la paix par la construction d'un système de sécurité dont une étroite entente franco-anglaise aurait été la première pierre ${ }^{359}$, wobei sich die englische Auffassung durchgesetzt habe.

Die deutsche Seite hingegen stufte die Ergebnisse des französisch-britischen Gipfels weniger spektakulär ein. Der deutsche Botschafter in London, Sthamer, berichtete,

daß die Unterhaltungen zwischen den Herren MacDonald und Herriot nicht so befriedigend verlaufen seien, wie der englische Staatsmann erhofft zu haben scheint. [...] Tatsächlich glaube ich, daß etwas bindendes in Chequers nicht vereinbart ist, daß man sich hauptsächlich höchstens auf eine breite Linie verständigt haben wird [...] Es geht aber aus diesen Erklärungen vor - und ich habe keinen Grund, an der Zuverlässigkeit des als ehrlich bekannten Norman Angell ${ }^{360}$ zu zweifeln -, daß Herr Herriot wie Herr MacDonald die Absicht haben, sich des Völkerbunds zu bedienen, um ihn als Instrument zur Regelung der Sicherheits- und allgemeinen Abrüstungspläne zu benutzen ${ }^{361}$.

Die Bewertung Sthamers ist wohl die plausiblere. Das Kommuniqué und auch die vorliegenden Gesprächsprotokolle liefern keine Hinweise, daß Herriot sich unvorsichtigerweise und voreilig auf Positionen festgelegt hätte, die die Position Frankreichs kompromittiert hätten (ebenso wenig übrigens wie MacDo-

${ }^{357}$ Zum folgenden siehe BARIÉTY, Relations franco-allemandes, S. 409-413.

${ }^{358}$ Ibid. S. 411.

${ }^{359}$ Ibid. S. $411 \mathrm{f}$.

${ }^{360}$ Angell hatte zu diesem Thema ein Interview mit Herriot für den $» N e w$ Leader« geführt, siehe Sthamer an AA (20.6.1924), ADAP A X, Nr. 157.

${ }^{361}$ Ibid. 
nald). Das hieße auch, den Charakter der Gespräche zu überschätzen, die wohl doch eher dem gegenseitigen Kennenlemen und der Positionsbestimmung dienten als der tatsächlichen Formulierung von gemeinsamen Zielen. Für Herriot ging es in erster Linie darum, das Einvernehmen mit der englischen Seite wiederherzustellen, denn das französisch-britische Verhältnis hatte unter Poincaré den ein oder anderen Schlag hinnehmen müssen. Insofern ist der symbolische Wert des Treffens nicht zu unterschätzen. Sicherlich bedeutete die $\mathrm{Zu}$ rückstellung der Kriegsschulden- und Sicherheitsfrage hinter die Reparationsfrage eine Schwächung der französischen Position für die Londoner Konferenz. Es bleibt aber die Frage zu stellen, ob solch eine Einbeziehung realistisch gewesen wäre: Der Dawes-Plan war nun mal ein Reparationsplan und kein Schulden- und Sicherheitsplan. Mit der prinzipiellen Annahme des Expertengutachtens - durch Poincaré, wohlgemerkt - hatte Frankreich implizit die Gesamtlösung der schwebenden Probleme aufgegeben. Es sprachen insbesondere praktische Erwägungen dafür, sich zunächst ganz auf die Reparationsfrage zu konzentrieren: Waren nicht alle vorangegangenen Konferenzen an der Verquickung von Reparationen, Schulden und Sicherheit gescheitert und machte es nicht Sinn, erst ein Problem zu lösen, um dann die übrigen anzugehen? Konnte die Lösung der Reparationsfrage nicht die Lösung der anderen Fragen erleichtern? Trotz des von angelsächsischer Seite geleugneten Zusammenhangs von Kriegsschulden und Reparationen war es doch so: War erst einmal eine verbindliche Lösung für das Reparationsproblem gefunden, konnte ausgehend von dieser Regelung ein Ausgleich über die Schulden erzielt werden. Für Herriot, wir haben es in seinem Plan gesehen, war das Schuldenproblem außerdem nur ein sekundäres, es war also ein Zugeständnis, was ihm vergleichsweise leichtgefallen sein dürfte. Wichtiger, vielleicht am wichtigsten, war für ihn die Sicherheitsfrage ${ }^{362}$. Hier konnte er von MacDonald die zugegebenermaßen vage - Zusage erhalten, den Völkerbund zu einem funktionierenden Instrument der Friedenssicherung auszubauen. Der Weg dorthin war zwischen London und Paris zwar umstritten, aber das Ziel war ein gemeinsames.

Auch den Engländern dürfte das Treffen vor allem zur Positionsbestimmung gedient haben. Dabei galt es für London, nicht nur die eigene Haltung festzulegen, sondern auch die Positionen von Deutschland und Frankreich abzugleichen: In einem Treffen zwischen Ruppel und Bradbury kam es im Vorfeld des Treffens von Chequers zu Gesprächen über einen Zeitplan für die Ruhrräumung ${ }^{363}$. Einen Tag vor dem französisch-britischen Gipfel legte Sthamer Crowe, der an den Gesprächen in Chequers teilnahm, die deutschen Forderungen in bezug auf den Reparationsplan vor, nämlich die Räumung von Düsseldorf,

${ }^{362}$ Siehe HERRIOT, Jadis, S. 143.

${ }^{363}$ Siehe BARIETTY, Relations franco-allemandes, S. 385f. 
Duisburg und Ruhrort, die bereits 1921 als Sanktion besetzt und zwischenzeitlich nicht geräumt worden waren, eine verbindliche Erklärung Frankreichs zur Ruhrräumung, die Wiederherstellung der administrativen, wirtschaftlichen und fiskalischen Einheit Deutschlands sowie eine generelle Amnestie für alle Ausgewiesenen ${ }^{364}$. Für die englische Regierung, die sich viele der deutschen Forderungen zu eigen machte, waren die Gespräche in Chequers also auch eine Möglichkeit, die deutsche und die französische Position zu eruieren.

Wie wenig sich Frankreich in Chequers festgelegt hatte, zeigte auch der Besuch Herriots in Brüssel, wo er auf seiner Rückkehr aus England Halt machte, um den belgischen Verbündeten über die Gespräche mit MacDonald zu informieren $^{365}$. Dort erklärte der französische Ratspräsident, er habe vom englischen Premierminister die Zusicherung für ein Defensivbündnis erhalten eine Aussage, die sich mit den Gesprächen in Chequers, soweit sie uns bekannt sind, kaum in Einklang zu bringen sind. War es das, was Herriot unter dem "moralischen Pakt" verstand? MacDonald jedenfalls war anderer Ansicht und erklärte am 26. Juni 1924 vor dem Unterhaus, daß es keinerlei Absprachen bezüglich eines militärischen Bündnisses zwischen Frankreich und dem Vereinigten Königreich gebe ${ }^{366}$.

Für die These, daß die Gespräche von Chequers, bis auf die im Kommuniqué festgelegten Punkte, wenig bindenden Charakter hatten, spricht der "Wirrwarr ${ }^{367}$ in den französisch-britischen Beziehungen, der nach den englisch-französischen Konsultationen herrschte. Neben der stark unterschiedlichen Interpretation der Ergebnisse von Chequers trug dazu auch das einseitige Vorgehen Londons bei der Vorbereitung der Londoner Konferenz bei: Die englische Regierung hatte - ohne Paris davon zu informieren - Einladungen an die Siegermächte des Krieges verschickt und dieser Einladung ein Memorandum bezüglich der Deutschlandpolitik beigefügt, das in keiner Weise dem französischen Standpunkt entsprach ${ }^{368}$. Herriot mußte davon aus dem "Écho de Paris« erfahren - ein dem Linkskartell nicht gerade wohlgesonnenes Blatt und war außer sich über das englische Vorgehen.

Die Verworrenheit der Lage machte - der Beginn der Londoner Konferenz rückte immer näher - eine Klärung der zwischen England und Frankreich umstrittenen Punkte notwendig. Am 8. Juli 1924 reiste MacDonald deswegen nach Paris, um mit der französischen Regienung zumindest den Rahmen einer gemeinsamen Haltung gegenüber Deutschland zu finden. Die französische Haltung war diesmal weniger unverbindlich als in Chequers ${ }^{369}$. Frankreich

\footnotetext{
${ }^{364}$ Siehe Stresemann an Botschaft London (18.6.1924), ADAP A X, Nr. 140 und Sthamer an AA (20.6.1924), ADAP A X, Nr. 146.

${ }^{365}$ Zu Herriots Belgien-Reise siehe BARIÉTY, Relations franco-allemandes, S. 416-422.

${ }^{366}$ Siehe SOULIÉ, Herriot, S. 163.

${ }^{367}$ Stresemann an Hoesch (13.7.1924), ADAP A X, Nr. 202.

${ }^{368}$ Siehe SouLÍ́, Herriot, S. 163.

${ }^{369}$ Hierzu BARIÉTY, Relations franco-allemandes, S. 475-477; HERRIOT, Jadis, S. 147.
} 
forderte, die militärische Ruhrbesetzung nicht zum Gegenstand der Londoner Konferenz zu machen, da für das Funktionieren des Expertenplans nur die wirtschaftliche Räumung notwendig sei. Außerdem müßten die Entscheidungen der Konferenz im Rahmen des Versailler Vertrags bleiben, dürften also nicht den Status der RepKo antasten oder die Möglichkeiten zu Sanktionen einschränken. Statt dessen sollten genaue Maßnahmen festgelegt werden, die in Kraft treten würden, falls Deutschland sich weigern sollte, den Bedingungen des Dawes-Plans nachzukommen, und diese Maßnahmen müßten formell vor dem französischen Parlament verkündet werden. Weiterhin stellte die französische Seite fest, daß sowohl die Kriegsschulden- wie auch die Sicherheitsfrage Teile des Reparationsproblems seien und mahnte eine baldige Lösung dieser beiden Komplexe an.

In den Gesprächen zwischen der französischen und der britischen Regierung mußte Paris jedoch einige Abstriche an seiner Position hinnehmen. In dem gemeinsamen Memorandum vom 9. Juli $1924^{370}$ wurde zwar die militärische Räumung nicht erwähnt und der Versailler Vertrag nicht in Frage gestellt, allerdings sollte die RepKo um ein amerikanisches Mitglied erweitert werden, was zwar den Status der RepKo selbst nicht beeinträchtigte, aber das Gewicht Frankreichs darin verringerte. Der Zusammenhang zwischen interalliierten Schulden, dem Sicherheitsproblem und den Reparationen wurde abgeschwächt und die Frage an die Experten übergeben ${ }^{371}$. Wie wirkte sich die französischbritische Erklärung auf die Verhandlungsposition Frankreichs aus? Eine Schwächung der französischen Position trat sicherlich dadurch ein, daß die Schulden- und Sicherheitsproblematik durch ihre Überweisung an die Experten explizit aus den Londoner Gesprächen ausgeklammert wurde, aber das war ja auch vorher schon faktisch der Fall gewesen ${ }^{372}$. Auch ist festzustellen, daß die eigentlich kritischen Fragen im Kommuniqué keine Erwähnung fanden, weil eine Einigung darüber wohl kaum zu erreichen gewesen wäre: Die Fragen der militärischen Räumung, der Zukunft der Eisenbahnregie, der deutschen Beteiligung an der Londoner Konferenz oder die Frage der Kommerzialisierung der Reparationsschuld wurden nicht thematisiert ${ }^{373}$. Eine gemeinsame englisch-französische Haltung war also nur oberflächlich gegeben.

In Deutschland traf die französisch-britischen Erklärung auf Ablehnung: Sie stelle einen wstarken Rückschritt gegenüber dem nach der Konferenz in Chequers aufgestellten englischen Memorandum ${ }^{374}$ dar, denn die Befugnisse der RepKo seien weiterhin zu groß, und sie habe nach wie vor darüber zu entscheiden, ob Deutschland seinen Reparationsverpflichtungen nachkomme oder

\footnotetext{
${ }^{370}$ Abgedruckt als Dokument Nr. 9 in: Weißbuch Londoner Konferenz.

${ }^{371}$ Siehe ibid.

${ }^{372}$ Siehe BARIÉTY, Relations franco-allemandes, S. 484.

${ }^{373}$ Siehe ibid.

${ }^{374}$ Siehe Runderlaß Maltzan (10.7.1924), ADAP A X, Nr. 194, siehe auch zum folgenden.
} 
nicht. Außerdem sei aus der Erklärung nicht erkennbar, nach welchen deutschen Vorleistungen der Dawes-Plan in Kraft treten solle. Einzig die Erklärung, daß Sanktionen nur einstimmig verhängt werden könnten, sei in diesem Zusammenhang positiv zu bewerten, auch wenn die vorgesehenen Schlichtungsgremien unzureichend seien. Allerdings stellte Maltzan fest, daß viele offene Punkte durch das Kommuniqué nicht geregelt seien, so daß es deshalb noch gelingen könne, »die vitalen deutschen Interessen mehr als bisher zu berücksichtigen ${ }^{375}$. Auch Hoesch kam zu dem Schluß: "Sachlich scheint mir durch franko-englische Presseverständigung nicht viel für uns verdorben ${ }^{376}$.

Sicherlich, die Verständigung mit Großbritannien hatte für Frankreich im Vorfeld der Londoner Konferenz Priorität. Dennoch hatte natürlich auch die deutsch-französische Perspektive Auswirkungen darauf, welches Land in welchem Umfang seine Interessen auf der Londoner Konferenz würde durchsetzen können. Die Reichsregierung forderte die wirtschaftliche Räumung der Ruhr und die Rücknahme aller Maßnahmen der Franzosen und Belgier zur Ausbeutung des Ruhrpfandes, also vor allem die Aufhebung der M.I.C.U.M.Verträge und das Ende der Eisenbahnregie, während besonders letztere für Frankreich einen besonderen sicherheitspolitischen Wert hatte ${ }^{377}$. Ein zweiter großer Streitpunkt zwischen Deutschland und Frankreich betraf die militärische Räumung des Ruhrgebiets und die damit zusammenhängende Frage der Kommerzialisierung der Reparationsschuld. Frankreich wünschte, die militärische Räumung des Ruhrgebiets davon abhängig zu machen, in welchem Umfang die Reparationsschuld kommerzialisiert wurde, was Stresemann jedoch ablehnte ${ }^{378}$. Er forderte statt dessen einen festgelegten Zeitplan, der nicht an die Kommerzialisierung gebunden sein sollte, denn er befürchtete, daß andernfalls der Dawes-Plan nicht durch den Reichstag zu bringen sei ${ }^{379}$.

Die Kommerzialisierung der Reparationsschuld war aus mehreren Gründen ein heikles Thema. Dahinter verbarg sich die Ausgabe staatlicher Schuldverschreibungen für einen Teil oder die Gesamtheit der Reparationsschuld auf den privaten Kapitalmärkten, ähnlich anderen staatlichen Anleihen, Rentenbriefen etc., und die Bedienung der privaten Gläubiger durch den Staat. Was trivial klingt, hatte erhebliche Konsequenzen auf den ganzen Charakter der Reparationen: Sie waren bislang in ihrer Höhe und den Zahlungsmodalitäten, trotz der in Spa festgelegten Zahlen, in höchstem Maße fiktiv. Ihre Streichung hätte theoretisch nur des Federstrichs der beteiligten Regierungen bedurft. Waren die Schuldtitel aber in den Händen privater Anleger, hätte die deutsche Regierung, die diese ja hätte bedienen müssen, so gut wie keinen Spielraum

\footnotetext{
${ }^{375}$ Ibid.

${ }^{376}$ Hoesch an AA (10.7.1924), ADAP A X, Nr. 195.

${ }^{377}$ Siehe BARJÉTY, Relations franco-allemandes, S. 438.

${ }^{378}$ Siehe Saint-Quentin an Quai d'Orsay (9.7.1924), MAE 1918-1940 Y (Internationale), 23.

${ }^{379}$ Siehe Stresemann an Botschaft London (30.6.1924), ADAP A X, Nr. 167.
} 
gehabt, die Reparationsschuld zu verringern ${ }^{380}$ : Denn dies hätte ja bedeutet, daß ein Teil der Schuldtitel wertlos geworden wäre. Das Vertrauen in Deutschland auf den internationalen Kapitalmärkten wäre ruiniert, ausländische Kredite würden abgezogen und an neue wäre nicht mehr zu denken. Frankreich hatte also deshalb ein Interesse daran, die Reparationen so schnell wie möglich in größtmöglichem Umfang zu kommerzialisieren, weil dadurch langfristig die Reparationszahlungen abgesichert und kurzfristig große Zahlungen, die dringend zum Wiederaufbau und zur Sanierung der französischen Währung notwendig waren, in den leeren französischen Staatssäckel gespült worden wären.

Deutschland hingegen wollte aus genau diesen Gründen die Kommerzialisierung verhindern, zumindest aber hinausschieben, um sich nicht längerfristig der Möglichkeiten einer Reduzierung der Reparationen zu berauben. Kalkül Stresemanns war es vielmehr, privates englisches und amerikanisches Kapital nach Deutschland zu holen. Sollte Deutschland in Zahlungsschwierigkeiten geraten, würden die amerikanischen und englischen Anleger darauf drängen, daß ihre Kredite Priorität vor den (nicht kommerzialisierten) Reparationen hätten und eine Senkung der Reparationen fordern ${ }^{381}$. Wären die Reparationen aber kommerzialisiert, hätten sie die gleiche Qualität wie die anderen Kredite auch, und Deutschland müßte wohl oder übel beide zahlen.

Ganz abgesehen von dem Wunsch Frankreichs nach schneller Kommerzialisierung und dem deutschen Widerwillen dagegen, bestand aber in diesem $\mathrm{Zu}$ sammenhang noch ein anderes Problem: Es mußte erst einmal das Kapital vorhanden sein, eine derart große Anleihe auf den internationalen Finanzmärkten unterzubringen. Als Anleger kamen nach Lage der Dinge vorwiegend Amerikaner und Engländer in Betracht, so daß die Frage der Kommerzialisierung eben nicht nur ein deutsch-französisches Problem war, sondern in erster Linie vom Wohlwollen der amerikanischen und englischen Bankiers abhängig war. Der französische Wunsch, die Räumung des Ruhrgebiets vom Fortschritt der Kommerzialisierung abhängig zu machen, hätte deshalb bedeutet, daß über den Abzug der Besatzungstruppen letztlich in der Wall Street und der City entschieden worden wäre, auf deren Haltung Berlin keinen Einfluß hatte.

Dissens bestand zwischen Berlin und Paris auch in der Frage der deutschen Beteiligung an der Londoner Konferenz: Die Reichsregierung war daran interessiert, möglichst von Anfang an mit am Verhandlungstisch zu sitzen, da andernfalls ein erneutes alliiertes »Ultimatum ${ }^{382}$ zu befürchten sei. Außerdem stieß in Deutschland die französische Forderung auf Widerstand, die zur Umsetzung des Dawes-Plans notwendigen Änderungen in den deutschen Gesetzen

\footnotetext{
${ }^{380}$ Siehe WURM, Sicherheitspolitik, S. 402.

${ }^{381}$ Siehe BARJÉTY, Relations franco-allemandes, S. 452.

${ }^{382}$ Aufzeichnung Schubert (30.6.1924), ADAP A X, Nr. 165.
} 
bereits vor Beginn der Londoner Konferenz zu verabschieden ${ }^{383}$. Stresemann lehnte dies ab, weil dies bedeutet hätte,

daß wir uns unsererseits endgültig binden, bevor sich Frankreich zu den von ihm zu treffenden Maßnahmen verpflichtet hat, daß wir uns hinsichtlich der Wiederherstellung unserer wirtschaftlichen und finanziellen Souveränität in den besetzten Gebieten auf den guten Willen der französischen Regierung verlassen, daß wir also ohne jede Gewähr der Gegenleistung schlichtweg vorleisten ${ }^{384}$.

Um die französische Seite dennoch zu einer weicheren Haltung zu bewegen und wegen der »augenscheinlich außerordentlich schwache[n] Stellung Herriots ${ }^{385}$, demonstrierte die Reichsregienung ihren guten Willen in der Frage der Militärkontrolle ${ }^{386}$ und antwortete auf die gemeinsame Note MacDonalds und Herriots zur Entwaffnungsfrage vom 22. Juni 1924 bereits am 30. Juni positiv $^{387}$. Trotz der Bedingungen, die die Reichsregierung in ihrer Note stellte nämlich daß die IMKK so schnell wie möglich nach Ende der Entwaffnungskontrolle aufgelöst werden sollte, die Bedingungen der Inspektion mit Deutschland abgestimmt werden sollten und die Inspektion bis spätestens Ende September 1924 abgeschlossen sein sollte -, war »die Note als ein uneingeschränktes und ehrliches Ja zu werten ${ }^{388}$. Die erwähnten Einschränkungen dienten vor allem der Beruhigung der Opposition im Reichstag, aber auch seitens von Seeckts und Reichswehrminister Geßlers ${ }^{389}$.

Außerdem versuchte die deutsche Regierung, die zum 15. Juni 1924 anstehende Verlängerung der M.I.C.U.M.-Abkommen zu benutzen, von Frankreich wenn schon nicht die Aufgabe, so doch die Modifikation der Verträge im deutschen Sinne zu erreichen, damit Paris dieses Druckmittel vor den Verhandlungen in London aus der Hand geschlagen wurde. Aufgrund des hartnäckigen französischen Widerstands mußte die Reichsregierung jedoch der Verlängerung der M.I.C.U.M.-Verträge bis zunächst Ende Juli zustimmen.

Vor dem Zusammentritt der Londoner Konferenz waren also noch folgende Fragen zwischen London, Berlin und Paris umstritten: Frankreich lehnte die Diskussion der militärischen Räumung ab, Berlin dagegen sah einen verbindlichen Zeitplan für den Truppenabzug als Voraussetzung für das Inkraftsetzen des Dawes-Plans als notwendig an. London neigte in dieser Frage tendenziell der Haltung Berlins zu. Frankreich forderte die Kommerzialisierung der Reparationen als Bedingung für die militärische Räumung, was wiederum von

\footnotetext{
${ }^{383}$ Siehe Saint-Quentin an Quai d'Orsay (9.7.1924), MAE 1918-1940 Y (Internationale), 23.

${ }^{384}$ Stresemann an Botschaft London (30.6.1924), ADAP A X, Nr. 167.

${ }^{385}$ Aufzeichnung Schubert (7.7.1924), ADAP A X, Nr. 184.

${ }^{386}$ Siehe Hoesch an AA (4.6.1924), ADAP A X, Nr. 118.

${ }^{387}$ Siehe Schubert an Hoesch (28.6.1924), ADAP A X, Nr. 163.

${ }^{388}$ Ibid.

${ }^{389}$ Siehe ibid. und Aufzeichnung Schubert (25.6.1925), ADAP A X, Nr. 154 sowie Ministerbesprechung (25.6.1924), AdR Marx III Bd. 2, Nr. 234.
} 
Deutschland und England abgelehnt wurde. Paris wünschte, daß die RepKo ihre Befugnisse in Reparationsangelegenheiten behielt, besonders hinsichtlich der Verhängung der Sanktionen, während Berlin und London die Sanktionsmöglichkeiten und die Rolle der RepKo beschränken, vor allem aber französische Alleingänge verhindern wollten. Strittig war außerdem die Frage, ob Deutschland die für den Dawes-Plan notwendigen Gesetzesänderungen bereits vor der Londoner Konferenz verabschieden sollte - was sowohl die deutsche wie auch die englische Regierung ablehnten. Auch die Teilnahme Deutschlands an der Reparationskonferenz war umstritten, wobei Berlin stärker noch als London auf eine möglichst frühe Einbeziehung Deutschlands drängte, was Paris jedoch zurückwies. Frankreich hatte sich nicht mit seinem Wunsch durchsetzen können, die Schulden- und Sicherheitsproblematik mit dem Reparationsproblem zu verknüpfen. An der Aufzählung der strittigen Punkte wird deutlich, daß die Gemeinsamkeiten zwischen Berlin und London größer waren als die zwischen London und Paris, so daß die französische Verhandlungsposition deshalb schon im Vorfeld eingeschränkt war.

Bei allen offenen Problemen war jedoch unstrittig, daß alle drei Regierungen am Erfolg des Dawes-Plans interessiert waren und Einigkeit darin bestand, daß das Ruhrgebiet wirtschaftlich geräumt und die wirtschaftliche, fiskalische und administrative Einheit Deutschlands wiederhergestellt werden sollte, auch wenn es in Einzelfragen - wie der Eisenbahnregie - unterschiedliche Auffassungen gab. In London mußte sich erweisen, welche Bedeutung die strittig gebliebenen Fragen für die einzelnen Akteure hatten, und ob sie bereit waren, deswegen die Konferenz scheitern zu lassen: Das schwierigste Problem war die militärische Ruhrräumung. Sie war der $»$ Kardinalpunkt ${ }^{390}$. Stresemann mußte »dem deutschen Volk sagen können, daß in absehbarer Zeit diese Gebiete frei werden, sonst wirft man mir den ganzen Sachverständigenplan vor die Füße $\ll^{391}$. Frankreich dagegen beharrte auf seiner Truppenpräsenz ${ }^{392}$.

Die Londoner Konferenz begann wie geplant zunächst unter Ausschluß Deutschlands am 16. Juli 1924. Drei Problemkreise standen im Mittelpunkt der Verhandlungen: Erstens die Implementierung des Dawes-Plans, das war der offizielle Grund des Zusammentreffens. Zweitens, eng mit dem ExpertenPlan im Zusammenhang stehend, die Frage der militärischen Ruhrräumung und drittens ein deutsch-französischer Handelsvertrag, der als Kompensationsobjekt für die militärische Räumung des Ruhrgebiets ins Spiel gebracht worden war. Dabei verliefen die Konfliktlinien nicht nur zwischen den ehemals Alliierten und Deutschland, sondern auch zwischen Frankreich und Großbritannien, während zwischen den Deutschen und Engländern in vielen Fragen Übereinstimmung herrschte. Es gab aber noch eine weitere Frontlinie,

\footnotetext{
${ }^{390}$ Stresemann an Hoesch (13.7.1924), ADAP A X, Nr. 202.

${ }^{391}$ Ibid.

${ }^{392}$ Maltzan an Sthamer und Dufour (15.7.1924), ADAP A X, Nr. 107.
} 
nämlich zwischen der französischen Delegation und den Interessen der amerikanischen und englischen Bankiers. Diese hatten der englischen Regierung wenige Tage vor Beginn der Londoner Konferenz ihre Bedingungen für die Gewährung der 800 Mio. GM Anleihe für Deutschland - einem Kernstück des Dawes-Plans - übermittelt, die sich weitgehend mit der deutschen und englischen Position deckten und im Gegensatz zur französischen Position stan$\operatorname{den}^{393}$. In ihrem Schreiben hatten die Bankiers gefordert, daß das Ruhrgebiet unverzüglich, auch militärisch, geräumt und alle Institutionen, die das Wirtschaftsleben in den besetzten Gebieten einschränkten (also vor allem die Eisenbahnregie und die M.I.C.U.M.), abgeschafft werden müßten. Außerdem sollten sich die europäischen Bankiers an der 800 Mio. GM-Anleihe beteiligen und deren Bedienung Priorität vor den Reparationsleistungen haben. Sie verlangten zudem, daß Sanktionen nur einstimmig von allen Alliierten verhängt werden sollten und die Kompetenz zur Feststellung der deutschen Nichterfüllung nicht in die Hände der RepKo, sondern des Transferkomitees gelegt würde. Für die französische Delegation waren die Forderungen der Bankiers deshalb nicht leicht zu ignorieren, weil man wegen der französischen Währungsprobleme ebenfalls auf ausländisches Kapital hoffte.

Die Arbeit der Konferenz, deren Vorsitzender auf Vorschlag Herriots MacDonald wurde, war auf drei Kommissionen verteilt ${ }^{394}$. Die erste Kommission unter Vorsitz des englischen Schatzkanzlers Snowden hatte die Aufgabe, die Garantien für die $800 \mathrm{Mio}$. GM Anleihe auszuarbeiten. Die zweite sollte die Bedingungen für die Wiederherstellung der wirtschaftlichen und fiskalischen Einheit Deutschlands ausarbeiten und wurde von James Henry Thomas geleitet. Kindersley, der auch schon Mitglied des Dawes-Komitees gewesen war, $\mathrm{sa}$ der dritten Kommission vor, die beauftragt wurde, die Bedingungen für die Transferzahlungen und die Sachlieferungen auszuarbeiten.

Am schnellsten kamen die Verhandlungen der zweiten Kommission über die Rahmenbedingungen der wirtschaftlichen Räumung voran, und bereits am 24. Juli 1924 konnten sich die Delegationen prinzipiell einigen ${ }^{395}$.

Am schwierigsten stellten sich die Verhandlungen in der ersten Kommission dar ${ }^{396}$. Hier verhärteten sich bald die Positionen von Franzosen und Engländern: Während die französische Delegation auf den Kompetenzen der RepKo und den Sanktionsmöglichkeiten beharrte, versuchte Snowden - zusammen mit den amerikanischen und englischen Bankiers - genau dies zu verhindern. Die französische Verhandlungsposition verschlechterte sich dadurch, daß Bel-

\footnotetext{
${ }^{393}$ Siehe JEANNESSON, Poincaré, S. 401.

${ }^{394}$ Zur Organisation der Londoner Konferenz siehe Protokoll der ersten (interalliierten) Vollsitzung (16.7.1924), Weißbuch Londoner Konferenz, Nr. 1; BARIÉTY, Relations francoallemandes, S. 522f.

${ }^{395}$ Siehe Weißbuch Londoner Konferenz, Nr. 16.

${ }^{396}$ Vgl. BARIÉTY, Relations franco-allemandes, S. $557 \mathrm{f}$.
} 
gien während des Konferenzverlaufs ankündigte, seine Truppen aus dem Ruhrgebiet zurückzuziehen. Herriot sah sich nun der gemeinsamen Front von Engländern, Belgiern und Bankiers gegenüber. Außerdem hatte die englische Delegation die Arbeit der ersten Kommission in der Frage der Sachlieferungen blockiert, ein Problem, daß für Frankreich außerordentlich wichtig war, weil es durch diese langfristig die Sicherung der Rohstoffversorgung der französischen Industrie, besonders in bezug auf Koks und chemische Grundstoffe, sichern wollte ${ }^{397}$.

In dieser Situation brachte MacDonald die militärische Räumung des Ruhrgebiets ins Spiel, über die zu sprechen Herriot sich nicht weigern konnte: Herriots Ablehnung hätte das Ende der Konferenz bedeutet, den Bruch mit England, die Schwächung seiner politischen Basis daheim und das Ende der dringend erhofften finanziellen Unterstützung der Amerikaner und Engländer bei der Stabilisierung des Franc. Derart in die Ecke gedrängt, stimmte die französische Regierung am 28. Juli 1924 auch der militärischen Räumung des Ruhrgebiets, zumindest im Prinzip, $\mathrm{zu}^{398}$. Seydoux schlug allerdings vor, die Ruhrräumung als Hebel für die Mobilisierung der Reparationsanleihen zu nutzen, indem sie nur in dem Maße erfolgen sollte, in dem die Anleihen mobilisiert würden. Außerdem sollte direkt mit den Deutschen verhandelt werden, um zu einer Lösung in der Kohlenfrage (durch die französische Beteiligung an deutschen Bergwerken) zu kommen ${ }^{399}$.

Als am 2. August 1924 die Einladung an die deutsche Delegation zur Teilnahme an der Londoner Konferenz erfolgte ${ }^{400}$, waren drei Problembereiche noch nicht gelöst: Die zukünftige Rolle der RepKo und die alliierten Sanktionsmöglichkeiten, die Bedingungen für die militärische Räumung des Ruhrgebiets sowie die Zukunft der Eisenbahnregie ${ }^{401}$.

Am gleichen Tag legte die Reichsregierung die Marschrichtung für die Londoner Verhandlungen fest ${ }^{402}$. Die wichtigste deutsche Forderung bestand in einem festen Datum für die Räumung des Ruhrgebiets, da andernfalls der DawesPlan nicht durch den Reichstag zu bringen sei. Außerdem müsse der Begriff des "manquement flagrant« bei der Reparationserfüllung präzisiert werden und die Rechte und Pflichten des Transferkomitees und des Generalagenten gegenüber der RepKo, wie im Expertenplan vorgesehen, erhalten bleiben. Auch die dauerhafte Präsenz französischer und belgischer Eisenbahner im Rheinland sei unbedingt $\mathrm{zu}$ verhindern. Als eventuelle Kompensations-

\footnotetext{
${ }^{397}$ Siehe ibid. S. 529.

${ }^{398}$ Siehe ibid. S. 568.

${ }^{399}$ Siehe ibid. S. 568-570.

${ }^{400}$ Siehe Weißbuch Londoner Konferenz, Nr. 26.

${ }^{401}$ Siehe BARIÉTY, Relations franco-allemandes, S. 591.

${ }^{402}$ Siehe Ministerrat (2.8.1924), AdR Marx I/II Bd. 2, Nr. 269.
} 
objekte für die deutschen Forderungen kämen Zugeständnisse bei den Sachlieferungen und bei den Handelsvertragsverhandlungen in Betracht.

Während die Verhandlungen zu den offiziellen Punkten der Londoner Konferenz - also Fragen im Zusammenhang mit der Implementierung des DawesPlans - bis zum 13. Juli 1924 im großen und ganzen abgeschlossen waren, blieb die militärische Ruhrräumung weiterhin problematisch ${ }^{403}$.

Die französische Seite versuchte, durch Ausweitung der Themen ihren Verhandlungsspielraum zu vergrößern. So brachte sie erneut die Sicherheitsfrage ins Gespräch und konnte von MacDonald das Zugeständnis erhalten, daß die Kölner Zone erst dann geräumt würde, wenn die deutsche Entwaffnung zweifelsfrei festgestellt worden sei. Außerdem einigte man sich darauf, daß die deutsche Entwaffnung nach dem Ende der IMKK durch ein noch näher zu bestimmendes Völkerbundsgremium überwacht 'werden sollte ${ }^{404}$. Allerdings stieß die französische Note vom 11. August 1924, in der Herriot ein französisch-britisches Defensivbündnis - eventuell unter Einschluß Belgiens - im Rahmen des Völkerbunds vorschlug, das gegebenenfalls durch einen Nichtangriffspakt mit Deutschland ergänzt werden sollte, in London auf keine $\mathrm{Zu}$ stimmung ${ }^{405}$. Auch in der Schuldenfrage konnte sich Frankreich eine gewisse Entlastung schaffen, nachdem Clémentel erreicht hatte, daß im November 1924 eine Konferenz zur Regelung der interalliierten Schulden stattfinden sollte ${ }^{406}$.

Außerdem versuchte die französische Regierung, die Verhandlungen zur Ruhrräumung zu nutzen, um Gespräche über einen deutsch-französischen Handelsvertrag in Gang zu bringen ${ }^{407}$. Im Vorfeld der Londoner Konferenz hatte es die Reichsregierung, besonders das AA, durchaus erwogen, die Handelsvertragsverhandlungen als Kompensationsobjekt für die militärische Ruhrräumung zu nutzen. Allerdings stieß dies bei der deutschen Industrie auf Widerstand. Besonders die Verlängerung der zollfreien Einfuhrkontingente für Elsaß-Lothringen als Gegenleistung für eine militärische Räumung des Ruhrgebiets wurden abgelehnt: „Unter keinen Umständen dürfe die Frage des

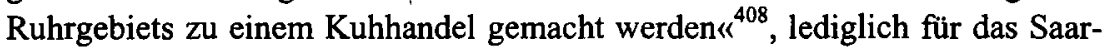
gebiet sollte eine Sonderregelung gelten. Der Reichsverband der Deutschen Industrie (RDI) forderte, erst nach dem Abschluß der Reparationsgespräche mit Handelsvertragsverhandlungen zu beginnen, um eine Vermengung von Reparations- und Handelsfragen zu vermeiden, damit die Interessen der deut-

${ }^{403}$ Siehe BARIÉTY, Relations franco-allemandes, S. 662.

${ }^{404}$ Siehe ibid. S. 638.

${ }^{405}$ Siehe WURM, Sicherheitspolitik, S. 197.

${ }^{406}$ Siehe BARIÉTY, Relations franco-allemandes, S. $638 f$.

${ }^{407}$ Siehe Aufzeichnung Seydoux für Clémentel (8.8.1924), MAE PAAP 261, 1.

${ }^{408}$ Protokoll der 3. Sitzung der Handelspolitischen Kommission des RDI (5.8.1924), BArch R 3101, 20458. 
schen Industrie besser geschützt würden. Dieser Ansicht schloß sich die Landwirtschaft grosso modo an ${ }^{409}$.

Nachdem aber ein Zeitplan für die Ruhrräumung festgelegt worden war, sank von deutscher Seite - wohl auch wegen des Drucks der Wirtschaftsverbände - das Interesse an Handelsvertragsverhandlungen rapide. Einziges greifbares Ergebnis diesbezüglich war, daß offizielle Handelsgespräche zwischen Deutschland und Frankreich am 1. Oktober 1924 beginnen sollten ${ }^{410}$. Nachdem schließlich eine Einigung darüber erzielt werden konnte, daß die belgischen und französischen Truppen binnen Jahresfrist das Ruhrgebiet verlassen sollten, konnte am 16. August 1924 die Londoner Konferenz beendet werden.

Gemäß den Verhandlungsschwerpunkten - Umsetzung des Dawes-Plans, Ruhrräumung und deutsch-französischer Handelsvertrag - lassen sich auch die Ergebnisse der Londoner Konferenz wie folgt zusammenfassen. Wichtigstes Ergebnis bezüglich des Dawes-Plans und der Reparationsfrage war sicherlich die wirtschaftliche Räumung des Ruhrgebiets und der besetzten Gebiete und die Widerherstellung der wirtschaftlichen, fiskalischen und administrativen Einheit des Deutschen Reiches ${ }^{411}$ : Bereits bevor der Dawes-Plan offiziell am 20. Oktober 1924 in Kraft trat, erließ die französische Regierung am 6. September 1924 eine Amnestie für alle Deutschen, die im Zusammenhang mit dem Ruhrkampf aus den besetzten Gebieten ausgewiesen worden waren. Ab dem 13. September konnten sie wieder auf ihren ursprünglichen Posten ihrer Arbeit nachgehen. Gleichzeitig begann die französische Regierung, dasjenige Personal bei den Streitkräften und der H.C.I.T.R. zu ersetzen, welches sich im Ruhrkampf und der Unterstützung der Separatisten besonders exponiert hatte. Am 20. September 1924 wurde die Erhebung der Kohlensteuer durch die französischen Besatzungsbehörden eingestellt, und tags darauf fiel die innerdeutsche Zollgrenze.

Kurz nach dem Inkrafttreten des Dawes-Plans stellte die M.I.C.U.M. am 21. Oktober 1924 ihre Arbeit ein, ab dem 28. Oktober wurden die beschlagnahmten Bergwerke zurückgegeben, die Zollverwaltung und die staatlichen Forste auf das Reich zurückübertragen. Die Eisenbahnregie wurde offiziell am 16. November 1924 aufgelöst.

Zweites wichtiges Ergebnis hinsichtlich der Reparationen war, daß der Einfluß der RepKo ebenso wie die Sanktionsmöglichkeiten im Falle der deutschen Nichterfüllung stark eingeschränkt wurden ${ }^{412}$. Besonders der französische Einflu $B$ in Reparationsangelegenheiten wurde merklich begrenzt: Die USA erhielten, durch die Person des Transferagenten, ein faktisches Veto gegenüber der RepKo in der Frage der vorsätzlichen Nichterfüllung des Dawes-

\footnotetext{
${ }^{409}$ Siehe REM Kanitz an deutsche Delegation London (11.8.1924), PAAA R, 105604.

${ }^{410}$ Siehe Aufzeichnung Seydoux (20.8.1924), MAE PAAP 261, 1. Siehe auch Kap. 4.2.2.

${ }^{411}$ Siehe JEANNESSON, Poincaré, S. 404f.

${ }^{412}$ Siehe KRÜGER, Außenpolitik, S. 245.
} 
Plans und sicherten sich so die Schlüsselrolle im neuen Reparationssystem, ohne sich selbst allzusehr politisch zu binden ${ }^{413}$. Ansonsten orientierte sich die in London verabschiedete Reparationsregelung an den bereits dargelegten Empfehlungen des Dawes-Gutachtens.

Aus französischer Perspektive stellten sich die Reparationsregelungen wie folgt dar: Man hatte zwar auf die in ihrer Legalität zweifelhaften wirtschaftlichen Druckmittel, wie die M.I.C.U.M., die Eisenbahnregie oder die direkte Ausbeutung von staatlichen Domänen usw. verzichten müssen, hatte diese Instrumente aber durch ein rechtlich einwandfreies System von Kontrollen und Pfändern, die sich nicht nur auf das besetzte Gebiet, sondern auf ganz Deutschland bezogen, ersetzen können. Obwohl die Kommerzialisienung der Obligationen vorerst ausblieb, waren die Reparationszahlungen an Frankreich verläßlicher geworden. Auch hinsichtlich der Sachlieferungen hatte Frankreich einige sehr vorteilhafte Regelungen erzielen können - dies galt vor allem für Kohlen und die Lieferung chemischer Grundstoffe -, die teilweise sogar über die Bestimmungen des Versailler Vertrags hinausgingen ${ }^{414}$. Zwar hatte Paris in bezug auf die RepKo und die Sanktionsmöglichkeiten einen deutlichen Einflußverlust hinnehmen müssen, doch war jetzt ein System etabliert worden, in das auch die USA, zumindest mittelbar, einbezogen worden waren ${ }^{415}$. In der Frage der interalliierten Schulden waren zumindest Gespräche vereinbart worden.

Wichtigstes Ergebnis bezüglich der Ruhrräumung war, daß ein verbindlicher Zeitplan vereinbart wurde ${ }^{416}$. Am 22. Oktober 1924 begann der Abzug der Besatzungstruppen, der am 25. August 1925 abgeschlossen war ${ }^{417}$. Neben den bereits angesprochenen reparationspolitischen Vorteilen hatte das Ende der Besetzung für Frankreich auch weitere Vorzüge: Es konnte seine Ausgaben fuir die Besatzungstruppen reduzieren und hatte von Großbritannien die $\mathrm{Zu}-$ sicherung erhalten, die Kölner Zone erst dann zu räumen, wenn die Entwaffnung Deutschlands durch die IMKK bestätigt würde. Daneben standen allgemeine Zusagen über die Fortführung der Entwaffnungskontrolle durch den Völkerbund und ein Ausbau desselben im Sinne der Gewährleistung von kollektiver Sicherheit.

Die Bewertung des Dawes-Plans soll aus vier Blickwinkeln vorgenommen werden: Aus der Sicht Frankreichs, aus deutscher Perspektive - wobei die Frage nach den Begrenzungen, die der Dawes-Plan für die Revisionspolitik mit sich brachte, besonders erörtert werden wird - und hinsichtlich der Ein-

\footnotetext{
${ }^{413}$ Siehe LINK, Ruhrkonflikt, S. $48 \mathrm{f}$.

${ }^{414}$ Siehe BARIÉTY, Relations franco-allemandes, S. 708.

${ }^{415}$ Siehe HERRIOT, Jadis, S. 162.

${ }^{416} \mathrm{Vgl}$. hierzu den Briefwechsel zwischen der deutschen, französischen und belgischen Regierung, Weißbuch Londoner Konferenz, Nr. 54-58.

${ }^{417}$ Siehe JEANNESSON, Poincaré, S. 405.
} 
flußmöglichkeiten der englischen und amerikanischen Bankiers auf die Verhandlungsmöglichkeiten, also die sogenannte »Dollardiplomatie«. Last but not least soll gefragt werden, welche Bedeutung der Dawes-Plan für den Prozeß der Modernisierung der Außenpolitik hatte.

Beginnen wir mit Frankreich. Herriot und seiner Politik wurde von Bariéty $^{418}$, Artaud ${ }^{419}$ und anderen ein ziemlich schlechtes Zeugnis ausgestellt. "[Ils] ont souligné l'amateurisme d'Herriot, son manque de connaissance des dossiers et sa faible pugnacité ${ }^{420}$. Andere, wie Girault ${ }^{421}$ und Jeannesson ${ }^{422}$, haben darauf hingewiesen, daß Herriot zumindest hinsichtlich der Kohlenversorgung gute und wichtige Ergebnisse für Frankreich erzielt habe ${ }^{423}$. Berstein ${ }^{424}$ betont zudem, daß Herriots Politik zu oft lediglich aus der Perspektive Poincarés beurteilt wurde, zumal, wie wir im vorherigen Kapitel festgestellt haben, Poincaré vielleicht weniger poincaréistisch war als allgemein angenommen. Die Aufgabe der französischen Pressionsmittel sei eben auch deshalb erfolgt, weil Herriot diese teilweise für moralisch bedenklich hielt, und er der Überzeugung war, daß sich Frankreich auf Dauer eine unilaterale Politik der Pression nicht würde leisten können, ohne die existentiell wichtigen französischbritischen Beziehungen zu gefährden ${ }^{425}$.

Zur etwas positiveren Beurteilung der Politik Herriots trug auch bei, daß die schwierigen wirtschaftlichen und politischen Rahmenbedingungen und die relativ kurze Einarbeitungszeit seiner Regierung hervorgehoben wurden ${ }^{426}$. Auf die beiden wichtigsten Aspekte, die parlamentarische Schwäche der Regierung Herriot und die wirtschaftlichen Schwierigkeiten, die vor allem durch die Franc-Krise hervorgerufen wurden, wurde bereits mehrfach hingewiesen. Sicherlich sind handwerkliche Fehler gemacht worden: Die Zusammensetzung der französischen Delegation war sehr heterogen ${ }^{427}$. Neben Militärs wie Desticker und Kriegsminister Nollet, die die militärische Besetzung unbedingt aufrechterhalten wollten, traten halboffizielle Mitglieder der S.F.I.O., die die Delegation nach London begleitet hatten und die den Abzug der französischen Truppen forderten. Es bleibt allerdings zu fragen, ob aufgrund der schwierigen parlamentarischen Lage die Heterogenität der Delegation überhaupt vermeidbar war. Allerdings war die Schwäche von Herriots Position in London nicht

\footnotetext{
${ }^{418}$ Siehe BARIÉTY, Relations franco-allemandes, S. $378 \mathrm{f}$.

${ }^{419}$ Siehe ARTAUD, Dettes interalliées, S. 666-668.

${ }^{420}$ MONIER, Années 20, S. 123.

${ }^{421}$ GiRAULT, Europe, S. $139 f$.

${ }^{422}$ Siehe JEANNESSON, Poincaré, S. 403f. Selbst Bariéty zollt Herriot in dieser Frage Zustimmung: BARIÉTY, Relations franco-allemandes, S. 708.

${ }^{423}$ Siehe MONIER, Années 20, S. 123.

${ }^{424}$ Siehe BERSTEIN, Herriot, S. 118.

${ }^{425}$ Siehe GiRAulT, Europe, S. 139.

${ }^{426}$ Siehe JEANNESSON, Poincaré, S. 405.

${ }^{427}$ Siehe WURM, Sicherheitspolitik, S. 194.
} 
nur von Nachteil für seine Politik, wie sich bereits im Vorfeld des DawesPlans gezeigt hatte: Die deutsche Regierung - sich durchaus der prekären Lage Herriots zu Hause bewußt - machte beispielsweise in ihrer Note vom 30. Juni 1924 in der Frage der Militärkontrolle Zugeständnisse, weil sie ein Interesse daran hatte, Herriot zumindest bis zur Annahme des Dawes-Plans im Amt zu halten. Stresemann führte vor dem Kabinett aus: "Wichtig sei die Frage, ob MacDonald und Herriot sich halten werden. Herriot sei nach den Mitteilungen von Herrn Hoesch ein ideologisch denkender Radikaler ${ }^{428}$. Mit seinem Sturz im Oktober sei zu rechnen, darum müßten wir bis dahin alles, was wir könnten, herausholen « ${ }^{429}$. Die Bewertung der Ergebnisse der Londoner Konferenz für Frankreich läßt es meines Erachtens nicht angezeigt erscheinen, von einem Mißerfolg für Frankreich zu sprechen ${ }^{430}$. Dies gilt nicht nur für die bereits erwähnten Sachlieferungen. Erstmals seit dem Krieg konnte Frankreich auf regelmäßig eintreffende Reparationszahlungen in erheblichem Umfang nicht nur hoffen, sondern zählen. Die in ihrer Legalität doch recht zweifelhaften Pfänder und Garantien Frankreichs aus dem Ruhrkampf - also die M.I.C.U.M., die Eisenbahnregie, die Zolleinnahmen im besetzten Gebiet, die direkte Ausbeutung von Bergwerken, Forsten usw. - wurden durch ein rechtlich einwandfreies, von allen Beteiligten einschließlich der USA und Deutschlands akzeptiertes Generalpfand ersetzt, das aus der Verpfändung von Staatseinnahmen, vor allem aber aus den Eisenbahn- und Industrieobligationen bestand. Es wurden Kontrollorgane etabliert, in denen Frankreich zwar nicht mehr ein so drückendes Übergewicht hatte wie beispielsweise in der RepKo, und auch die Möglichkeit der Sanktionen wurde stark eingeschränkt, aber auch hier galt, daß ein System geschaffen wurde, das die USA und Deutschland einbezog, dessen Legalität zweifelsfrei war, das allgemein akzeptiert wurde und sich nicht nur auf die besetzten Gebiete, sondern die gesamte deutsche Volkswirtschaft bezog. Angesichts dieser Vorteile ist die Abgabe von individuellem Handlungsspielraum durch die französische Regierung, der sich selbst im Ruhrkampf als relativ begrenzt erwies, wohl zu verschmerzen. Dabei soll jedoch nicht unterschlagen werden, daß die ganze Reparationsregelung so lange unvollständig blieb, bis die Obligationen nicht mobilisiert würden. In der damaligen Situation, im: August 1924, stellte das Dawes-

\footnotetext{
${ }^{428}$ Hier natürlich gemeint im Sinne des Programms der radikalen Partei.

${ }^{429}$ Ministerbesprechung (25.6.1924), AdR Marx VII Bd. 2, Nr. 234.

${ }^{430}$ Anders wiederum Bariéty: "Die historische Bedeutung des Dawes-Plans ist nach unserer Auffassung dies: er schafft eine faktische wirtschaftliche Solidarität zwischen Deutschland, England und Amerika, um die politischen Ambitionen Frankreichs zurückzudrängen«, Jacques BARIÉTY, Der Platz Frankreichs in der Westorientierung der Weimarer Republik während ihrer Stabilisationsphase (1924-1929), in: Wolfgang MrCHALKA, Marshall M. LEE (Hg.), Gustav Stresemann, Darmstadt 1982 (Wege der Forschung, 539), S. 304-323, hier S. 315.
} 
Abkommen also für Frankreich einen großen wirtschaftlichen, aber auch politischen Fortschritt dar ${ }^{431}$.

Für die Bewertung der Ruhrräumung gilt ebenfalls, daß ein in seiner Rechtmäßigkeit umstrittenes Instrument in ein legales umgewandelt wurde, das den Vorteil hatte, auch von den Engländern getragen zu werden. Die Fortsetzung der Besetzung hätte Frankreich weiterhin von den angelsächsischen Mächten isoliert. Herriot stellt dazu fest: "Toute mon action extérieure, de quelque façon on la juge, a été dominé par le souvenir de concours dont la France avait eu besoin, entre 1914 et 1918, et par cette idée que, si elle était attaquée de nouveau, elle ne pourrait pas triompher seule d'un ennemi supérieur en nombre et féroce « ${ }^{432}$.

Meiner Meinung nach ist das Ergebnis, die Besetzung der Kölner Zone so lange aufrechtzuerhalten, bis die deutsche Entwaffnung zweifelsfrei festgestellt wurde, wesentlich wertvoller als die stillschweigende Hinnahme der in ihrer Rechtmäßigkeit nicht nur von England angezweifelten Ruhrbesetzung ${ }^{433}$. Zum Zeitpunkt, als der Dawes-Plan in Kraft trat, paßte die Ruhrbesetzung einfach nicht mehr in die Zeit, ihre Aufgabe durch Herriot war kein Zeichen der Schwäche, sondern nur logisch ${ }^{434}$, zumal Poincaré selbst mit der prinzipiellen Annahme des Dawes-Plans im April 1924 »die Rechtsgrundlage für seine Politik der produktiven Pfänder an der Ruhr aufgegeben [hatte] - auch wenn Poincaré dies vielleicht auch nicht wahrhaben wollte ${ }^{435}$. Vielleicht ist gerade das der Grund, weshalb er selbst die Außenpolitik Herriots nicht kritisierte ${ }^{436}$.

Auch ist fraglich, ob der Verzicht Herriots auf die Verknüpfung von Reparations-, Schulden- und Sicherheitsfrage eine entscheidende Schwächung der französischen Position in London bedeutet hat und falls ja, ob diese Schwächung nicht unausweichlich war. Die Ausklammerung der Schulden- und Sicherheitsproblematik lag in der Logik des Dawes-Plans. Poincaré selbst hatte bei der Formulierung des Arbeitsauftrages für die Dawes-Kommission dafür gesorgt, daß diese nicht Thema wurden. Zwar war seine Intention dabei, die anderen Pfänder in der Hinterhand zu behalten, er konnte aber nicht verhindern, daß der Dawes-Plan - inklusive der Beschränkung auf die Reparationsfrage - eine Eigendynamik entwickelte, die eine Einbeziehung der Sicher-

431 Was im RWiM übrigens genauso gesehen wurde, siehe Aufzeichnung Lautenbach (19.7.1924), BArch R 3101, 20437. Siehe auch BERSTEIN, Herriot, S. 119.

${ }_{432}$ HERRIOT, Jadis, Bd. 2, S. 164.

${ }^{433}$ Noch am 16.8.1924 hatte die britische Regierung der belgischen und französischen Regierung mitgeteilt, daß »[d]ie britische Regierung [...] die Rechtmäßigkeit der Ruhrbesetzung oder die Auslegung des Versailler Vertrags, auf die ihre Alliierten ihr Vorgehen gestützt haben, niemals anerkannt [hat] $\ll$, MacDonald an Marx, Weißbuch Londoner Konferenz, Nr. 59.

${ }^{434}$ So auch MONIER, Années 20, S. 123 und JEANNESSON, Poincaré, S. 403.

${ }^{435}$ SCHWABE, Ruhrkrise, S. 76.

${ }^{436}$ Siehe BARIÉTY, Relations franco-allemandes, S. 490. 
heitsprobleme und der Kriegsschulden schwierig machte. Der Dawes-Plan war eben nicht nur ein unteilbares Ganzes - man konnte auch nicht ohne weiteres draufsatteln, ohne ihn zu gefährden. Ich bin durchaus der Ansicht, daß - neben anderen Gründen - eine wesentliche Ursache dafür, daß die Reparationsfrage bis zum Dawes-Plan nicht geregelt werden konnte, darin lag, daß die Frage der Reparationen im Zusammenhang mit zu vielen anderen Fragen, vor allem denen der Sicherheit, betrachtet wurde. Es waren einfach zu viele Bälle in der Luft, die die Beteiligten unmöglich alle gleichzeitig jonglieren konnten. Es mag sein, daß durch den Verzicht auf die Verknüpfung von Dawes-Plan, Sicherheit und Schulden die französische Verhandlungsposition geschwächt worden ist. Ein Scheitern der Londoner Konferenz infolge der Überfrachtung durch alle diese Probleme wäre jedoch noch weniger im französischen Interesse gewesen, zumal Paris in der Frage der Entwaffnung und Räumung der Kölner Zone wichtige Zugeständnisse erreichen konnte und für andere Probleme, wie die Schuldenfrage und die Sicherheit, zumindest Zusagen erhalten hatte. $\mathrm{Daß}$ beispielsweise das Genfer Protokoll, das die Sicherheitslage Frankreichs erheblich verbessert hätte und im September 1924 im Völkerbund diskutiert wurde, scheitern würde, war am 16. August 1924, dem letzten Tag der Londoner Konferenz, beim besten Willen nicht vorhersehbar.

Die Vorteile, die die Londoner Konferenz Deutschland bescherte, waren evident ${ }^{437}$ : Im Ruhrgebiet und den übrigen besetzten Gebieten wurde die deutsche Wirtschafts-, Finanz- und Verwaltungshoheit wiederhergestellt und die Ausgewiesenen konnten zurückkehren. Für die Räumung des Ruhrgebiets lag ein verbindlicher Plan vor - sie sollte innerhalb eines Jahres abgeschlossen werden -, und die Sanktionsmöglichkeiten Frankreichs wurden erheblich eingeschränkt. Durch die 800 Mio. GM Anleihe wurde die wirtschaftliche Konsolidierung und die Währungsstabilisierung abgesichert und Deutschland als Anlageplatz für ausländische Investitionen geöffnet. Allerdings ging mit dieser Anleihe auch ein verstärkter Einfluß der USA und Großbritannien auf die deutsche Wirtschaft und Politik einher ${ }^{438}$. Dies war zwar - als Gegengewicht zu Frankreich - durchaus erwünscht, stellte aber nichtsdestotrotz einen Verlust an eigener Manövrierfähigkeit dar, der durch die internationale Kontrolle von Reichsbahn und Reichsbank verstärkt wurde. Die schwebende Kommerzialisierung der Eisenbahn- und Industrieobligationen konnte darüber hinaus zu einer weiteren, wenn auch zunächst nur potentiell schweren Belastung für die deutsche Reparationspolitik werden. Auch durch den Dawes-Plan blieb die Reparationsbelastung hoch. Der schwerwiegendste Fehler des Reparationssystems bestand darin, daß es sich nicht an der Handelsbilanz, sondern an der Zahlungsbilanz orientierte ${ }^{439}$, die aufgrund der nach Deutschland strömenden

${ }^{437}$ Siehe NIEDHART, Internationale Beziehungen, S. 60.

${ }^{438}$ Siehe JEANNESSON, Poincaré, S. 78.

${ }^{439}$ Siehe Johannes HOUWINK TEN CATE, Hjalmar Schacht als Reparationspolitiker (1926- 
Auslandskredite künstlich geschönt war. Geflissentlich übersehen wurde dabei, daß für Deutschland langfristig der einzige Weg, die Reparationen zahlen zu können, nur darin bestehen konnte, Außenhandelsüberschüsse zu erzielen. Hier rächte sich, daß die Sachverständigen des Dawes-Plans weitaus stärker Finanz-, nicht aber unbedingt Wirtschaftsexperten waren und deshalb sehr viel stärker auf monetäre Größen achteten als auf realwirtschaftliche. Außerdem bezogen sie deshalb natürlich auch stärker die Interessen der Bankiers - und nicht die der Gesamtwirtschaft - in ihre Betrachtungen ein. Die volkswirtschaftlichen Folgen dieser Perspektive sind bekannt: Hohe Zinsen und beständiger Devisenabfluß verlangsamten die Investitionstätigkeit in Deutschland und verzögerten den Abbau der durch Kriegswirtschaft und Inflation geschaffenen Strukturprobleme der deutschen Wirtschaft - mit auch sozial und gesellschaftlich ernsten Konsequenzen, da die Verteilungsspielräume klein waren und die Verteilungskämpfe entsprechend größer wurden. Auch die Rolle des Reparationsagenten war für die deutsche Politik und Wirtschaft nicht unproblematisch. Qua Amt sollte er dafür sorgen, daß der Wert der deutschen Währung stabil blieb und konnte, falls er das nicht gewährleistet sah, ein Moratorium bewirken. Dies bedeutete aber auch den permanenten Appell an eine sparsame Haushaltspolitik (und somit tendenziell eine Verringerung der öffentlichen Investitionen) und eine restriktive Geldpolitik (also wiederum hohe Zinsen). Außerdem war die Möglichkeit eines Moratoriums für Reparationszahlungen in der Realität stark eingeschränkt und - paradoxerweise - nicht in deutschem Interesse. Das Signal eines solchen Schrittes hätte auf ausländische Anleger verheerend gewirkt und vermutlich zu einem Abzug ausländischen Kapitals aus Deutschland geführt - wo Geld sowieso knapp war.

Für eine Außenpolitik, die sich vor allem auf wirtschaftliche Macht stützte, hatte diese Reparationsregelung also mehrere wichtige Konsequenzen. Wegen der Beschränkungen in der Geldpolitik - Geld ist und bleibt nun mal das Schmiermittel der Wirtschaft - konnte das deutsche wirtschaftliche Potential nicht voll genutzt werden. Die dadurch erzeugten strukturellen Probleme (relativ hohe Arbeitslosigkeit, geringe Verteilungsspielräume in der Sozialpolitik) förderten tendenziell die bereits vorhandene Instabilität des politischen Systems und schadeten damit wiederum auch der Außenpolitik. Die Reparationen zementierten zumindest die Ungleichgewichte im Welthandelssystem und erschwerten dadurch die von Deutschland verfolgte Politik des wirtschaftlichen Interessenausgleichs, die durch eine liberale Handelspolitik befördert werden sollte. So sehr viel besser das vom Dawes-Plan etablierte System der Reparationszahlungen auch sein mochte als alles vorherige: Das Problem bestand eben nicht darin, einen austarierten Mechanismus für die Aufbringung und Transferierung der Reparationen zu erdenken, das Problem waren und 
blieben die Reparationen selbst, ganz abgesehen einmal von dem politischmoralischen Komplex, der an dieser Frage hing.

Auch in einer anderen Hinsicht bedeutete der Dawes-Plan eine Einschränkung der Wirkungsmöglichkeiten deutscher Außenpolitik. Mit der Anerkennung des Dawes-Plans und dem erklärten Willen zu seiner Durchsetzung hatte Deutschland auch die Regeln des Versailler Vertrags akzeptiert. Natürlich stand es Deutschland immer noch frei, den Versailler Vertrag zu umgehen, nach den Erfahrungen des Ruhrkampfs, des wirtschaftlichen Ruins und des drohenden Zerfalls der Reichseinheit war das allerdings eine wenig verlockende Aussicht. Dadurch beschränkte sich der deutsche Spielraum in der Frage der Revision des Versailler Vertrags nur noch auf Mittel, die im Vertrag selbst vorgesehen waren oder mit den Vertragspartnern verhandelt werden konnten.

Verglichen mit der geradezu verzweifelten Lage Deutschlands im Ruhrkampf bedeutete der Dawes-Plan natürlich eine entscheidende Verbesserung und Konsolidierung der deutschen Situation und der Verhandlungserfolg der deutschen Delegation war unbestreitbar. Die politischen Vorteile der Wiederherstellung der wirtschaftlichen, fiskalischen und administrativen Souveränität und der Abzug der Besatzungstruppen aus der Ruhr lagen auf der Hand, und auch wirtschaftlich bedeutete das Ende der Zwangsmaßnahmen eine wesentliche Verbesserung der Lage, so daß selbst Teile der DNVP den Ergebnissen der Londoner Konferenz nicht ihre Zustimmung verweigern konnten ${ }^{440}$.

Andererseits war diese Konsolidierung durch die genannten Faktoren stark beschränkt und bedeutete keinesfalls den Anfang vom Ende des Versailler Vertrags. Im Grunde genommen stand das durch den Versailler Vertrag entworfene System niemals so nahe an seiner Vollendung wie nach der Londoner Konferenz: Die Reparationen flossen, der Wirtschaftsriese Deutschland lag gefesselt, der territoriale Status quo war für den Moment wenigstens anerkannt, die ehemals mächtige deutsche Armee war weitgehend entwaffnet und in der Sicherheitsfrage schien sich eine Lösung im Rahmen des Völkerbunds

440. Otto Hoetzsch, selbst MdR für die DNVP, begründete seine Zustimmung wie folgt: Die Beteiligung der USA bedeute die "Drehungen in der Weltkonstellation zu Deutschlands Gunsten«, die erst die Revision des Versailler Vertrags ermögliche. Erst durch den Druck der DNVP sei die militärische Räumung des Ruhrgebiets erreicht worden, eine Ablehnung des Dawes-Plans hätte dagegen schwere Schäden für die deutsche Wirtschaft und die besetzten Gebiete bedeutet; außerdem hätte eine Ablehnung des Dawes-Plans die Auflösung des Reichstags zur Folge gehabt mit der wahrscheinlichen Konsequenz einer großen Koalition, die es zu verhindern gelte. Das Wiederaufflammen des Separatismus im Rheinland, die Moglichkeit der Regierungsbeteiligung der DNVP und das Entgegenkommen der Reichsregierung bzgl. der Forderungen der DNVP, besonders in der Kriegsschuldfrage, seien weitere Gründe für die Annahme der Ergebnisse der Londoner Konferenz gewesen. „Die äußere Politik der Woche (das deutschnationale Ja zum Londoner Pakt)«, Kreuz-Zeitung (3.9.1924). Ausführlich zur Kampagne zur Annahme der Dawes-Gesetze: BAECHLER, Stresemann, S. 551-556. 
anzudeuten, die eine wirksame und dauerhafte Integration Deutschlands bewirken konnte. Außerdem waren die USA, nachdem sie den Versailler Vertrag nicht ratifiziert hatten, durch die Reparationsfrage zumindest teilweise wieder in Europa engagiert.

Einige Worte noch zum Einfluß der Bankiers und generell zum Einfluß von wirtschaftlichen Interessen auf die Gestaltung des Dawes-Plans und den Verlauf der Londoner Konferenz. Es ergibt sich in der Tat der Eindruck, daß »[1]a diplomatie du dollar et des banquiers veut réussir là ou celle des gouvernements et des conférences internationales a échoué « ${ }^{441}$.

Ganz so einfach war es jedoch nicht. Die Entscheidung, eine Kommission von Wirtschaftsexperten einzusetzen und deren Empfehlungen anzunehmen, war eine überaus politische. Auch die Auswahl der Experten erfolgte nach politischen Kriterien. Es handelte sich deshalb zwar nicht um die Unterordnung der Wirtschaft und speziell der Bankiers unter die Politik, denn nachdem sich die Regierungen darauf verständigt hatten, den Wirtschaftsexperten die Lösung der Reparationsfrage zu übertragen, erlangten letztere natürlich eine gewisse Autorität in dieser Frage, die ihnen in letzter Konsequenz allerdings wiederum von der Politik zuvor zugewiesen worden war. Bariéty stellt treffend fest, daß

le recours aux experts juridiques, comme aux experts économistes ou banquiers d'ailleurs, apparaît comme un moyen, pour les politiques, de sortir d'une difficulté et d'un dilemme, en leur permettant de se retrancher derrière un avis qui, puisqu'il est émis par des experts, ne saurait être fondé, et doit donc correspondre à une nécessité inéluctable devant laquelle les politiques, quoi qu'ils aient, ne peuvent que s'incliner. C'est le recours à la technique pour emporter, ou couvrir, une décision politique; [...]. L'intermède juridique prend place dans l'opération politique d'ensemble ${ }^{422}$.

Die Einbeziehung von Experten ist also ein politisches Mittel, durch das die Notwendigkeit bestimmter (besonders: unliebsamer) Maßnahmen der Öffentlichkeit dadurch schmackhaft gemacht werden soll, daß die scheinbare objektive Richtigkeit einer Politik demonstriert wird. Bei allem Sachverstand der Experten ist dies natürlich zum Gutteil Fiktion. Auch für Fachleute stellen sich Bewertungs- und Interpretationsprobleme, so daß auch ihre Entscheidungen letztendlich nicht völlig objektiv sind und sein können. Allerdings kann auch die nur scheinbare Objektivierung eines Problems zu dessen Lösung beitragen. Von daher ist der Rückgriff auf Experten eben nur zum Teil ein Manöver, aber eben auch eine Problemlösungsstrategie.

Im Falle des Dawes-Plans haben wir außerdem gesehen, daß die Einbeziehung der Experten die Lösung des Reparationsproblems nicht nur deshalb leichter gemacht hat, weil es scheinbar oder tatsächlich objektiver betrachtet

441 JEANNESSON, Poincaré, S. 396.

442 BARIÉTY, Relations franco-allemandes, S. 593. 
wurde. Die Einsetzung der Fachleute bewirkte auch eine deutliche Eingrenzung des Themas, indem die Schulden- und die Sicherheitsfrage explizit von den Reparationen getrennt wurde. Durch diese Beschränkung wurde es erstmals möglich, einheitliche Maßstäbe an die Beurteilung des Reparationsproblems anzulegen. Die Übertragung des Themas Reparationen an Wirtschaftsexperten bedeutete: Der Maßstab zur Bewertung des Problems war nun ein ökonomischer, und die Methode zur Lösung des Problems war eine ökonomische. $\mathrm{Da}$ die Experten alle einen recht vergleichbaren professionellen und intellektuellen Hintergrund hatten, fiel es ihnen außerdem natürlich leichter, zu einer Lösung zu kommen. Wie gesagt, die internationalen Konferenzen zwischen 1919 und 1922 krankten eben auch daran, daß sie sich stets mit zu vielen Themen befaßten, und es zu viele unterschiedliche Bewertungsmaßstäbe gab. Natürlich hatten die Reparationen auch einen sicherheitspolitischen Aspekt. Wenn aber die eine Seite die Reparationen aus sicherheitspolitischer Sicht beurteilt und die andere aus ökonomischer, ist eine Einigung nur schwer möglich, denn unter Umständen besteht zwischen Sicherheit einerseits und Wohlstandsmaximierung andererseits ein nicht unerheblicher Zielkonflikt.

Die Einbeziehung von Experten trug also deshalb zum Erfolg des DawesPlans und der Londoner Konferenz bei, weil alle Beteiligten die Fiktion der Objektivität der Experten anerkannten, und das Problem auf eine einheitliche - das heißt in diesem Fall wirtschaftliche - Betrachtungsweise eingeschränkt wurde.

Die Einbeziehung von Experten ist selbstverständlich nicht unproblematisch. Neben dem philosophischen Aspekt der Objektivierbarkeit von Problemen und der Frage, ob Fachleute nicht bloß ein Teil des politischen Spiels sind, stellt sich natürlich auch das Problem der Legitimität. Sie sind nicht gewählt, sie werden ernannt, und zwar in der Regel von Regierungen, die nur einen Teil der politischen Öffentlichkeit, nämlich in der Regel deren Mehrheit, repräsentieren. Indem Aufgaben an Experten übertragen werden, entziehen sie sich außerdem der politischen Kontrolle, die Politik gibt Einflußmöglichkeiten zumindest teilweise auf und begibt sich in ein bestimmtes Abhängigkeitsverhältnis zu den Fachleuten. Die Politik wiederum kann unter dem Verweis auf die Expertenmeinung Verantwortung und Schuldzuweisungen abwälzen. Zu einem Gutteil sind diese Probleme - bei komplexer werdenden politischen, gesellschaftlichen und wirtschaftlichen Fragestellungen - sicherlich unvermeidbar. Die Frage, ob die Einsetzung einer Expertenkommission gerechtfertigt und legitim war, oder inwieweit sie ein politisches Verschleierungsmanöver darstellte, muß also stets fur den Einzelfall beantwortet werden.

Dies gilt auch für das Problem, ob und inwieweit die Beschränkung des Arbeitsauftrages für die Experten zulässig ist oder nicht. Wie dargestellt, lag eine Ursache des Erfolges des Dawes-Plans darin begründet, daß die Experten einen genau definierten Arbeitsauftrag hatten und andere schwebende Probleme 
ausgeklammert worden waren. Diese Einschränkung hatte aber auch zur Folge, daß das Kardinalproblem der Reparationen - ihr wirtschaftlicher Sinn oder Unsinn - nicht behandelt wurde. Ihr Auftrag lautete lediglich, die geeigneten Mittel für die Reparationsleistung und -übertragung zu finden, nicht zu untersuchen, welchen Einfluß die Reparationen auf das Welthandels- und Währungssystem hatten - wie Keynes das getan hatte. Der schädliche Einfluß der Reparationen generell war es jedoch, der die wirtschaftliche Erholung vor allem in Deutschland - mit seinen negativen sozialen und politischen Konsequenzen - beschränkte. Da half es wenig, daß die Methoden zur Aufbringung und Übertragung der Reparationen verbessert wurden. Andererseits - das zeigte die unterschiedliche Diskussion um Keynes' "The Economic Consequences of the Peace« in Frankreich und in Deutschland - war die Zeit noch nicht gekommen, um die Reparationen als solche in Frage zu stellen. Dies hatte Deutschland im Ruhrkampf bitter erfahren müssen. Insofern stellte der DawesPlan unter den gegebenen Umständen eine tragbare Zwischenlösung für das Problem der Reparationen und den Wiederaufbau der weltwirtschaftlichen Strukturen dar, vor allem im Hinblick auf die schwierige Nachkriegszeit, mehr aber auch nicht.

Welche Folgen hatten Ruhrkampf, Dawes-Plan und Londoner Konferenz für die Modernisierung der Außenpolitik? Orientieren wir uns an den drei Hauptlinien des liberalen Modells der Friedenssicherung - kollektive Sicherheit, wirtschaftliche Liberalisierung und Demokratisierung -, so ist die Bilanz relativ ernüchternd.

Bezüglich der Gewährleistung von Sicherheit hatte der Dawes-Plan zu kaum greifbaren Ergebnissen geführt: Es gab eine vage Zusicherung der englischen Regierung, die Sicherheitsfrage im Rahmen des Völkerbunds unter Einbeziehung Deutschlands zu erörtern. Außerdem war die Sicherheitslage in Europa durch die konstruktive Atmosphäre, in der die Londoner Konferenz stattgefunden hatte, und infolge der Erkenntnis, daß die Machtpolitik des Ruhrkampfs nichts eingebracht hatte und die Lösung durch Verhandlungen erreicht werden mußte, verbessert worden. Auch das stärkere Engagement der USA und Großbritanniens, das aber weitgehend ökonomisch blieb, dürfte die Sicherheitslage in Europa konsolidiert haben. Diesem Mehr an Sicherheit in Westeuropa stand ein Weniger an Sicherheit für Frankreich gegenüber: Paris hatte auf wichtige Druckmittel ökonomischer und militärischer Art freiwillig verzichtet oder verzichten müssen, dies galt vor allem für die im Zusammenhang mit der Ruhrbesetzung ergriffenen Maßnahmen. Auch führte der DawesPlan zu einem Wiedererstarken Deutschlands - was die Position Frankreichs relativ schwächte. Der Dawes-Plan führte jedoch auch dazu, daß die Bündnisse Frankreichs mit den Staaten Osteuropas und das deutsche Verhältnis zur Sowjetunion abgeschwächt wurden: Sowohl für Frankreich als auch für Deutschland bedeutete der Dawes-Plan eine stärkere Orientierung nach We- 
sten, ohne daß dadurch jedoch die Beziehungen zur Kleinen Entente bzw. zur Sowjetunion nachhaltig belastet wurden. Im Sinne unseres Modells der Friedenssicherung ist diese Entwicklung der Relativierung der jeweiligen Partner im Osten insofern als positiv zu werten, als zwei potentiell gegeneinander gerichtete Staatenverbände (Frankreich und Polen und in geringerem Maße auch die Kleine Entente gegen Deutschland und die Sowjetunion, die wiederum ihren Hauptgegner in Polen sahen) geschwächt wurden. Ein kollektives Sicherheitssystem, das dauerhaften Frieden in Europa in Aussicht hätte stellen können, war mit dem Dawes-Plan aber noch nicht in Sicht, auch wenn sich die Grundlagen dafür verbessert hatten.

Bezüglich der Sicherheit kann man also zusammenfassend sagen, daß es durch den Dawes-Plan zwar gesamteuropäisch eine gewisse Konsolidierung gegeben hatte, daß die Sicherheitslage Frankreichs sich aber - verglichen mit dem Jahr 1923 - eher verschlechtert hatte. Bezuiglich des Aufbaus von kollektiven Sicherheitsstrukturen bedeutete der Dawes-Plan keinen Fortschritt, weil dadurch die Sicherheitsfrage weitgehend ausgeklammert wurde, und diese erst im Anschluß daran erörtert werden sollte.

Auch bezüglich der zweiten Säule des liberalen Friedensmodells blieben die Ergebnisse der Londoner Konferenz bruchstückhaft: Die wirtschaftliche Erholung Europas und die Wiederherstellung eines relativ freien Welthandels erfolgte nur zögerlich. Zwar hatte der Expertenplan die Aufbringung der Reparationen leichter gemacht und zu Entlastungen gefuhrt. Mit dem Amt des Generalagenten wurde zudem versucht, die negativen Aspekte der Transfers einzudämmen. Dies änderte jedoch nur wenig an der Tatsache, daß die Reparationen (und auch die Kriegsschulden) selbst ein zentrales Hindernis für die wirtschaftliche Gesundung Deutschlands und Europas bildeten. Ein gewisser Hoffnungsschimmer ließ sich immerhin erkennen, und zwar in Form der Handelsvertragsverhandlungen zwischen Deutschland und den westlichen Mächten: Zwischen Deutschland und den USA war es bereits Ende 1923 zu einem Handelsvertrag gekommen, zwischen Deutschland und Großbritannien wurde bis zum Ende des Jahres 1924 ein Abschluß erreicht. Auch zwischen Deutschland und Frankreich sollten, wie in London vereinbart, im Oktober 1924 Handelsgespräche beginnen ${ }^{443}$. Auch in diesem Bereich der Modernisierung der Außenpolitik blieben die Ergebnisse der Londoner Konferenz also spärlich.

Der Einfluß der Ereignisse der Jahre 1923 und 1924 auf die Demokratie in Deutschland, die man zu Recht als einen wesentlichen Faktor der Friedenssicherung für ganz Europa sehen muß, waren gemischt: Zwar hatte die Demokratie in Deutschland den Ruhrkampf gerade noch überlebt, und durch die ausländischen Finanzspritzen im Zuge des Dawes-Plans wurde zweifelsohne eine gewisse Erholung der deutschen Wirtschaft erreicht, die wiederum stabilisie- 
rend auf die deutsche Gesellschaft gewirkt haben dürfte. Allerdings darf auch nicht vergessen werden, daß der Ruhrkampf und seine Folgen das demokratische System in Deutschland nachhaltig geschädigt haben dürften. Die Folgen der Hyperinflation des Jahres 1923 für die deutsche Gesellschaft und das republikanische System waren verheerend. Die Praxis der Regierung Stresemann, mittels Notverordnung zu regieren, deutete darüber hinaus an, wie wenig krisenfest die demokratischen Institutionen in Deutschland waren. In den Reichstagswahlen vom Mai 1924 profitierten dann auch nicht die Regierungsparteien, sondern vor allem die rechte DNVP. Der Dawes-Plan selbst wiederum trug dazu bei, daß sich, wegen der hohen budgetären Belastungen durch die Reparationen und ihre Auswirkungen auf die Geldpolitik des Deutschen Reiches, die wirtschaftliche Erholung des Reiches und damit auch die gesellschaftliche Konsolidierung verzögerte.

Für die Modernisierung der Außenpolitik waren die Ergebnisse des DawesPlans also sehr begrenzt, teilweise widersprüchlich und bedeuteten lediglich einen Anfang für einen weitergehenden Modernisierungsprozeß. Der eigentliche Wert des Dawes-Plans bestand denn auch nicht so sehr im konkret Erreichten, sondern vielmehr im Methodischen. Nach dem Ruhrkampf und den einseitigen Maßnahmen vor allem Frankreichs und Belgiens gegenüber Deutschland bedeutete der Dawes-Plan den eigentlichen Beginn der multilateralen Konferenzdiplomatie nach dem Ersten Weltkrieg. Warum nur den Beginn? Natürlich war Deutschland zu den Verhandlungen eingeladen, aber die Zweiteilung der Konferenz machte deutlich, daß Deutschland eben noch keine gleichrangige Macht war.

Die Londoner Konferenz verfestigte zudem eine Tendenz, die bereits mit der Einberufung des Expertenkomitees begonnen hatte: die Rückkehr zur Legalität und zur Rechtsgebundenheit der zwischenstaatlichen Beziehungen. Durch die Rücknahme der in ihrer Legalität zumindest zweifelhaften französischen und belgischen Maßnahmen -- so legitim diese auch Anfang 1923 ihren Führern erschienen waren - kehrte das Recht in die zwischenstaatlichen Beziehungen zwischen Deutschiand und den Westmächten zurück, so wie es im Versailler Vertrag festgeschrieben worden war. Eine wesentliche Neuerung dabei war, daß Deutschland nun erstmals seit dem Krieg den Versailler Vertrag auch faktisch anerkannte. In Berlin liebte man den Versailler Vertrag deswegen nicht mehr als vor dem Ruhrkampf, es hatte sich aber die Erkenntnis Bahn gebrochen, daß die Pflichten (aber auch die Rechte), die sich für Deutschland aus dem Friedensvertrag von Versailles ergaben, besser waren, als quasi rechtlos dem Recht des Stärkeren, wie es sich durch die französischen Besatzungstruppen im Januar 1923 manifestiert hatte, ausgeliefert zu sein. Der deutschen Außenpolitik wurde zudem klar, daß die Revision des Versailler Vertrags nur in dem rechtlichen Rahmen möglich sein würde, den der Vertrag selbst lieferte. Auch Frankreich hatte sich wieder auf den rechtli- 
chen Rahmen des Friedensvertrags zurückgezogen. Dies war einerseits notwendig geworden, weil das einseitige Vorgehen Frankreichs seine bereits vom Krieg geschwächten Ressourcen überdehnt hatte. Ohne aber den zumindest teilweise bei der französischen Führung vorhandenen Willen, zum Zustand eines rechtlich geregelten zwischenstaatlichen Lebens zurückzukehren, ist die auf der Londoner Konferenz gefundene Lösung meines Erachtens jedoch nicht zu erklären. Dieser Wille, der Herrschaft des Rechts den Vorzug gegenüber dem Unilateralismus zu geben, ist, bei allen Unterschieden und Gemeinsamkeiten, nicht nur in der Außenpolitik Herriots, sondern auch bei Poincaré erkennbar.

Der vorsichtige Neuanfang in der Außenpolitik, wie er durch die Londoner Konferenz eingeleitet wurde, fand ihren Niederschlag übrigens auch bei wichtigen personellen Umbesetzungen in den auswärtigen Diensten Deutschlands und Frankreichs. In Deutschland räumte Ende 1924 der für den Rapallo-Vertrag verantwortlich zeichnende Staatssekretär Maltzan seinen Platz für den stärker nach Westen orientierten Schubert, um als Botschafter nach Washington zu gehen ${ }^{44}$. Auch in Frankreich deutete sich ab Oktober 1924 ein smouvement diplomatique $\wedge^{445}$ an, indem viele wichtige Posten in der Zentrale und in einigen Auslandsvertretungen umbesetzt wurden: »Im allgemeinen kann man als Richtlinie, die die Regierung bei dem Revirement leitet, feststellen, daß sie bestrebt war, insbesondere die hochtrabenden Auslandsvertreter der Poincaré'schen Gewaltpolitik bezw. [sic] solche Persönlichkeiten .zu beseitigen, von denen es ihr schien, daß sie den neuen Männern der Linken nicht genügend Achtung entgegenbrachten ${ }^{446}$. So wurden Saint-Aulaire in London und Jusserand in Washington durch die verständigungsbereiteren Fleuriau und Bérenger ersetzt, und auch die Beförderung Seydoux' zum directeur-adjoint des affaires politiques et commerciales wurde deutscherseits begrü $B \mathrm{t}^{447}$.

Die Beschlüsse der Londoner Konferenz wurden so zu einer wichtigen methodischen Grundlage für die moderne Entwicklung der Außenpolitik. Sie transformierten die im Ruhrkampf erwachsene Erkenntnis in Politik, daß Konfliktlösung durch Verhandlungen und nicht durch Gewalt erfolgen muß und bewirkten, daß der Versailler Vertrag die nun auch allgemein anerkannte Grundlage dieser Konfliktlösung war. Die Londoner Konferenz war aber nur ein erster Schritt hin zu einem modernen europäischen System. Das Sicherheitsproblem und die Frage der Reetablierung einer liberalen Wirtschaftsordnung, in der die Reparationen einen zentralen Störfaktor bildeten, waren nach wie vor ungelöst, und die im Versailler Vertrag festgeschriebene Asymmetrie zwischen Siegern und Besiegten bestand fort. Aber immerhin, ein Anfang war gemacht.

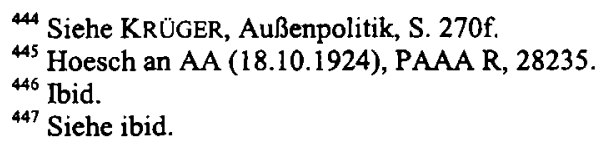


